\title{
THE INCOME DISTRIBUTION PROBLEM IN LATIN AMERICA AND THE CARIBBEAN
}

\section{Samuel A. Morley}

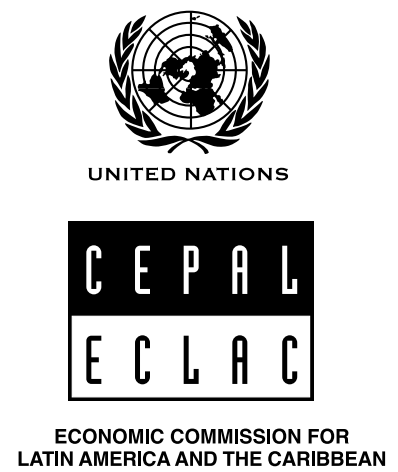

Santiago, Chile, 2001 


\section{Libros de la CEPAL}

This book has been prepared by Samuel Morley, currently a visiting researcher at the International Food Policy Research Institute (IFPRI) and fomerly a consultant of ECLAC, and published by the Economic Commission for Latin America and the Caribbean (ECLAC).

This book has been published as part of a project funded by the Netherlands Ministry for Development Cooperation and with contributions from the International Development Research Centre of Canada (IDRC), the Ford Foundation, and the Swedish International Development Agency.

Cover illustration and design by Andrés Hannach.

Composition by Gilabert\&Domeyko Ltda.

United Nations Publication

LC/G.2127-P

ISBN: 92-1-121293-6

Copyright (C) United Nations, May 2001. All rights reserved

Sales No. E.01.II.G.20

Printed in Chile

Applications for the right to reproduce this work are welcomed and should be sent to the Secretary of the Publications Board, United Nations Headquarters, New York, N.Y. 10017, U.S.A. Member States and their governmental institutions may reproduce this work without prior authorization, but are requested to mention the source and inform the United Nations of such reproduction. 


\section{TABLE OF CONTENTS}

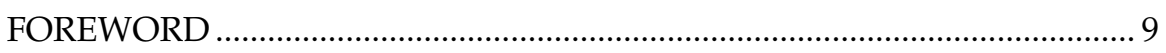

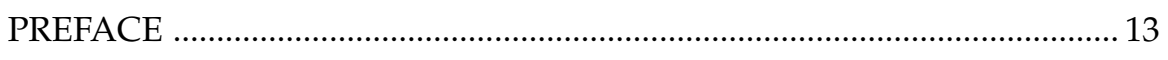

Chapter I

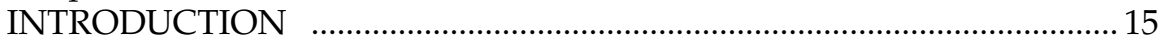

A. Latin America: The Highest Inequality in the World .................... 17

B. A Closer Look at Region-wide Data for Latin America and the Caribbean ........................................................... 18

C. Inequality within Latin America and the Caribbean ....................... 21

D. Trends in Inequality Over Time within Latin America and the Caribbean ............................................................... 23

Chapter II

DETERMINANTS OF THE DISTRIBUTION OF INCOME .......................... 27

A. A Schematic Model of the Distribution Process ………………...... 27

B. The Impact of Growth on the Distribution of Income..................... 33

C. The Adoption of Reforms ………………………................................. 36

D. The Impact of the Structural Reforms ............................................. 46 


\section{Chapter III}

WHY IS THE DISTRIBUTION OF INCOME IN

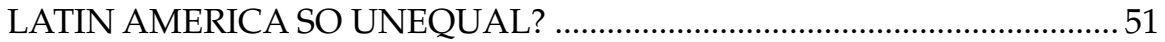

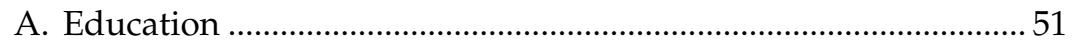

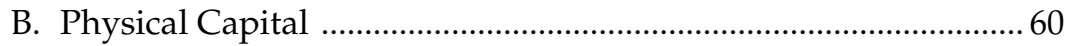

C. The Distribution of Land and Unskilled Labour ............................. 63

D. The Contribution of Inequality at the Top of the Distribution .... 65

\section{Chapter IV}

THE EFFECT OF REFORM AND GROWTH ON

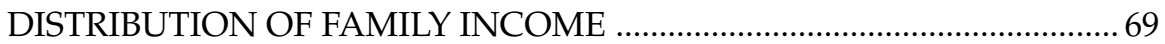

A. The Model for the Level of Distribution ........................................ 72

B. The Effect of Growth on the Distribution: An Application of the Estimated Kuznets Curve .......................... 82

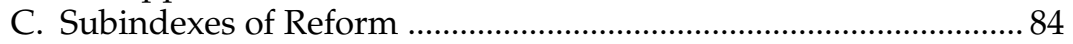

D. Results for the Model of Changes in Inequality ............................. 87

E. Conclusions ........................................................................................ 91

\section{Chapter V}

EVIDENCE FROM COUNTRY CASE STUDIES ………………...................93

A. Historical Evidence on Factor Prices and Relative

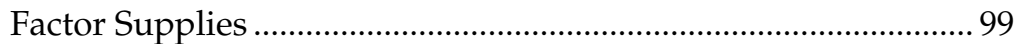

B. Factor Shares and the Rate of Return to Capital .......................... 102

C. The Link between Labour Market Performance

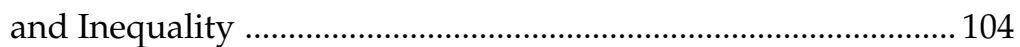

D. Patterns of Sectoral Growth in the 1970s and 1990s ................... 110

E. What Explains the Big Increases in Inequality in Chile, Argentina and Mexico?

\section{Chapter VI}

THE COMPONENTS OF INCOME INEQUALITY ...................................... 115

A. Decompositions of Inequality …………………........................... 117

B. The Effect of Changes in Education and Skill Differentials ....... 123

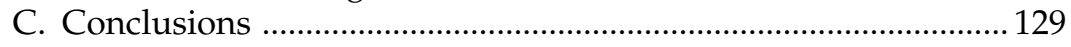

\section{Chapter VII}

THE RICH AND THE POOR IN THE POST-REFORM PERIOD ................ 131

A. A Profile of the Rich ...................................................................... 132

B. Contribution of the Rich to Total Inequality ................................. 135 
C. The Role of University Graduates in Explaining Inequality ..... 140

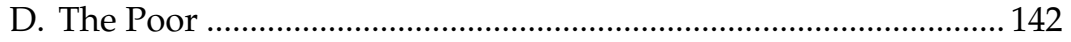

E. Reforms and Poverty Reduction ................................................. 147

Chapter VIII

CONCLUSIONS AND POLICY IMPLICATIONS

A. Why is Inequality So High in Latin America and the Caribbean? ............................................................................ 149

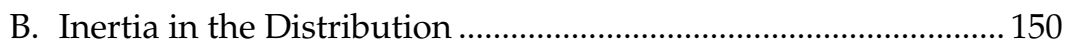

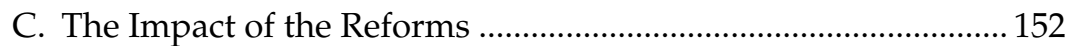

D. Policies that Can Help ................................................................... 153

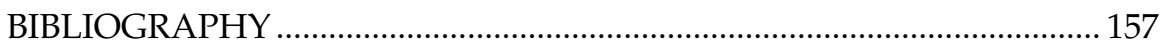

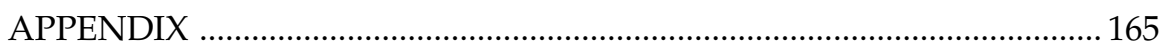





\section{FOREWORD}

At the start of the new decade, the debate on economic policy centres on the consequence of the reforms implemented in Latin America and the Caribbean in the last two decades. Trade and financial liberalization and the privatization of production activities have radically altered the rules of the game governing labour and business. The macroeconomic policy changes that accompanied or preceded the reforms sometimes strengthened the latter's specific objectives, especially the growth of exports, but on other occasions they had the opposite effect. That combination of factors prompted the emergence of new market structures and transformations in microeconomic behaviour.

Assessing the effects of the reforms on economic growth, employment and income distribution is of more than academic interest. Governments, political parties and social actors require a thorough evaluation of the results, so as to devise or propose policies that complement the reforms or counter their unwanted consequences. The Economic Commission for Latin America and the Caribbean (ECLAC) actively participates in this process.

This book is part of a project carried out by ECLAC, in conjunction with researchers from nine countries, to study the impact of the reforms. Directed by Dr. Barbara Stallings, the project has produced 14 books and 70 working papers. The summary appears in the first volume, entitled Growth, Employment and Equity: The Impact of the Economic Reforms in Latin America and the Caribbean. It is complemented by four issue-specific volumes analysing investment, technological change, employment and equity. Additionally, another nine country volumes examine the particular characteristics of the reforms in Argentina, Bolivia, Brazil, Chile, Colombia, Costa Rica, Jamaica, Mexico and Peru. The working papers are available at ECLAC's web site (www.cepal.cl). 
One feature of the project that distinguishes it from other comparative studies of economic reform is that it specifically addresses the interaction between macroeconomic and microeconomic processes. To understand the impact of the reforms more fully, it is necessary to disaggregate the regional level and to study the differences between countries and in the microeconomic behaviour of firms according to sector, size and ownership. The globalization of the economy and government policies such as structural reform affect different countries and groups of firms in different ways. Some have been able to exploit the new opportunities, while the situation of others has deteriorated. The outcome of such developments gives rise to aggregate trends that others have observed and measured, but to design economic policy measures and improve future performance, it is essential to know what underlies those aggregates.

This book by Samuel Morley, currently a visiting researcher at the International Food Policy Research Institute (IFPRI) and formerly a consultant of ECLAC, deals with a topic of growing concern in Latin American and Caribbean countries: the distribution of income. Distribution in the region is the most unequal in the entire world, a situation that has been true for as long as the statistics have been kept. Since 1980, inequality has increased. No doubt some of that is due to the recessions of the 1980s, but recent studies indicate that the region's economies saw very little improvement in the 1990s as they recovered from their earlier recessions. The consensus is that distribution has stayed about the same or even worsened slightly since 1990.

Morley identifies three contributing factors that help explain Latin America's high level of inequality. First, Latin America has a highly unequal distribution of education and the highest skill differentials for university graduates in the world. Second, the combination of a highly skewed distribution of land and an increase in the growth rate of the labour force in recent decades has driven down the relative wage of the unskilled. Third, the rich in Latin America are much richer relative to the remainder of the population than they are elsewhere.

Unfortunately it does not appear that growth will improve the distribution very much, if at all. One reason is that growth is more skill intensive now than it used to be. This may be simply a Latin American phenomenon, but more likely it reflects changes in technology that are being felt all over the world. Skill-intensive growth has favoured university graduates. So far, this group contributes less to overall inequality than the rich do because many in the group are not rich. Unlike the rich, however, Morley shows that this group's contribution to inequality rose sharply in the post-reform period. In the nine-countries examined in the book, inequality would have fallen in every case had it not been for the rising relative incomes and size of the university group.

The evidence is mixed on the impact of the structural reforms on income distribution, because it is difficult to separate the effect of the reforms from all 
the other changes that were happening at the same time. In the aggregate, the reforms appear to have had a regressive effect on distribution, but the effect is small and only marginally significant. The reason is that reforms in different areas have offsetting effects on equity. Tax and trade reforms are unambiguously regressive though not highly significant, but opening the capital account is unambiguously progressive. Results for other reforms were not consistent enough to give a clear answer.

ECLAC could not have carried out a project of this scale without the cooperation of many individuals and institutions. We wish to thank the researchers that participated in each of the nine countries, as well as the coordinators of the thematic and national volumes. We are also indebted to the members of the project's External Advisory Committee: Nancy Birdsall, Director of Economic Programs at the Carnegie Endowment for International Peace; René Cortázar, Executive Director of Chilean National Television; Norman Hicks, senior economist at the World Bank; Juan Antonio Morales, President of the Central Bank of Bolivia; Pitou van Dijck, Professor of Economics at the University of Amsterdam; and Dorothea Werneck, Executive Director of the Brazilian Agency for Export Promotion.

External financing came from a number of international donors. First, we wish to recognize the central role of the Netherlands Ministry for Development Cooperation, which provided the project's basic donation. The International Development Research Centre of Canada (IDRC) also made a substantial contribution that allowed us to expand the scope of the project significantly. These two sources were supplemented with funds from the Ford Foundation and the Swedish International Development Agency. We offer our deepest thanks to all the donors, without whose support this project would not have been possible. 



\section{PREFACE}

This book is the result of my participation in the ECLAC project, "Growth, Employment, and Equity: The Impact of the Economic Reforms in Latin America and the Caribbean." Early on, I decided that the questions I wanted to address were broader than just the impact of the reforms, important as that is. Rather I wanted to ask why the distribution is so unequal, how growth, reform and changes in education structure affect the distribution and what distributional impact we should expect from the new, post-reform mode of growth in the region.

To address some of these questions, ECLAC commissioned case studies of income distribution in nine countries in the region. These equity case studies formed part of the country component of the overall study of the impact of the reforms, and they have all been published as part of the ECLAC working paper series on Economic Reforms. I used the data from the nine studies to examine how changes in income distribution before and after the reforms were related to changes in wage differentials, education structure, labour market conditions and the income share of the rich.

Comparison of the distribution of income before and after the reforms is not a fully satisfactory way to determine the impact of the reforms because so many other things changed at the same time. To address this problem I augmented the nine-country sample with aggregate data from a much wider sample of countries over a longer time period. That sample was used for an econometric study in which measures of the distribution were related to growth, reform, education structure and other variables. When combined with the case study analysis, the results give a consistent view of the impact on equity of the reforms, growth and other factors. They also highlight the important role of increasing skill intensity as a factor inhibiting future improvements in the distribution. 
This book reflects the inputs of ideas, suggestions, data and encouragement of a great many people, and it is a pleasure to acknowledge them. First, there were the authors of the nine case studies: Oscar Altimir and Luis Beccaria for Argentina, Luis Carlos Jemio for Bolivia, Marcelo Neri for Brazil, Osvaldo Larrañaga for Chile, Mauricio Cárdenas and Raquel Bernal for Colombia, Juan Diego Trejos for Costa Rica, Damien King and Ashu Handa for Jamaica, Rodolfo de la Torre for Mexico and Jaime Saavedra and Juan José Díaz for Peru. They provided the data and the analysis upon which most of the case study components on this book are based.

At ECLAC, I was fortunate, indeed, for the help of many colleagues. First and foremost was Barbara Stallings, the coordinator of this project. I could not have written this book without her encouragement, probing questions and careful reading of every word I wrote. Graciela Moguillansky pushed me hard on my assumptions and econometrics and, although we generally disagreed, the book is better because of the attention she paid to it. I also want to acknowledge Jürgen Weller for the help he gave me and for the information and analysis of labour markets that he developed for the project. His book on the impact of the reforms on labour markets is an important complement to what I have done here. Among the many other colleagues at ECLAC, I particularly want to thank Ricardo Bielschowsky, Beatriz David, John Durston, Hubert Escaith, Ricardo Ffrench-Davis, Pascual Gerstenfeld, André Hofman, Luis Felipe Jiménez, Jorge Katz, Arturo León, Pancho León, José Antonio Ocampo and Osvaldo Rosales. They provided a stimulating intellectual environment as well as a warm welcome for a temporary visitor.

I also wish to thank Albert Berry, Nancy Birdsall, François Bourguignon, Eduardo Lora, Stephany Griffith-Jones, Enrique Ganuza, Richard Newfarmer, Miguel Székely, Anthony Tillett, Rob Vos and the participants in seminars at LACEA, the Brookings Institution, the Carnegie Endowment, the Institute of Social Studies, Oxford University and ECLAC for their comments on previous drafts of the book. Many thanks also to Alejandra Tagle and María Eugenia Johnson for their support and secretarial assistance, and to Ximena Sánchez who performed many feats of computer magic in turning my raw manuscript into a publishable format. Needless to say I alone am responsible for any remaining errors, data problems or analytical gaps in this book. 


\section{CHAPTER I}

\section{INTRODUCTION}

The clamour about income distribution in Latin America is increasing. The region's distribution is the most unequal in the entire world, which has been true for as long as statistics have been kept. Too much of the fruits of economic growth in the region has gone to those who already had a high income, too little has trickled down to those who needed it. Many critics feel that the new economic model now being followed in Latin America is making the situation worse. Opening national borders to low-wage imports, freeing capital flows from government control, privatizing State enterprises and shifting away from progressive income tax systems to broad-based taxes on consumption: all of these reforms might reasonably be expected to shift the distribution of income toward the rich.

Empirically, the critics appear to have a point. Since 1980, the distribution of income has worsened in Latin America. No doubt some of that is due to the recessions of the 1980s. According to recent studies (for example, Londoño and Székely, 1997), however, inequality diminished very little in the 1990s as the Latin American economies recovered from their earlier recessions. The consensus is that distribution stayed about the same or even worsened slightly after 1990.

Both the factual basis and the implications for such aggregate statements are questionable. Not every country has a distribution problem, and some have made progress. Yet there clearly is a serious problem. Inequality rose sharply in the biggest economies in the region -namely, Argentina, Brazil, Chile and Mexico- and showed no tendency to decline after 1990. Indeed, it rose still further in Argentina and Mexico. A large part of this book is devoted to explaining why this happened, how much was due to the adoption of reforms, and what can be done to improve the situation. 
The book proceeds on two tracks. The first uses all the available evidence for all the countries in the region. That evidence is based on the distribution of income across families or individuals, which is the distribution relevant for welfare comparisons. The second track presents a clearer picture of the impact of the reforms by focusing on a nine-country sample from the region. That sample highlights the distribution of the income from production among those who produce it (that is, the primary earnings distribution), because that is the distribution most closely related to the forces of supply and demand in the economy. One of the book's main interests is the impact of the recent economic reforms. If the reforms had any distributional impact, it should appear first in factor returns, relative wages and factor markets. Therefore changes in the primary earnings distribution should help explain what the impact of the reforms has been. Generally, that distribution and the distribution of income across families or individuals move together, which is why the smaller sample of countries can be used to understand just how growth and the reforms affected distribution.

The layout of the book is as follows. The next section of this first chapter sets the stage with a short profile of inequality in the region and a summary of recent trends by country. Chapter II discusses measurement issues, presents a schematic model of the distribution process and then uses that schematic model as a basis for a discussion of the impact of economic growth and the reforms on the distribution. Chapter III addresses the question of why income distribution in Latin America is so unequal. Chapter IV presents econometric evidence on the determinants of the distribution, using a large pooled time series cross section of observations of the family distribution from 16 countries in the region. Chapter V summarizes the evidence from special studies commissioned by ECLAC for the smaller sample of nine countries. This sample features information on factor supplies and relative factor returns, as well as conditions in the labour market before and after the adoption of reforms. Comparisons of these indicators give a better understanding of how the reforms affected factor markets and distribution, as well as the channels through which that happened.

In chapter VI, special decompositions of the distribution data help determine the sources of observed changes in the primary earnings distribution, in order to learn more about the sources of changes in the distribution and to find out why the distribution has not changed appreciably in some countries despite changes in relative wages, educational structure and economic growth. Chapter VII reports on special studies of the rich, defined either as the top $10 \%$ of income earners or as university graduates. This part of the study is a response to the finding that a very large part of overall inequality is explained by differences between the rich and everyone else (IDB, 1998). I wanted to find out to what extent changes in inequality during the reform period could be coming from changes in the relative earnings 
of a small group at the top of the income pyramid. In other words, have the reforms mainly benefited the rich? Finally, chapter VIII summarizes the findings.

\section{A. Latin America: The Highest Inequality in the World}

A number of different measures are available for gaining an overview of inequality in the region. The most direct and straightforward is a comparison of household income per capita across the population, ordered by level of income. One standard measure of inequality is the Gini coefficient, which measures the percentage difference between the actual distribution and a perfectly equal distribution in which each person receives exactly the same income. The Gini coefficient varies between zero and one, with zero representing perfect equality and one a hypothetical situation in which one individual receives all the income.

Regardless of the method for measuring income inequality, Latin America on average has the most unequal distribution in the world. Deininger and Squire (1996) at the World Bank recently collected a set of comparable national Gini coefficients for 108 countries around the world, going back over thirty years. Table I-1 gives their estimates of the median Gini by region and decade. Not only is the Latin American distribution the most unequal in the world, but it has been that way at least since the 1960s.

Table I-1

\section{MEDIAN GINI COEFFICIENTS BY REGION AND DECADE}

\begin{tabular}{lcccc}
\hline REGION & $1960 \mathrm{~s}$ & $1970 \mathrm{~s}$ & $1980 \mathrm{~s}$ & $1990 \mathrm{~s}$ \\
\hline Eastern Europe & 25.1 & 24.6 & 25.0 & 28.9 \\
South Asia & 36.2 & 33.9 & 35.0 & 31.9 \\
OECD and high income countries & 35.0 & 34.8 & 33.2 & 33.7 \\
Middle East and North Africa & 41.4 & 41.9 & 40.5 & 38.0 \\
East Asia and Pacific & 37.4 & 39.9 & 38.7 & 38.1 \\
Sub-Saharan Africa & 49.9 & 48.2 & 43.5 & 46.9 \\
Latin America & 53.2 & 49.1 & 49.7 & 49.3 \\
\hline
\end{tabular}

Source: Klaus Deininger and Lyn Squire, "A new data set measuring income inequality", World Bank Economic Review, vol. 10, No. 3, Washington, D.C., World Bank (1996).

Other than the very large differences between Latin America and the other regions of the world, what is striking is the lack of convergence over time. 
Indeed, the opposite appears to be the case. Latin American inequality fell slightly in the 1970s, but then it reversed in the 1980s. In contrast, inequality fell substantially in the Middle East and Africa, the other two areas whose inequality indexes were somewhat comparable to those in Latin America up to the 1970s. Whatever the process that generates inequality, events since 1970 have had different effects in Latin America than anywhere else. In the developed countries, inequality has remained roughly constant at a low level. In the other developing regions where inequality was once high, it has fallen quite sharply. Only in Latin America has inequality remained at its high initial level. ${ }^{1}$

The differences between regional Gini coefficients translate into large differences in the amounts or shares of income going to the rich and poor. In the 1990s in Latin America, the top 5\% of the population received 25\% of total income on average, while the bottom $30 \%$ got only $7.5 \%$. In Southeast Asia the top $5 \%$ received only $16 \%$ of income while the bottom $30 \%$ got $12.2 \%$; the comparable figures for Africa are $24 \%$ and $10.1 \%$, respectively. In the developed countries the top $5 \%$ got only $13 \%$ of total income while the poorest $30 \%$ got $12.7 \%$ (IDB, 1998). These shares imply that in Latin America the average income of the richest $5 \%$ is 20 times that of the poorest 30\%. In Southeast Asia the richest $5 \%$ have average incomes only 8 times those of the poorest $30 \%$.

\section{B. A Closer Look at Region-wide Data for Latin America and the Caribbean}

Londoño and Székely (1997) recently calculated both the Gini coefficients and quintile shares for 13 countries in the region for the period from 1970 to 1995. Their data considerably expand on the Deininger and Squire data set, particularly for the 1990s. For the region as a whole, they made their calculations both by averaging individual country-level distribution estimates and by combining all the countries together into a single distribution from which aggregate Ginis were calculated. The differences between the two methods do not affect the overall trends, though they do affect the magnitude of the changes. Table I-2 summarizes some of their results.

1 Clearly Eastern Europe is a special case in which the shift to a private-enterprise market economy resulted in a one-time upward shift in inequality, but the higher level is still the lowest in the world. 
Table I-2

\section{DISTRIBUTION DATA FOR LATIN AMERICA AND THE CARIBBEAN, 1970-1995}

\begin{tabular}{lcccc}
\hline & \multicolumn{4}{c}{ GINI COEFFICIENT } \\
\cline { 2 - 5 } GRouP & 1970 & 1980 & 1990 & 1995 \\
\hline Total Latin America and the Caribbean ${ }^{\mathrm{a}}$ & .580 & .550 & .583 & .577 \\
Weighted average & .552 & .525 & .557 & .558 \\
Simple average & .512 & .494 & .516 & .515 \\
Share of top quintile $^{\mathrm{b}}$ & .553 & .534 & .553 & .556 \\
Share of bottom quintile $^{\mathrm{b}}$ & .039 & .040 & .035 & .036 \\
\hline
\end{tabular}

Source: Juan Luis Londoño and Miguel Székely, "Persistent Poverty and Excess Inequality: Latin America, 1970-1995", OCE Working Paper Series, No. 357, Washington, D.C., Inter-American Development Bank (IDB) (1997).

aAgregate of 13 countries.

${ }^{\mathrm{b}}$ Shares in top and bottom quintiles are non-weighted averages.

All the series in the table give the same message. Inequality fell in the 1970s, which was the last period of steady, widespread growth in the region. Those favourable trends reversed in the 1980s due partly to recession, partly to structural adjustment and partly to sharp increases in inflation in a number of countries. This reversal eliminated all the progress made in reducing inequality in the 1970s. By 1990 the income shares of the top and bottom quintiles were back to their 1970 values and so was the Gini.

Inequality rises during recessions for a number of reasons, particularly when the recession is accompanied by rising inflation, as was the case in Latin America in the 1980s. Recessions bring rising unemployment. In countries where there is little or no unemployment insurance, rising unemployment is sure to pull down income at the bottom. When countries are attempting to control inflation, they typically delay minimum wage adjustments. In the 1980s the average real purchasing power of the minimum wage fell by a fourth (Edwards, 1991). That, too, tends to reduce real income at the bottom of the income pyramid and widen income inequality. Those are two reasons that Londoño and Székely find that real income of the bottom decile fell by over $15 \%$ during the 1980 s. $^{2}$

2 They show the income share of the bottom decile falling by $15 \%$. However, that means that real income must have fallen by a greater percentage, because overall real income in the region was itself declining. 
What is more worrisome and more surprising is that rising inequality has not been reversed significantly during the recovery in Latin America since 1990. If inequality went up in the 1980s because of recession, it should have gone down as the region recovered and grew in the 1990s. Something more than cyclic influences seems to be at work since what was lost by the poor in the recessions of the 1980s was not recovered in the 1990s.

The Londoño-Székely study is the broadest and most careful investigation of inequality trends that exists in the region. They synthesize a great deal of information and make a real effort to build a consistent database for the region. Yet several limitations of their study could have a bearing on both the level of inequality and the changes over time. The most important is the exclusion of countries with urban-only surveys, which meant excluding Argentina, Bolivia, El Salvador, Paraguay and Uruguay. Of these, Argentina, Uruguay and to a lesser extent El Salvador have low levels of urban inequality, while Bolivia, Uruguay and El Salvador had declining inequality in the 1990s. Thus the exclusion could have affected the estimates.

Another thing to keep in mind is the meaning of any estimate at the aggregate level. Obviously, it is not difficult to calculate an aggregate distribution index, but the region is anything but uniform, with respect to growth or trends in inequality. Some countries are growing strongly, but Brazil and Mexico -the two largest economies in the region- are still caught in stopand-go cycles. ${ }^{3}$ In any weighted average of distribution statistics, what happens in those two countries is going to have a big influence on aggregate outcomes. In a purely definitional sense, one might say that despite recovery, inequality did not decline in the 1990s, but that is misleading because neither Brazil nor Mexico recovered. What needs to be clarified is whether inequality declined in those countries that recovered or -more to the point for this studythat carried out reforms and reached some sort of a steady growth path.

Another issue also affects the interpretation of the region-wide data in the Londoño-Székely paper. For a number of their statistics, they combine all the available national distributions into one region-wide distribution and then calculate the Gini coefficients and average incomes of the top and bottom centiles (see table I-2). This is equivalent to treating Latin America as if it were a single country. Since there are very large differences in average incomes across countries, however, it is likely that most of those at the bottom of the region-wide distribution will come from the poorest countries. Therefore a statistic such as the changes in the real income of the top or bottom centile is more likely to reflect the different growth rate of incomes across countries than the differences in income growth between the rich and the poor within

3 Argentina, the third biggest economy in the region, is not in the sample. 
countries. If each country represents a separate experiment, so to speak, which shows the effect of growth and reform on the distribution, then the simple average of the national Ginis is a better indicator than either the region-wide or the weighted average Gini.

In table I-2 the trends in all three Ginis are similar, but there are quite large differences in the size of the movements, particularly during the 1980s. Both the region-wide and weighted average Ginis show nearly a $10 \%$ increase in inequality between 1980 and 1990, but the simple average rises by less than $5 \%$ between those same two years. Indeed over the entire period from 1970 to 1995, the simple average of the Ginis for the 13 countries in the LondoñoSzékely sample varies between a high of .517 in 1994 and a low of .488 in 1979. For all intents and purposes, this implies that the average level of inequality in the region has remained virtually constant over the last 25 years.

\section{Inequality within Latin America and the Caribbean}

The discussion of aggregation problems points to the need to take a closer look at differences in inequality between countries and differences in intracountry trends in inequality over time. Figure I-1 displays the most recent estimates available for the Gini coefficients for 20 countries in the region. Five of the countries have observations for 1996 and nine for 1995. For Guatemala the most recent is 1989. Thus the estimates are relatively recent, and cover more than $90 \%$ of the population of the region.

Figure I-1

\section{RECENT GINI COEFFICIENTS FOR 20 COUNTRIES IN LATIN AMERICA AND THE CARIBBEAN}

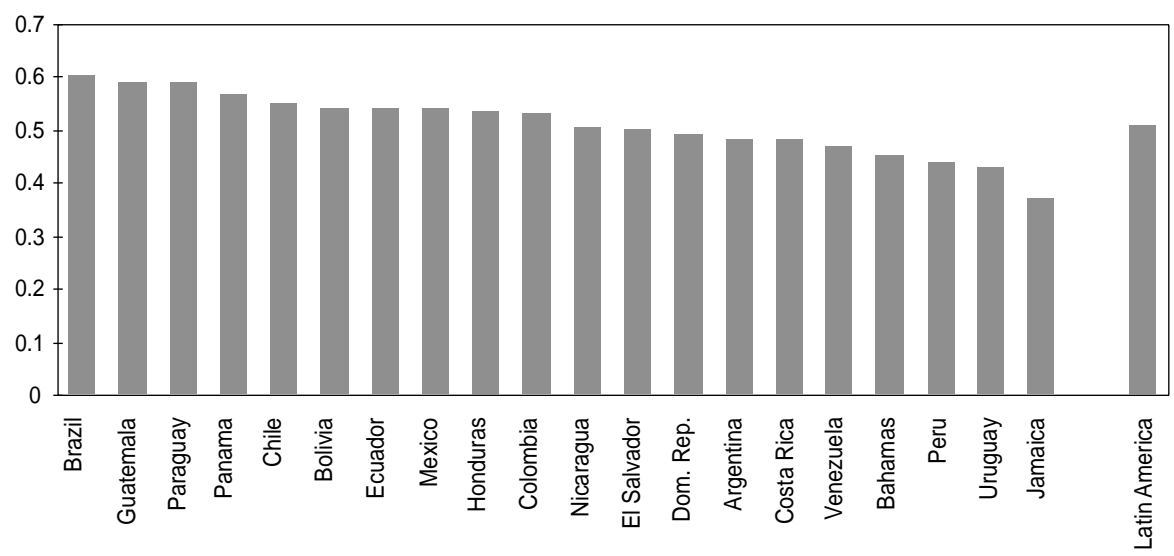

Source: Appendix table A-1. 
The first thing the data show is the extent of high inequality in the region. With the possible exception of Jamaica, whose survey is based on expenditure rather than income, no country in the region reaches even the median level of the Gini for Sub-Saharan Africa, the most inequitable region in the world after Latin America. Latin America's high average inequality is not due to one or two outlying countries. No less than 12 of the 20 countries in the figure have Ginis over .50, which is higher than the maximum Gini in all but 14 of the 88 non-Latin American countries in the Deininger and Squire data set.

Classifying the countries by the degree and persistence of inequality shows that Brazil, Chile, Guatemala, Honduras, Mexico and Panama have the highest inequality in the region, while Costa Rica, Jamaica, Uruguay, Venezuela and, surprisingly, Peru are the most equal. For some countries such as Bolivia and Paraguay, the national surveys are too recent to indicate the persistence of their inequality.

An interesting question that the book explores later is the relation between inequality and the level of development. Figure I-2 plots the level of per capita income measured in constant purchasing power dollars against the recent Gini coefficients for the 20 countries shown in figure I1. Disregarding the Bahamas, which is an outlier in the income dimension,

Figure I-2

\section{THE RELATION BETWEEN INEQUALITY AND INCOME}

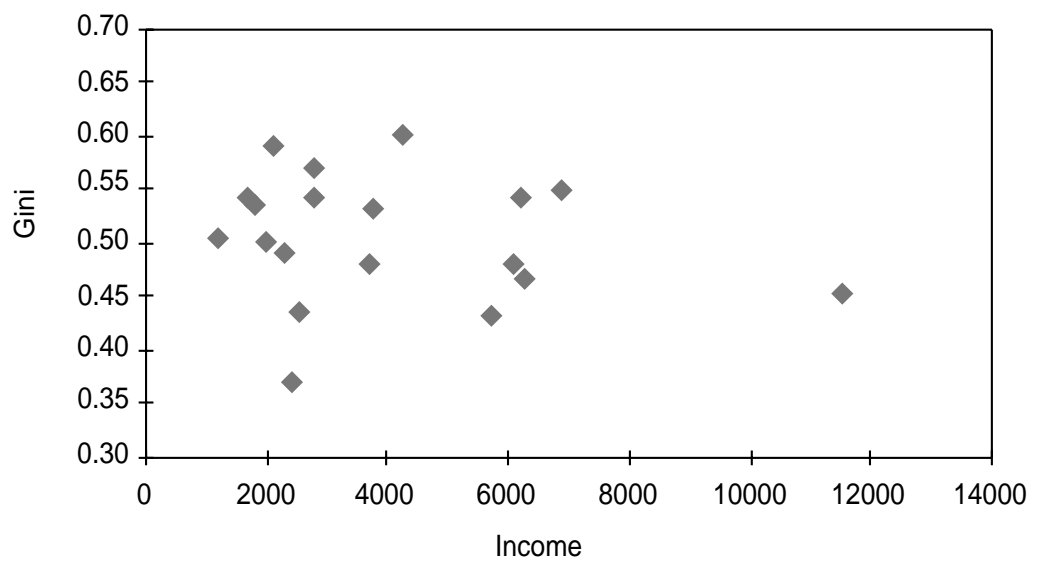

Source: Gini coefficients from appendix table A-1 (this volume); income from Robert Summers and Alan Heston, The Penn World Tables: Version 5.6, diskette version (1995). 
and Jamaica, which is an outlier in the Gini dimension, the two variables do not demonstrate any relation at all. Some of the higher income countries such as Uruguay and Argentina have low levels of inequality, but others such as Brazil, Chile and Mexico have high levels. By the same token there is an equally wide dispersion of inequality among the low-income countries, with Jamaica and Peru at the bottom of the scale and Guatemala, Paraguay and Panama at the top.

\section{Trends in Inequality Over Time within Latin America and the Caribbean}

As mentioned above, the evidence on distribution trends in the region indicates that distribution improved in the 1970s, worsened in the 1980s and was roughly constant in the 1990s. While that description may fit the aggregate data, however, it hides as much as it reveals. Some very significant differences among countries or within the same country over time are not represented by the aggregate data. Examining the impact of the reforms requires some idea of how the level of inequality differs between reformers and non-reformers, and how it may change over time in response to reform in any given country. Table I-3 estimates trends in distribution as measured by the Gini coefficient over the last three decades.

First a word of explanation about the table. In no country is there a consistent set of data going all the way back to 1970. The table therefore reflects the most consistent observations available over the relevant decades. Because many changes are small, any decadal movement that was less than $5 \%$ of the initial value of the Gini was arbitrarily labelled constant. This means that for a Gini around .50, anything falling in the band .475-.525 is considered constant. In each constant case, an increase or decrease in inequality over the decade is indicated by a plus or minus. No surveys are available Guatemala and Nicaragua. For Bolivia, Ecuador and Paraguay, the only information available is for the urban sector; since the rural population is large in all three of these countries, the urban distribution does not accurately reflect the national distribution. All three of these countries now have national-level surveys, but they only start in 1995 or 1996. In the case of Argentina and Uruguay (the other two countries for which only urban surveys are available), trends are estimated on the basis of the urban data. The justification for this difference in treatment is the large proportion of the total population residing in urban areas in these two countries. Given its small size, it is highly unlikely that the rural sector could reverse the trends observed in the urban sector.

The countries with data at the beginning and end of the 1970s demonstrate big differences in inequality trends. The assertion that the distribution improved seems to depend on Argentina, Mexico and Venezuela. In Brazil, 
Table I-3

TRENDS IN DISTRIBUTIONAL INEQUALITY SINCE 1970

\begin{tabular}{|c|c|c|c|}
\hline & 1970 s & 1980s & 1990s \\
\hline Argentina & rose & rose & rose \\
\hline Bahamas & constant- & constant+ & constant+ \\
\hline Bolivia & n.a. & n.a. & n.a. \\
\hline Brazil & constant & rose & constant- \\
\hline Chile & rose & rose & constant- \\
\hline Colombia & constant+ & rose & constant- \\
\hline Costa Rica & constant+ & constant- & constant+ \\
\hline Dominican Republic & n.a. & rose & n.a. \\
\hline Ecuador & n.a. & n.a. & n.a. \\
\hline El Salvador & n.a. & n.a. & fell \\
\hline Guatemala & n.a. & n.a. & n.a. \\
\hline Honduras & n.a. & n.a. & fell \\
\hline Jamaica & rose? & fell & fell \\
\hline Mexico & fell & rose & constant+ \\
\hline Nicaragua & n.a. & n.a. & n.a. \\
\hline Panama & n.a. & rose & n.a. \\
\hline Paraguay & n.a. & n.a. & n.a. \\
\hline Peru & constant+ & n.a. & fell \\
\hline Uruguay & constant+ & fell & fell \\
\hline Venezuela & fell & rose & rose \\
\hline
\end{tabular}

Source: Klaus Deininger and Lyn Squire, "A new data set measuring income inequality", World Bank Economic Review, vol. 10, No. 3, Washington, D.C., World Bank (1996); IDB, Economic and Social Progress in Latin America, 1997 Report, Washington, D.C. (1997); Damien King and Sudhanshu Handa, "Changes in the distribution of income and the new economic model in Jamaica", Reformas económicas series, No. 57 (LC/L.1353), Santiago, Chile, Economic Commission for Latin America and the Caribbean (ECLAC) (March 2000); Jaime Saavedra and Juan José Díaz, "Desigualdad de ingreso y del gasto en el Perú antes y después de las reformas estructurales", Reformas económicas series, No. 34 (LC/L.1225), Santiago, Chile, Economic Commission for Latin America and the Caribbean (ECLAC) (July 1999); Osvaldo J. Larrañaga, “Distribución de ingresos y crecimiento económico en Chile", Reformas económicas series, No. 35 (LC/L.1226), Santiago, Chile, Economic Commission for Latin America and the Caribbean (ECLAC) (July 1999); and José Antonio Ocampo and others "Macroeconomía, ajuste estructural y equidad en Colombia: 1978-1996", Política macroeconómica y pobreza en América Latina y el Caribe, Enrique Ganuza, Lance Taylor and Samuel Morley (eds.), Madrid, Grupo Mundi-Prensa, United Nations Development Programme (UNDP) (1998).

Note: Constant refers to Gini coefficients that stayed within a 5\% band; increases or decreases within this band are indicated by a plus or minus. 
Chile, Colombia, Costa Rica, Peru and Uruguay, distributional inequality was either constant or rising. The two countries that made the most significant structural reforms in the 1970s -namely, Chile and Uruguay-both experienced quite a large increase in inequality.

Very little difference is seen between the aggregate trends and individual country experience in the 1980s. Inequality rose in all but three countries in the sample, and in eight of them the rise was greater than $5 \%$. This similarity between the country and aggregate trends disappears again in the 1990s. Overall, inequality does not change much because of offsetting trends (many of them significant) going in opposite directions in individual countries. Only two countries (Argentina and Venezuela) experienced a clear and significant rise in inequality in the 1990s. The Gini coefficient also rose in the Bahamas, Costa Rica and Mexico but the increase was less than 5\%. In contrast, five countries demonstrate a significant decline in inequality and another three (all large) saw inequality fall, though not by a significant amount. Thus the aggregate distribution data give a misleading picture of the 1990s. There was apparently a good deal of change, but it was positive in some countries and negative in others. Those differences are important for investigating the impact of reforms, growth and technical change in the region.

In short, there is great heterogeneity in the region. One subgroup of countries has high levels of inequality (El Salvador, Honduras, and Peru), but they made progress in the 1990s. In another group (Costa Rica and Uruguay), inequality fell to a low level, but it is unlikely to fall much further simply because there are lower limits to inequality in any society. These two countries have reached levels of inequality associated with developed countries. In the third group, however, inequality rose sharply in the past and now seems stuck at a high level. This group consists of Argentina, Brazil, Chile and Mexico. I would put Colombia and Venezuela in this problem group as well, because although their inequality fell earlier, it rose throughout the 1990s, particularly in the urban sector (ECLAC, 1999). A fourth group of countries (Bolivia, Ecuador and Paraguay) is only now beginning to report on inequality at the national level, because they have only recently begun to carry out rural surveys. In all three of these countries, the recent data show a high level of national inequality. Unfortunately, the nine countries in these last two groups together contain over $75 \%$ of the total population of the region. Thus, most of the people in the region are living in countries with very high levels of inequality -higher in most cases than in the past. And what is worse, there are few if any encouraging signs of improvements. This is the reality and the problem addressed in this book. 



\section{CHAPTER II \\ DETERMINANTS OF THE DISTRIBUTION OF INCOME}

The discussion now turns to the determinants of the distribution of income. First, a schematic view of the process helps to clarify the channels whereby important economic factors affect the primary earnings distribution and by which demographic factors affect the family or per capita distribution. This is followed by an analysis of the relation between economic growth and distribution, and a discussion of the impact of the structural reforms on factor markets, relative returns and equity.

\section{A. A Schematic Model of the Distribution Process}

Figure II-1 presents a schematic overview of the main features of the process by which the primary distribution of income is determined at a point in time and over time. The key component of the model is an abstraction, called the factor markets. These so-called markets are not a physical location, but rather a network of contracts, pricing arrangements and understandings that determine the prices of each of the factors of production. For simplicity only four factors are considered: physical capital, human capital or skilled labour, unskilled labour and land. In reality, of course, there are many different kinds of physical capital, each with a different return, and many gradations of skilled labour.

As in other economic markets, prices are determined in factor markets by the interaction of the supply of each factor and the demand for factor services. Markets clear at a price at which someone is willing to use the available supply of each of the factors. That set of market clearing factor prices 
determines the relative price of skilled and unskilled labour and the rate of return on capital and land. In the labour market, demand may well be so low that many are forced to work part time in the informal sector or are completely unemployed because the legally prescribed minimum wage in the formal sector exceeds the marginal product of a fully employed labour force.

On the demand side, economic growth and expansionary macroeconomic policy increase the demand for each of the factors, which tends to raise each of their prices (arrow from box 3 to box 2 in figure II-1). What happens to relative factor prices depends on the nature of the growth process. If it is skill intensive, skill differentials widen. If it is led by sectors such as agriculture, which use mainly unskilled labour, the reverse should occur. Structural reforms change the composition of output by shifting output toward certain sectors and away from others. That is, the demand side determines the position of factor demand curves, which should depend negatively on own prices and the prices of complements and positively on the prices of substitutes.

The supply side is critical to understanding the dynamics of the process. In the short run, the supply of factors is fixed because each of the factors is a stock which produces a flow of services. That stock can change, but it takes time. This analysis artificially cuts time into periods short enough to consider the stocks as constant. In each of these time periods, a fixed stock of factors is determined by past investment decisions and a set of factor demand curves. The two together produce the short-run set of factor prices shown in the diagram (arrows from boxes 1 and 3 to box 2 and from box 2 to box 5).

While this process sets the valuation of the factors of production, the distribution of ownership of the factors of production determines the primary earnings distribution, since it is the owner who receives the payment for the factor services. In the short run, the primary distribution is thus determined jointly by the relative factor prices that come from the factor market and by the pattern of ownership of the factors of production (arrows from boxes 4 and 5 to box 8 ).

The dynamics of the process come from the supply-side factors (box 7 on the left side of the figure). Investment increases the stock of physical capital, while the education system produces graduates who enter the labour force and change the supply of both skilled and unskilled labour. Training and experience also increase the stock of skilled labour (i.e., human capital). Migration changes the position of factor supply curves, and it could affect either unskilled or skilled labour.

It is important to remember not only that investment takes time, but also that the amount that can be added to the stock of any of the factors is relatively small over any short-run time period. Thus, in any period as short as, say, a year, it is impossible to shift the factor supply curves out by more than 3-5\%. This means that in the short run, changes coming from the demand side are most likely to explain observed changes in the primary distribution. Over time, however, the stocks change because of additions to the physical capital stock, education, retirements and so on (represented by arrow from box 7 to 
Figure II-1

\section{THE INCOME DISTRIBUTION PROCESS}

Time period $t$

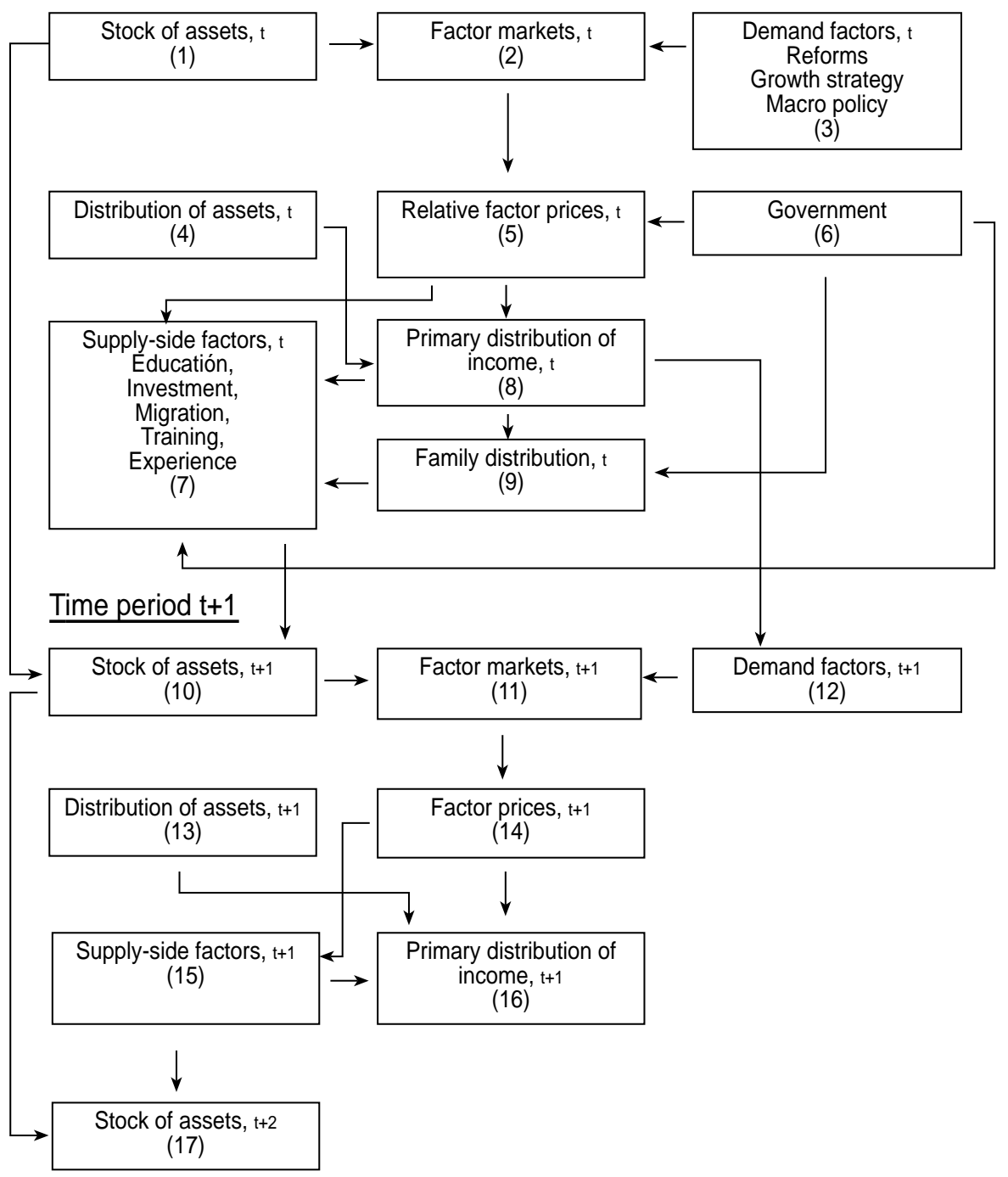


box 10). At the same time, factors on the demand side are likely to be changing as well. Thus the relative prices over time reflect changes in both supply and demand, such that it may not be possible to detect any apparent historical relation between changes in the stock of human capital and relative wages.

Another important feature of the distribution process is the dynamic feedback between factor prices and changes in factor supplies through investment. The arrow between factor prices (box 5 ) and the changes in supply (box 7) represents that feedback. That arrow represents the idea that relative prices or returns on physical capital determined in the factor market affect investment and education decisions. If the rate of return on capital rises, investment in physical capital increases. Similarly, an increase in the wage differential between skilled and unskilled labour, or between university and high school graduates, tends to increase the demand for university education. Fewer people enter the labour force immediately after high school, and more continue on to earn a university degree. Over time, those decisions increase the supply of educated labour. If the demand side does not change, this increase in the supply of skilled or educated labour should reduce the skill differential. The initial rise in the skill differential or the return to capital thus serves as a dynamic signal that sets in motion an investment process that eventually adjusts factor supplies and relative factor prices to a long-run equilibrium. By definition that equilibrium is one in which additions to supply are just sufficient to offset changes in the demand for factor services coming from economic growth and technological change.

From the point of view of the primary earnings distribution, a rising skill differential that tends to increase inequality in the short run is also a signal that expands the supply of educated labour or physical capital in the long run. These long-run changes on the supply side may well reverse the shortrun rise in inequality that induced them, since they tend to drive down the rate of return to capital, both human and non-human. For human capital, in addition the expansion in the supply of well-educated workers implies a rise in upward mobility for youth, more of whom will enter the labour market with a university education instead of just secondary or primary schooling.

A rise in the skill differential or the rate of return to capital thus has different effects in the short and long runs. In the short run an increase in either of these two is almost surely regressive. In the long run, however, so long as the supply side reacts positively to these changes in the rate of return, the change could be progressive, either because of upward mobility or because the increase in physical capital drives down the rate of return and raises the productivity and the average wage of workers.

This ambiguous situation results from the dual function of income in a market system. On the one hand, relative income determines the distribution at each point in time. Any relative increase in the income of the rich is regressive. But on the other hand, income is the signal or incentive by which 
economic agents are encouraged to change their behaviour. A rise in the skill differential induces socially desirable investment in education. Similarly, a rise in profits induces investment and a shift of productive resources from less desirable to more desirable uses. It would be a serious error of interpretation to concentrate only on the short-run regressive effect of changing factor returns without taking into account progressive long-run supply responses.

There are important caveats to this optimistic picture, however. Most important, the ability of students to continue their education rather than entering the labour market depends on whether they or their families are able to finance the cost of that education as well as the foregone income they would have earned in the labour market. These financial constraints are strongly affected by the level and distribution of family income; in figure II-1, this is represented by an arrow between family distribution (box 9) and the change in factor supplies (box 7). The positive signal for more education given by rising returns to education could be partially or completely offset by a rise in inequality in the family distribution coming from the same signal. In that case, the progressive long-run adjustment of factor supplies to a rise in the rate of return will be slowed down or stopped.

The government plays an important part in the distribution process. To begin with, it directly provides education services at both the secondary and university levels. Expanding the capacity of these systems should raise the skill level of the young when they enter the labour market. At the same time the government sets the price of publicly provided education. All of this is represented by an arrow from government (box 6) to factor supply (box 7).

A contentious debate has taken place in recent years over how much the beneficiaries should pay for public education, particularly at the university level. Since the bulk of public university students come from higher-income families, any government subsidy that reduces the cost of university education to students is highly regressive. By the same token, however, if those subsidies are removed without any complementary actions being taken, an important channel of upward mobility will be closed. More to the point, the progressive factor supply responses that reduce long-run earnings inequality will be either damped or stopped altogether. Removing subsidies to public education on the grounds that they are inequitable is thus likely to raise the skill differential and increase earnings inequality relative to what it would have been had the subsidy remained in place. The obvious policy solution to this paradox is to couple the elimination of subsidies to public education with a system of meanstested student loans or grants. This should enable students from poor families to continue their education in spite of their personal financial constraints.

Many other government actions also have important effects on distribution. For example, the government sets the minimum wage, which affects relative factor prices and employment (arrow from box 6 to box 5). It 
also operates transfer programmes such as nutrition programmes, retirement pensions, unemployment subsidies and the like. All of these affect the relation between the primary earnings distribution and the family or personal distribution. Most are intended to transfer income or goods to the poorest members of society, thereby limiting the regressive outcome that would otherwise be observed in the pure market solution. All this is represented by the arrow between government (box 6) and family distribution (box 9).

Macroeconomic policy is another critically important area through which the government affects the distribution of earnings and income (arrow from box 6 to box 3). Experience shows that economic cycles and volatility have large and significant effects. In the short run, the supply of factors is fixed. The impact of cyclic changes in income is felt through their effect on the demand for factors. Here the key question is whether recessions reduce the demand more for skilled or for unskilled labour, and whether the profit share rises or falls. All of these are empirical questions that must be settled by an examination of different countries over their economic cycles, because there is no compelling theoretical reason to expect one result or the other. Theoretically, recessions and recoveries could be either progressive or regressive.

Recessions reduce the demand for all factors of production. What happens to the skill differential should depend on which falls more: demand for skilled or unskilled labour. Two issues complicate the picture, however. First, institutional or other restrictions may limit wage flexibility. At the bottom of the labour pyramid, the rigidity could come from either the minimum or the subsistence wage, and further up it could come from union contracts. In developed countries the minimum wage puts a floor under unskilled wages. The minimum wage has never been reduced during a recession. ${ }^{4}$ In very poor countries, the subsistence wage or the reservation wage in subsistence agriculture may play the same role that the minimum wage plays in more developed countries. In either case, if a recession drives down the wages for skilled labour, the skill differential could narrow and wage inequality could be reduced for those with earned income. Latin American and Caribbean countries are probably intermediate between these two extreme cases. The region's wages for unskilled labour are above the subsistence level and fall in recessions, particularly in real terms. In the 1980 s reductions of $25-30 \%$ in the real value of the minimum wage were common, and they were caused in every case by rising rates of inflation or delays in inflation adjustments. Wages for skilled labour fell less sharply, which is why the skill differential widened in the 1980s in most countries (Edwards, 1991). 
Second, since recessions reduce the total number of jobs, they generally lead to some bumping downward, that is, the displacement of the less skilled by the better qualified. During recessions, skilled workers typically do not become unemployed, but rather take over jobs previously held by the less skilled or less experienced. Ph.D.s drive taxicabs or teach in primary school; engineers take jobs as draftsmen; blue-collar workers with experience replace younger workers with fewer years on the job. This sort of bumping has two effects, both of which are regressive: it is likely to widen the skill differential, and it increases unemployment, particularly for the young and less skilled. Wages for skilled labour fall because these workers take lower-paying jobs previously held by the less skilled, but the less skilled also move down the job ladder or lose their jobs altogether. They face falling real wages and rising unemployment, as well.

Inflation is another factor with important implications for equity. High inflation was a strongly regressive factor in many countries during the 1980s. At the time, economists hypothesized that this was because the poor were unable to protect their savings from inflation. A more significant factor now seems to be that the real wages for the unskilled were closely related to the real value of the minimum wage, which was controlled by the government through its policy on nominal wage adjustments. In each country that faced hyperinflation, the government policy of only periodically adjusting the nominal value of the minimum wage resulted in sharp reductions in the real value of the wage simply because of adjustment lags. To the extent that skilled workers were able to get more frequent wage adjustments, they were able to avoid the contraction in the real purchasing power of their wages, and the skill differential widened. Government macroeconomic management that avoids hyperinflation and reduces the size and number of economic cycles thus has favourable effects on distribution.

\section{B. The Impact of Growth on the Distribution of Income}

In a classic article, Simon Kuznets empirically analysed the relation between growth and equity, using the historical experience of England and the United States (Kuznets, 1955). He found that over the course of the nineteenth century, inequality rose as both countries grew, but somewhere around the beginning of the twentieth century the trend reversed and inequality began to decline. This non-linear, inverted U-shaped relation between output per capita and inequality has been labelled the Kuznets Curve; it has been the subject of a vast literature that has looked for similar relations in other countries and in international cross sections between countries.

Kuznets' rationale for the relation is based essentially on the idea that the growth process is specific rather than universal. It starts somewhere specific, 
in either a sector, a region or a city. From that starting point, its effects spread through a variety of linkages to the rest of the economy. In the first stages of this process, inequality rises. Later, as the effect of the growth stimulus spreads in the population, inequality begins to decline.

In the Kuznets study, the growth process was the industrial revolution. Industrialization started in the urban centres of essentially agricultural economies. Incomes in the industrial nuclei were much higher than those in the agricultural sector. As the nascent industrial part of the economy expanded, inequality increased at first because the profits and wages of industry and other urban activities benefited only a small proportion of the population. That is, inequality rose because the growth process increased the small number of those in the high income sector. Relative to the rest of the population, growth increased the proportion of the rich.

This is the phase of growth when the Kuznets curve has a positive slope: when growth increases inequality. But that is not the end of the story. Industrial expansion created a wide variety of urban jobs, most of which paid more than rural wages and most of which had to be filled by rural migrants. Gradually, the relative size of the urban sector expanded and the rural sector contracted. When the urban sector got big enough, its further growth reduced inequality rather than increasing it. Once the majority of people had joined the highincome sector, the number left behind in the low-income rural sector mainly determined inequality. After that point, further growth reduced inequality because it reduced the proportion of the poor or those in the low-income sector.

Kuznets offers a hypothetical explanation which may or may not account for the trends in inequality in the United States and Great Britain. However, it illustrates two points that are crucial for investigating inequality and growth in Latin America. First, growth is specific, not universal. Second is the idea of linkages. Linkages are the connections between other sectors or economic actors and the sector in which growth is occurring. In the Kuznets account of industrialization, the linkage was rural to urban migration. Urban jobs were created and then filled by rural migrants who moved to the cities to take advantage of industrial urban expansion.

Another example of a Kuznets process can be seen in the relation between education and growth. Growth creates jobs for educated labour. Returns to education rise, and the proportion of university and secondary graduates in the labour force gradually expands. At first, inequality rises because the variance of education in the labour force increases. When the proportion of poorly educated workers has fallen far enough, however, further expansion in the proportion of the labour force with university and secondary education will begin to reduce educational variance. This is analogous to the rural-urban migration case developed by Kuznets, although in this case there is no physical migration. Rather, those who would have gone into the labour force with low levels of education obtain higher levels to take advantage of the job opportunities created by growth. 
These Kuznets-type linkages are not the only ones that are relevant in considering the relation between growth and inequality. Hirschman-type linkages are also important channels by which the benefits of growth in dynamic or leading sectors reach the rest of the economy. In the Hirschman case, the benefits of growth do not come from migration; they come from the expanded demand for inputs to the dynamic sector (backward linkages) or from cost reductions and expanded production possibilities downstream (forward linkages). The stronger these linkages are, the broader or wider are the impacts of the initial growth stimulus. Yet another type of linkage comes from the consumer demands of the initial beneficiaries of growth. As those in the dynamic sector increase their consumption, a multiplier effect increases the demand for housing, urban services and consumer products. All of this helps spread the income from the initiating, dynamic sector throughout the rest of the economy.

Linkages are a key determinant of the relation between growth and inequality, for they determine the "spread effect" of growth in the economy. The stronger they are, the faster and further the benefits of growth will spread, and the more equitable growth will be. This notion can be applied in a variety of important ways in Latin America. Some economies feature large regions or indigenous populations that are only weakly or marginally connected to the modern, dynamic sector where growth is occurring. The north-east and north of Brazil, the Andean region of Peru and the indigenous areas of southern Mexico are powerful and tragic examples. In these three cases, and many more besides, linkages are weak. The areas themselves have a significant proportion of the nation's population, which means that their relative income levels will have a noticeable effect on inequality, but for reasons that are not entirely understood, growth in the dynamic sectors does not induce much forward or backward linkage activity. As a result, when these countries grow, the spread effect to their backward or poor regions is quite limited. Growth under these conditions tends to be inequitable. One could say that in these countries inequality is high because of growth, in the sense that if the entire country had remained in the same conditions as its backward regions, inequality would be lower. Growth always leaves some people behind. The key point here is that if the linkages are weak and the areas left behind are large, then the economy will experience little movement toward the Kuznets turning point, and the interval in which growth is inequitable is likely to be a long one.

For the same reason, inequality is likely to rise with growth in counties that have large indigenous populations. Typically the links between indigenous people and the rest of the economy are weak. When growth occurs, it provides little stimulus to the incomes of the indigenous population. Conversely, inequality is likely to be lower in smaller, more homogeneous economies. Small countries with homogeneous populations are unlikely to have backward 
regions or groups that are disconnected from the modern economy. Examples include Argentina and Uruguay, where the bulk of the population lives in a small number of interconnected urban areas. When this sort of country grows, a greater share of the population benefits, because most people are directly or indirectly linked to the sector where the growth stimulus began. Heterogeneity is a key issue in comparisons of the distribution statistics of small, urban economies like Hong Kong or Singapore with those of big, diverse economies like Brazil or Mexico.

If linkages and relative homogeneity are important, urban income distributions should have a lower level of inequality than nationwide distributions, and so they do. In a cross-sectional study discussed below, the urban Ginis are systematically three to five points lower than the national Ginis, and these differences are highly significant. Furthermore, the relation between changes in income and changes in distribution is also different in the urban sector. Because linkages are higher across a greater fraction of the urban than the national population, the spread effects of growth are larger in the urban sector. Growth tends to benefit more of the population of the cities. To put it another way, the Kuznets curve should be flatter in the urban sector because the economy is more homogeneous and the trickle-down effect of growth is stronger in the cities. It is not that growth does not create wide income differentials between the dynamic leading sector and the rest of the urban economy, but rather that the leading sector has a lot of backward and forward linkages within the remainder of the urban economy.

\section{The Adoption of Reforms}

Over the last 25 years a dramatic change in development policy has occurred in Latin America and the Caribbean. As countries came to accept that the old model of State-directed import substitution industrialization was not sustainable, profound structural reforms were implemented in tariffs, taxes, the control of the international and external financial system and, to a lesser extent, the role of State enterprises and labour regulation. All of these reforms aim to open up the internal economy to foreign competition, reduce the role of the government in directing the allocation of resources and production in the economy and limit the distorting effect of the tax system on private decision-making. (For an overview of the reforms and their impact, see Stallings and Peres, 2000.)

5 For the poor, these feedbacks may be nothing more than an increased demand for guards, drivers, gardeners and domestics, all of which will be provided by urban unskilled labour. This is a trickledown effect of growth that helps to reduce urban poverty. 
This book measures the impact of these various reforms on the distribution of income. This requires some sort of quantifiable index with which to compare the extent of reforms between countries or the progress of reforms over time in a single country. Morley, Machado and Pettinato (1999), building on the work of Eduardo Lora at the Inter-American Development Bank (IDB), provide a set of reform indexes that are useful for econometric analysis (see Lora, 1997). These indexes give a good idea of what was reformed in each country, when the change occurred and how far the process has proceeded to date. They are a useful benchmark for both econometric analysis and simple comparisons of distributions before and after the reforms.

To the extent possible, the indexes measure government efforts to implement the reform package. The aggregate index is a simple average of reform indexes in five areas: trade, finance, tax, privatization and capital account. Each area incorporates indicators such as tariff or tax rates which reflect government policy, rather than proxies for those policies such as openness to trade or the government deficit. Each index is normalized to fall between zero and one, with one representing the country and year in which the sector was the most reformed or free from distortion or government intervention, and zero the country and year with the greatest degree of intervention. ${ }^{6}$ This procedure does not imply that a high value for an index is necessarily better than a low one, but only that the sector is closer to a pure, non-government market solution.

The trade reform index is the average of two subcomponents, the average level and the dispersion of tariffs. One of the weaknesses of the index is the lack of a satisfactory measure of non-tariff restrictions; in some cases, such as Brazil, it significantly affected the timing of trade reform. Domestic financial reform is the average of three subindexes: the control of bank borrowing and lending rates and the reserves-to-deposit ratio. Tax reform has four subcomponents: the maximum marginal tax rate on corporate income, the maximum marginal tax rate on personal income, the value added tax (VAT) rate and the efficiency of the VAT. The index for privatization is one minus the percentage of value added in State-owned enterprise to non-agricultural GDP. Capital account reform is the average of four subcomponents reflecting the extent of government control of foreign investment, limits on profit and interest repatriation, controls on external borrowing and capital outflows. Unlike the other indexes, this one is based on a subjective interpretation of the descriptions in the annual Balance-of-Payments Arrangements published by the International Monetary Fund (IMF).

6 Formally each sub index is defined as $I_{i t}=\left(I_{i t}-M i n\right) /(M a x-M i n)$, where IR is the raw value of the index in country $\mathrm{I}$, year $\mathrm{t}$, and Max and Min are the Maximum and Minimum values of the raw index for all countries over the period 1970-1995. 
This definition of reform makes a clear distinction between structural reforms and macroeconomic policy changes such as government deficit reduction, inflation control and exchange rate management. In many countries the reforms and macroeconomic policy changes were adopted together in the face of balance-of-payments or hyperinflation crises. This book explicitly studies the structural reforms only. The impact of macroeconomic policies is captured through their effect on inflation and the level of income.

To some extent, the choice of what to include in the measurement of structural reform is arbitrary. Arguably, the most important exclusion is labour market reform. It is excluded because in Lora's work, the labour reform index by country changed so little between 1985 and 1995, and because his measure does not capture the important changes that occurred in the Southern Cone countries in the 1970s. Elimination of price subsidies is another excluded reform that probably had important effects in some countries.

\section{Reforms by Component}

Figure II-2 presents the region-wide averages for each of the reform indexes. It gives a quick picture of what has been reformed most and when the process occurred. The figure shows that the reform process has been anything but uniform. It started in the 1970s in three of the five areas -trade, financial liberalization and tax reform- and was confined primarily to Argentina, Chile, Colombia and Uruguay. These early reformers were responsible for virtually all of the rise in the trade and financial reform indexes during the 1970s. This period also saw a rise in the tax reform index, reflecting the adoption of value added tax systems in quite a large number of countries. Furthermore, capital account controls were tightened significantly in the early 1970s, due principally to policy changes under the Perón government in Argentina and the military government in Peru. Subsequently, however, there was significant liberalization under the military governments in Argentina and Chile. In this early period, the only privatization was the sale of a large number of relatively small government enterprises in Chile.

After 1982, the Latin American debt crisis not only stalled the reform process but even reversed it in several of the early reformers. Chile, Bolivia and Argentina responded to the debt crisis by imposing temporary controls on capital account transactions. Many countries, including Argentina, Brazil, Chile, Colombia and Peru, also increased tariff and non-tariff restrictions on imports. The process of financial liberalization was either reversed or stalled during this period, and no further progress was made in either tax reform or the opening of the capital account.

Around 1985 a far more general and widespread adoption of the structural reform package began, with a significant acceleration after 1990. Countries 
Figure II-2

\section{REFORM INDEXES, 1970-1995a}

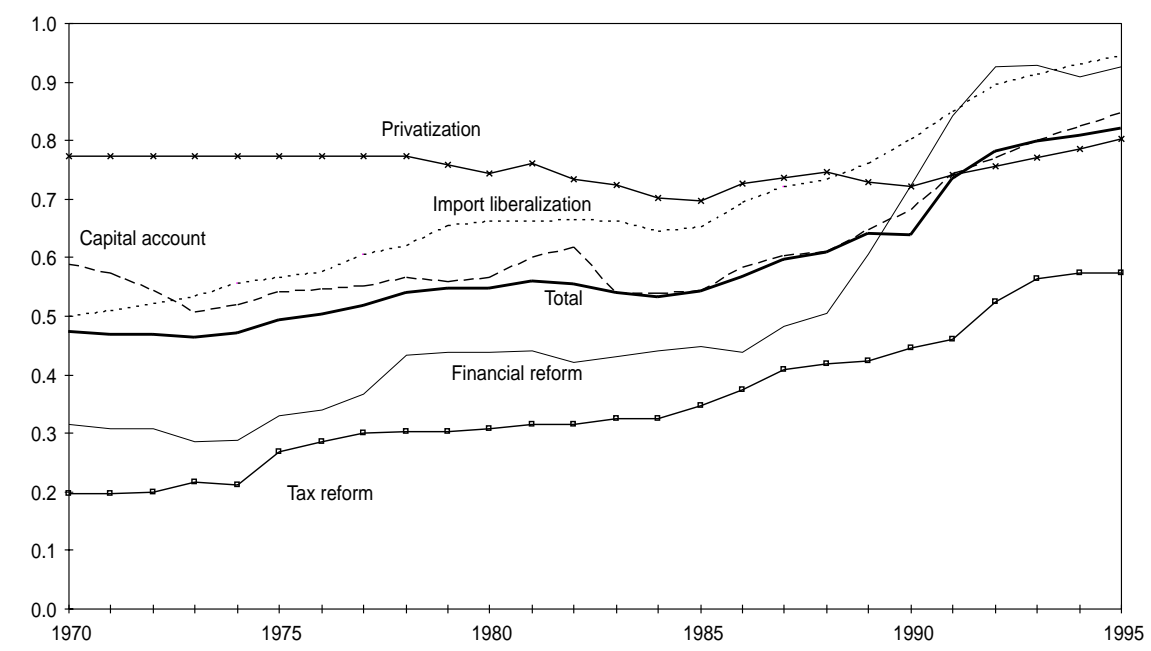

Source: Samuel A. Morley, Roberto Machado and Stefano Pettinato, “Indexes of Structural Reform in Latin America", Reformas económicas series, No. 12 (LC/L.1166), Santiago, Chile, Economic Commission for Latin America and the Caribbean (ECLAC) (January 1999).

aSample includes the nine project countries plus Dominican Republic, Ecuador, El Salvador, Guatemala, Honduras, Paraguay, Uruguay, and Venezuela.

such as Argentina, Chile and Uruguay, which had been leaders in the first round, continued to extend their reforms by further tariff reductions, financial and capital account liberalization and tax reform. ${ }^{7}$ Most of the other countries in the region followed the early reformers by lowering tariffs, eliminating credit and interest rate controls and reforming their tax systems. The government's relation to both internal and external financial markets clearly underwent a major change in this period. Internally, almost all countries decontrolled their interest rates. Externally, there was a quite massive and widespread move to integrate domestic and international capital markets more closely.

7 Chile liberalized the capital account substantially after 1985. However, thanks to the encaje (i.e., compulsory reserve requirements) and other restrictions, even as late as 1995 Chile's capital account reform index was still one of the lowest in the region. 
(i) Trade reform. The reform process started in the 1970s with significant trade, tax and financial reforms in the Southern Cone countries. The biggest and earliest changes were in tariffs and trade regimes. Argentina, Chile and Uruguay were the leaders. For example, Chile went from having the second highest level of tariff protection in the region in 1970 to the lowest in 1982. Uruguay lowered its tariff rates by an even greater percentage. These were not the only countries opening their internal markets, however. For the seventeen countries for which data are available, average tariffs were cut in half over the 1970s. Tariff dispersion and non-tariff barriers such as import quotas were similarly reduced.

After the debt crisis in 1982, trade liberalization suffered a temporary reversal as did other areas of reform, particularly in Chile and Argentina. Quantitative import restrictions were increased until the crisis passed after the middle of the decade. Subsequently, the trade reform process started again and spread to all the remaining countries of the region. The average tariff in the region, which was $46 \%$ in 1985, fell to only $12 \%$ ten years later. By 1995 no country in the region was using its tariff system to protect domestic industry or to promote particular sectors, except for the Brazilian automobile industry. The highest average tariff rate was $18 \%$ in the Dominican Republic, and the average variance of tariff rates between products within countries was reduced from $20 \%$ in 1986 to $6.4 \%$ in 1995.

(ii) Domestic financial liberalization. At the beginning of the $1970 \mathrm{~s}$ government ceilings on interest rates, particularly on loans, were present in most countries in the region. Agood deal of credit was allocated by government decision rather than by supply and demand. In an effort to maintain the financial soundness of the banking system, central banks typically imposed high reserve requirements. The net result of all this was what the development literature called financial repression: that is, a system in which savings and financial intermediation were discouraged. Not only was the resulting volume of investment funds likely to be smaller than it would have been in a reformed system, but it was also likely to be misallocated because of credit controls.

As in the area of trade, financial reforms started first in the 1970s in a few countries (Chile, Colombia and Uruguay). There was then a pause, or even a reversal, for several years after 1982, with the process starting again in most of the countries of the region in the late 1980s and early 1990s. During this period, two reforms were widely accepted: decontrolling interest rates and abandoning directed credit. By 1995 only Venezuela had controls on loan rates, and no country in the sample controlled deposit rates. Information on credit controls is less precise, but clearly the private market, not the government, is now the primary allocator of credit.

(iii) International financial liberalization. Opening the internal financial market to external capital is more recent, more controversial and less widespread than the two reforms considered above. The literature features 
an ongoing debate over the proper sequencing and role of opening economies to trade and foreign capital. Latin American policy makers have reached a clear consensus on the advisability of trade liberalization, but less consensus has been formed on how to treat restrictions or controls on external capital transactions. This is partly due to the risks and increased volatility that come with greater integration of domestic and foreign capital markets. No one doubts that foreign capital can play a positive role in investment and development, but the rapid inflow of foreign capital, particularly in the 1990s, not only increased the exposure to volatility but also tended to drive up the value of the local currency, with adverse effects on the domestic production of tradable goods (see Rodrik, 1998; Ffrench-Davis and Reisen, 1998).

In 1970, all but a couple of Latin American countries maintained a high degree of control over external capital transactions, both for their citizens and for foreigners wishing to invest. Many countries limited the sectors that were open to foreign investors and placed ceilings on the repatriation of interest and dividends. Domestic banks were limited in their ability to borrow abroad, and in most countries capital outflows required previous authorization of the central bank.

Unlike trade and domestic financial reform, opening external capital transactions did not start in a general way in the 1970s. Argentina, Costa Rica, Honduras, Peru and Venezuela had relatively open systems in 1970. Other than Uruguay, however, no country made a major opening in its system prior to the 1982 debt crisis. Indeed, Argentina and Peru significantly increased governmental control over external financial transactions. Only in the late 1980s did capital account liberalization start in earnest, and even then in only a handful of countries, including Argentina, Costa Rica and Guatemala. In the 1990s many more countries adopted this reform. Most of these were smaller economies such as the Dominican Republic, El Salvador and Jamaica. The bigger economies -namely, Brazil, Chile, Colombia and Mexico-all continued to maintain significant controls over foreign capital transactions.

(iv) Tax reform. The fourth component of the reform package is tax reform. Two major elements have been widely adopted. The first was the value added tax (VAT). Reformers argued that while all taxes have distorting effects on private decisions, these are less serious with an across-the-board VAT than with either tariffs or high marginal income tax rates. In addition, tax evasion should be less pervasive with the VAT than with a tax system based on income. The VAT was introduced in the 1970s in nine of the 17 countries for which data are available. In the 1980s all the remaining countries in the region adopted the VAT, and its coverage or efficiency increased in most countries.

A second element of tax reform was the reduction of marginal tax rates on corporate and personal income, which significantly reduced the progressivity of the income tax. Every country in the region reduced its top marginal tax rate after 1970. Not all have gone as far as Uruguay, which 
eliminated personal income tax altogether, but overall the average marginal rate on personal income fell from around 50\% in 1970 to about 25\% in 1995. The average corporate rate fell from $37 \%$ in 1970 to $29 \%$ in 1995. Almost all these changes took place after 1985.

(v) Privatization. The next reform component considered here is privatization. State enterprises were an important part of the old development model, which depended critically not only on tariff protection and directed credit allocation, but also on ownership of key elements of the production structure, especially basic industries such as mining and petroleum companies and infrastructure. Many of these companies performed badly. They often ran significant deficits, which added to the government fiscal problem. ${ }^{8}$ They were chronically short of capital for expansion, depending as they did on the central government for funding. In addition, the level and quality of public utility services failed to keep abreast of either public expectations or demand. Increased demand for accountability and objective standards of resource allocation led governments to turn these companies into private enterprises, thus subjecting them to the discipline of private capital and product markets.

While privatization may make sense to reformers on objective economic grounds, it has often sparked acrimonious political battles in practice. Privatization has therefore been less widespread across countries or across public entities within countries than the other reforms considered above. Chile started the process in the 1970s. Between 1974 and 1978, it privatized more than 500 firms, most of which had been nationalized during the Allende regime (1970-1973). A short reversal of the process occurred after the 1982 banking crisis, but by $199296 \%$ of all Chilean State enterprises had been sold (Edwards, 1995, pp. 171, 186).

The second country to embark on a significant privatization campaign was Mexico under Salinas. By the end of his presidency in 1993, the number of State-owned enterprises had been reduced from 1155 to less than 80 (Edwards, 1995, p. 191). In neither country did the government privatize the biggest natural resource companies (CODELCO in Chile and PEMEX in Mexico). As a result, the change in the share of government enterprises is far smaller with regard to the value of production than for the number of such enterprises. In terms of the volume of transactions between 1985 and 1994, Argentina, Bolivia, Jamaica and Peru were other countries that embarked on significant privatization programmes in the 1990s. In terms of the volume of sales, Argentina and Mexico were the largest reformers, with sales representing between $1 \%$ and $2 \%$ of GDP.

8 Operating losses by government enterprise did not necessarily indicate inefficiency. Some resulted from government price controls on the goods or services these enterprises provided to the public. 
Not all countries undertook privatization. For some, like the Dominican Republic, El Salvador and Guatemala, government enterprise was never a significant component in the economy, while others, such as Ecuador, Jamaica and Venezuela, resisted privatizing important oil or mining enterprises, as well as other government companies.

(vi) Labour market reform. The labour market is the area which has had the least reform in terms of laws and institutional arrangements, with the very important exception of changes under the Southern Cone military regimes in the 1960s and 1970s. According to Lora (1997) only five countries made any significant changes in the 1985-1995 period: Argentina, 1991; Colombia, 1990; Guatemala, 1990; Panama, 1995; and Peru, 1991.

The basic idea behind labour market reform is to increase flexibility and reduce distortions. By flexibility, reformers mean making labour more responsive to changes in demand and production technology. All countries have regulations stipulating how much a firm has to pay a permanent employee whom they want to fire. After one year Bolivia, Ecuador and Mexico require a payment of from 3 to 5.5 months of salary (Lora, 1997). After ten years, the majority of countries in the region require at least 6 months, and eight countries require more than 12 months. Complementary regulations limit the ability to hire temporary labour in 14 countries, and only four (Argentina, Colombia, Ecuador and Peru) have introduced partial liberalizations.

Whether this sort of regulation looks good or bad depends on the perspective of the observer. For workers in permanent jobs, the regulations clearly increase job security and reduce competition from temporary employees. At the same time, the regulations have two costly side effects (see Burki and Perry, 1997). First, they are likely to induce a substitution of capital for labour. They turn labour into a semi-fixed factor of production, which is risky in an uncertain world: unlike capital, workers have to be paid whether or not product demand justifies their presence. The second effect, which is regressive, is that the regulations create a distorted or segmented labour market. A privileged subgroup of workers hold permanent, well-paid jobs, and the rest of the labour force works in unprotected, temporary jobs, many in the informal sector. The reforms sought to reduce the cost of firing, increase the use of temporary labour contracts and set up some sort of unemployment insurance scheme for workers. Except for the sub-group of countries mentioned above, little progress has been made in carrying out this project. In distribution terms, labour reform should help capital, since it increases flexibility and lowers the cost of labour. It should also help those at the bottom of the labour pyramid relative to those in protected, permanent jobs.

A second component of the labour reforms was to reduce the fixed charges or taxes that are based on worker salaries and levied on firms, particularly those charges in which the benefits bear little relation to the contribution. Examples include social security contributions, family allowances, and 
disability, death, sickness and maternity benefits. If these contributions were linked to benefits, they could be regarded as worker compensation that could reasonably be taken into account in determining pay packages. When they are not linked to benefits, they are essentially a tax on labour, which again tends to make production more capital-intensive than it should be, given that labour is an abundant factor in the region. In general, these wage surcharges are high in Latin America, and they were not significantly reduced in the 1985-1995 period (Lora, 1997).

In Chile, the military government reduced the coverage of the minimum wage, relaxed conditions for the dismissal of workers, suspended labour unions, closed the labour courts, limited the permissible activities of labour unions and encouraged the organization of competitive labour unions within enterprises (Ffrench-Davis and Raczynski, 1990, p.8). In Argentina under the military regimes between 1976 and 1983, union activities were prohibited and wage increases were set by the government. This new labour environment, coupled with inflation and the drastic recession after 1982, led to a sharp decline in real wages between 1976 and 1983 (see Beccaria, 1991; Altimir and Beccaria, 1999a). Some of these changes are similar to the labour reform package, but most are not. Rather, what took place in Chile and Argentina in the 1970s was a change of regime, which drastically curtailed the power of independent labour unions vis-à-vis either management or the government and reduced the influence of labour in setting wages. To some extent the latter effect, which also took place in Brazil in the 1960s and Uruguay in the early 1970s, was part of an anti-inflation stabilization programme rather than labour reform as described here. This change of regime had dramatic and regressive effects on distribution in each of the four countries where it occurred.

\section{The Reform Process by Country}

This section disaggregates the overall reform index by country to show more explicitly the timing and degree of reforms (see figure II-3). This average is based only on the five subindexes shown in figure II-2, such that it excludes labour market reforms and the lifting of price controls. The figure shows the level of each country's general reform index at five points of time: 1970, 1982, 1985, 1990 and 1995. The figure is ordered by the level of the indexes for the most recent period, and it holds some surprises. In particular, Uruguay appears as the most reformed country in the region, followed by Argentina and El Salvador. Chile, the quintessential early reformer, is only seventh by 1995 .

There are several reasons for these results. One is convergence. Countries

such as the Dominican Republic, El Salvador, Paraguay and Peru were relatively late in adopting reforms. Once they did, however, they adopted reforms wholesale and across the board. In Chile, reforms were more selective: 
Figure II-3

\section{REFORM INDEXES BY COUNTRY, 1970-1995}

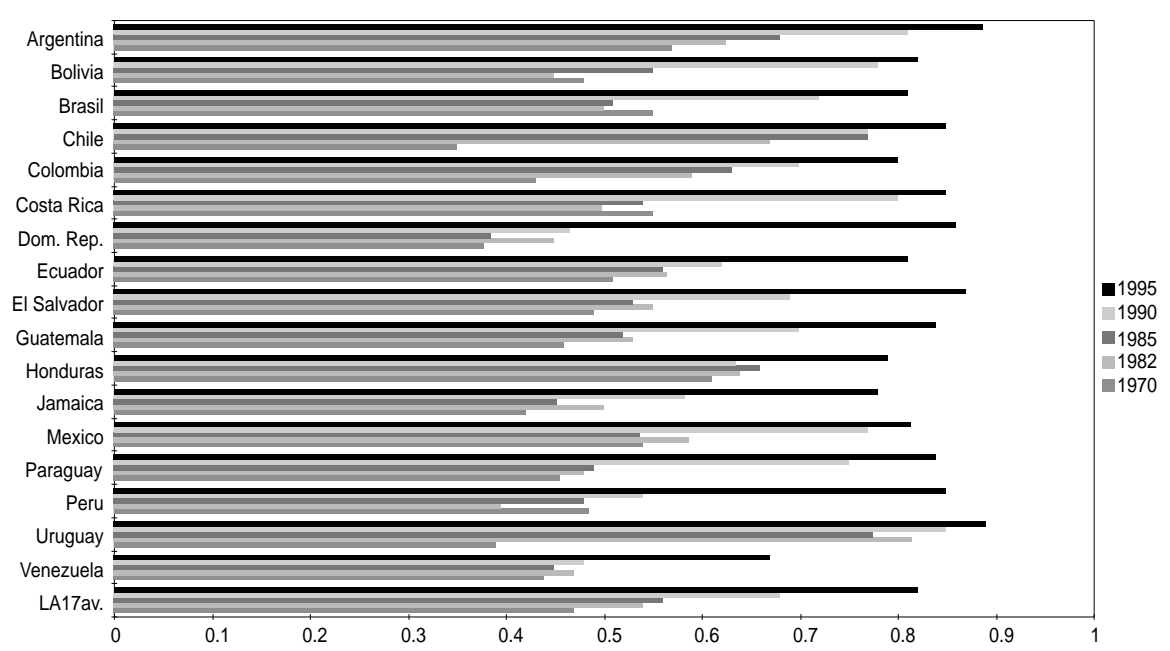

Source: Samuel A. Morley, Roberto Machado and Stefano Pettinato, “Indexes of Structural Reform in Latin America", Reformas económicas series, No. 12 (LC/L.1166), Santiago, Chile, Economic Commission for Latin America and the Caribbean (ECLAC) (January 1999).

Chile has low tariffs and a reformed tax system, but it is below the average in capital account liberalization and only slightly above the average in privatization.

Who were the major reformers in different periods? If "major" is defined arbitrarily as changes in the reform index of more than $50 \%$ over a period, only Chile and Uruguay qualify during 1970-1982. Between 1985 and 1990, the significant reformers were Bolivia, Costa Rica and Paraguay. After 1990, Brazil, the Dominican Republic, El Salvador and Peru all raised their reform index by over $50 \%$. Among the remaining countries, either the process of reform was more gradual, as in the case of Guatemala, Jamaica and Mexico, or, like Honduras, the economy was already fairly liberalized at the beginning of the 1970s. ${ }^{9}$

9 Honduras had the highest reform index of .597 in 1970, and it made very little change over the subsequent decades. 


\section{The Impact of the Structural Reforms}

The previous section described the massive structural policy changes implemented over the last two decades in Latin America. How have these changes affected equity? The broad thrust of the reform package as a whole was to remove any sort of insulation from market-determined resource allocation. Trade reforms removed tariff protection for domestic production; financial reforms and privatization reduced government influence over the allocation of resources. Balance-of-payment reform integrated foreign and domestic capital markets and reduced the capacity of governments to control capital movements. Similarly, labour market reform increased labour flexibility or, to put it another way, reduced labour's ability to defend itself against market-driven fluctuations in demand or wage reductions. Altogether this adds up to quite a breathtaking leap into a new world, justified by expected increases in efficiency, income and growth. Regardless of whether the reforms have had these expected positive benefits, little attention has been paid to the winners and losers in the process or to its distributional implications. Note that the emphasis here is on the structural economic reforms only, not on the impact of the macroeconomic policy changes that led to lower inflation and smaller fiscal deficits.

Several recent studies examine the relation between reforms and distribution. Albert Berry (1998) presents a set of case studies on nine countries in the region. He finds that in every case but Costa Rica, and possibly also Colombia, the period of reforms coincided with a very sharp increase in inequality. The expectation that trade reform would lead to a narrowing in wage differentials has not been borne out in practice, indicating either that Latin America's comparative advantage does not lie in unskilled-labourintensive products or that the opening has forced a shift in technology in favour of more capital- and skill-intensive production. The data for Berry's study end fairly early in the decade of the reforms, so it is unclear whether the rises in inequality that he observes are part of a short-run adjustment or an unfavourable long-run trend.

Victor Bulmer-Thomas' book (1996) comes to equally pessimistic conclusions, though for somewhat different reasons. A theoretical analysis of each of the different reforms leads the contributors to this volume to conclude that, taking all the reforms together, real wages will fall, unemployment will go up, real interest rates will rise, informalization will increase and wealth will become more concentrated, all of which are regressive. However, these predictions are made on the basis of data only through 1992. The book's main conclusion, therefore, is that the problem with the new economic model had less to do with equity than with whether or not the new dependence on markets 
and the private sector would be capable of producing steady and sustainable growth rates in per capita income.

Londoño and Székely (1997) of the IDB come to quite a different conclusion. Using cross-country regressions as opposed to country case studies, they find that equity is positively related to both growth and investment. These, in turn, are positively related to the structural reforms of the new economic model, leading to the conclusion that the reforms are in fact progressive. This is confirmed by a direct correlation of the income shares of different quintiles of the population with indexes of the different reforms. While no significant relation was found between income shares and most of the indexes, trade liberalization was positively related to the income share of the bottom quintile and negatively related to the share of the top quintile. Unlike many other researchers, then, these authors conclude that trade reform helped the poor and unskilled.

A growing literature addresses the effects of trade reform on wage inequality (Robbins, 1995 and 1996; Wood, 1994 and 1997; Edwards, 1997; Ocampo and Taylor, 1998). All these studies conclude that wage inequality has generally risen in countries that opened their internal markets to external competition. While an increase in wage inequality does not necessarily translate into an increase in inequality of total income, these results suggest caution in accepting the Heckscher-Ohlin assertion that trade should help countries with large supplies of unskilled labour. Wood (1994) argues that the experience of East Asia in the 1960s and 1970s supports the theory that greater openness to trade tends to narrow the wage gap between skilled and unskilled workers in developing countries. In Latin American since the mid-1980s, however, increased openness has widened wage differentials. Wood (1997) considers that this conflict of evidence probably does not result from differences between East Asia and Latin America, but rather from differences between the 1960s and the 1980s, especially the entry of China into the world market and perhaps the advent of new technology that is biased against unskilled workers.

Spilimbergo, Londoño and Székely (1997) point out that what really matters is each country's factor endowment, including land, relative to the average world effective supply of each factor. They, too, find that trade openness is associated with higher inequality, for given factor endowments, but the effect depends on the relative abundance of each type of factor. Inequality increases in countries that are relatively well endowed with skills, but it declines in countries that are well endowed with physical capital and land. Since, in their sample, factor endowments in Latin America are relatively close to world averages, the effect of opening on inequality is modest: a rise of $10 \%$ in their openness index only raises the average Gini coefficient by .63 of a point. Latin America, in their empirical specification, does not have a high level of unskilled labour relative to the weighted average of the factor 
endowments of the rest of the world, which is consistent with the entry of China and other large Asian countries into the world trading system. If true, this would explain why, even in a Heckscher-Ohlin world, openness has not reduced the wage differential.

The purpose of trade reform is to switch the production of tradables away from inefficient import substitutes to exportables in which countries have a comparative advantage. The connection with income distribution comes from the differences in factor demand between these two types of products: it is a question of relative factor intensity. However, the demand side must also be taken into account. The success of the old import-substitution, inward-looking development strategy depended to a large extent on a growing internal market. For that sort of strategy to generate satisfactory growth, there has to be a growing middle class with growing purchasing power. Growing real wages are an integral part of that strategy. The mature capitalist economies long ago discovered that both the owners of capital and their workers could profit from a strategy in which rising wages simultaneously increased both costs and profits, because of increases in the size of the internal market induced by rising wage payments.

The export-led growth strategy is completely different. Its success depends on controlling costs, such that the internal market is irrelevant. Rising real wages are a clear threat to growth in the export model. They do not have the positive indirect effect through demand that they have in the inward-looking growth strategy. Countries embarking on the outward-looking growth path are making their wage levels hostage to the wage levels and labour costs in other countries. The advantages of greater efficiency in export production in comparison to that of import substitution may well outweigh the disadvantages of this wage competition, so that in the end workers are better off. That is not immediately obvious, however, particularly in the large economies.

What is the likely effect of liberalizing the capital account? This reform integrates the local and international capital markets more closely, bringing local interest and profit rates (adjusted for risk) closer to rates in the rest of the world. Whether or not this is progressive depends on the reactions of foreign and domestic owners of capital. If foreign investors have been deterred from entering a country because of controls on capital and profit repatriation, the reforms should induce an inflow of foreign capital. The distributional effect is ambiguous. Wage-to-profit ratios should rise because of the rise in the capitalto-labour ratio, which is progressive. At the same time if capital and skilled labour are complementary, the skill differential will rise, which is regressive. A similar ambiguity results from the actions of domestic owners of capital. Part of the liberalization of the capital account involves the removal of restrictions on capital outflows by domestic savers and investors. If the demand for foreign exchange was excessive under capital controls, the reforms should 
cause a capital outflow, with results just the opposite of those described for foreign capital inflows.

Aside from the effect of these reforms on factor supplies and factor demand, removing barriers to capital movements increases the bargaining power of capital in its negotiations with both labour and the government. That is likely to be regressive, for if investors are free to move from one country to another, governments will find it far more difficult to tax capital or to pass regulations that force businesses to shoulder more of the cost of infrastructure or labour regulation. Indeed, in a world of perfect capital mobility, countries would be forced to compete in offering generous tax holidays, subsidized credits and other costly assistance as a way of attracting foreign capital. The same argument is valid for domestic capital. Both government and labour would be forced to accept arrangements that are generous enough to induce domestic entrepreneurs and holders of wealth to leave their money invested in their home country. In this way, opening up the capital account shifts the balance of power in favour of the holders of capital. This is one of the reasons that most Latin American countries have shifted away from the taxation of corporate profits and significantly reduced the top marginal income tax rate in recent years.

Financial reforms eliminated controls on interest rates, lowered the compulsory reserve requirements of banks and reduced the use of directed or subsidized credit. The direct effect of this on the distribution is probably small, but to the extent that these reforms increased private saving and investment, they should be progressive.

The fourth component of the reform project is tax reform, which lowered rates on corporations and personal income and reinforced the role of the VAT. From the distribution perspective, the effect of these changes in the tax system was to shift the tax burden away from the wealthy and toward the middle and lower classes. The introduction and later expansion of the value added tax was a shift away from the taxation of income toward the taxation of consumption. Since the poor consume a greater fraction of their income than do the rich, this change must have been regressive, except in certain countries that exempted basic necessities from the tax. Changes in the income tax amplified the regressive trend. Top marginal tax rates on personal income were lowered, and the corporate tax rate was cut by over $20 \%$. While a full analysis of the incidence of all these changes is beyond the scope of this paper, it is almost certain that they were regressive.

Another important component of reform in the region was privatization. State-owned enterprises were a key component of the old development model, which was dramatically redesigned by the reforms analysed here. The impact of privatization on distribution depends on three elements. First, if the sales price of the assets of the State-owned enterprises is less their true market value, buyers have received a gift from taxpayers. Second, for public utilities like 
electricity, telephone and water companies, the impact depends on what happens to the price of the services they provide to the public. In many cases publicly owned utilities subsidized their customers by selling below cost. Transferring that sort of company to the private sector and eliminating the subsidy could be either progressive or regressive, depending on who their customers were. At first sight, the reform appears regressive. However, a study of gasoline and electricity pricing in Peru and Venezuela came to the opposite conclusion because those wealthy enough to have electric appliances and cars came from the top, not the bottom, of the distribution (Hausmann and Rigobón, 1993). The fact is that most of this sort of subsidy probably benefited the middle class.

Neither of these first two effects are reflected in the distribution data, because they reflect earnings and not expenditure or wealth. But the third effect of privatization is reflected in the earnings data, namely, its effect on labour demand and employment. Labour productivity in the typical Stateowned enterprise was low. For political reasons, many governments seemed more interested in using these enterprises to create jobs than to provide good service at the lowest possible cost. This changed when the State-owned enterprises were sold. Privatizations in places like Argentina and Chile were blamed for a good deal of the job destruction and rising unemployment that accompanied reform. The distributional impact of this depends on who the displaced employees were. There is no good study of this question, but judging from the profile of the labour force of the typical State-owned enterprise, these jobs largely came from the middle of the earnings distribution table. Privatization is thus likely to have mainly hurt the middle class, which represented both the main users of subsidized services of State-owned enterprises and also their main employees. 


\section{CHAPTER III

\begin{abstract}
WHY THE DISTRIBUTION OF INCOME IN LATIN AMERICA IS SO UNEQUAL
\end{abstract}

The comparative figures on equality by region in chapter I make it clear that high inequality is not a recent phenomenon. It is not just a result of the recessions of the 1980s or the economic reforms, but comes from conditions going back far into the past. This chapter addresses the question of why this is so. What structural factors, environmental conditions or government policies can explain such high and persistent inequality?

In the short run, the primary distribution of income is determined by the interaction of three factors: the quantity of factors of production, their ownership and the interplay of supply and demand for those factors. What is critical to an understanding of persistent, high inequality is the role played by the supply and distribution of productive assets in society. There are four assets to consider here: land, skilled labour, unskilled labour and capital. Two of these, skilled labour and capital, are scarce in Latin America, which means that their rates of return are high, and all but unskilled labour are distributed unequally compared with both the industrialized countries and other developing areas. More than anything else, this unequal distribution of scarce assets explains Latin America's excessive inequality. The situation has no doubt been exacerbated by the relatively skill- and capital-intensive growth strategy, which raised profit rates and the return to education. That would not have mattered so much, however, if the ownership of human and physical capital was more widely dispersed.

\section{A. Education}

Education is one of the keys to the distribution puzzle. Latin America has a highly unequal distribution of education and the highest skill differentials 
in the world. Dozens of studies show that level of education and experience are the major determinants of an individual's position on the income distribution scale (see in particular Birdsall and Londoño, 1997; Londoño and Székely, 1997). It is therefore reasonable to expect that a large part of the explanation of earnings inequality must lie in the educational profile of the population and in the skill differential.

Another puzzle is how to explain Latin America's high and persistent education wage differentials. Surprisingly, they cannot be explained by a relative scarcity of university graduates. Compared to the typical Asian economy, the proportion of university graduates in the adult population is actually higher in Latin America. Yet the returns to university education are higher in Latin America than they are in Asia. Furthermore, the share of university graduates in the labour force has expanded rapidly in Latin America since 1970, yet skill differentials have widened. These are critical factors for explaining why inequality has not decreased in the region, but they do not explain why the expansion of supply has not driven down education differentials and rates of return to university education. This is one of the questions addressed in this section.

Good historical or comparative data on wage differentials between skilled and unskilled labour or between different education groups are surprisingly scarce. Lora and Márquez (1998) compare average white- and blue-collar wages in Latin America and several other regions. Their data show that the whitecollar differential in Latin America in 1982 was twice as high as in the developed countries and 50\% higher than in the four Asian Tigers..$^{10}$ Since 1982 that differential has fallen everywhere but in Latin America, where it has actually risen sharply since 1988 despite increases in the share of college and high school graduates.

Figure III-1 presents simple averages of wages for various occupations. Such statistics aggregate the effect of experience, education and other factors. Another way of estimating education wage differentials is to run cross-section regressions of earnings on education, experience, gender and other relevant factors and then to use the coefficients on education to calculate rates of return by educational level. Returns to higher education are high in all developing countries (at least $20 \%$ ). In every part of the world they are higher than those of both secondary and primary education (see IDB, 1998, figure 2.23). This same pattern holds within most Latin American countries (see IDB, 1998, figure 2.24). From a comparative perspective, the return to higher education in Latin America is higher than in Asia or the industrialized countries, which is consistent with the evidence in figure III-1.

10 Hong Kong (China), Republic of Korea, Singapore and Taiwan (Province of China). 
Figure III-1

\section{RELATIVE WAGES: WHITE COLLAR VERSUS BLUE COLLAR, 1982-1997}

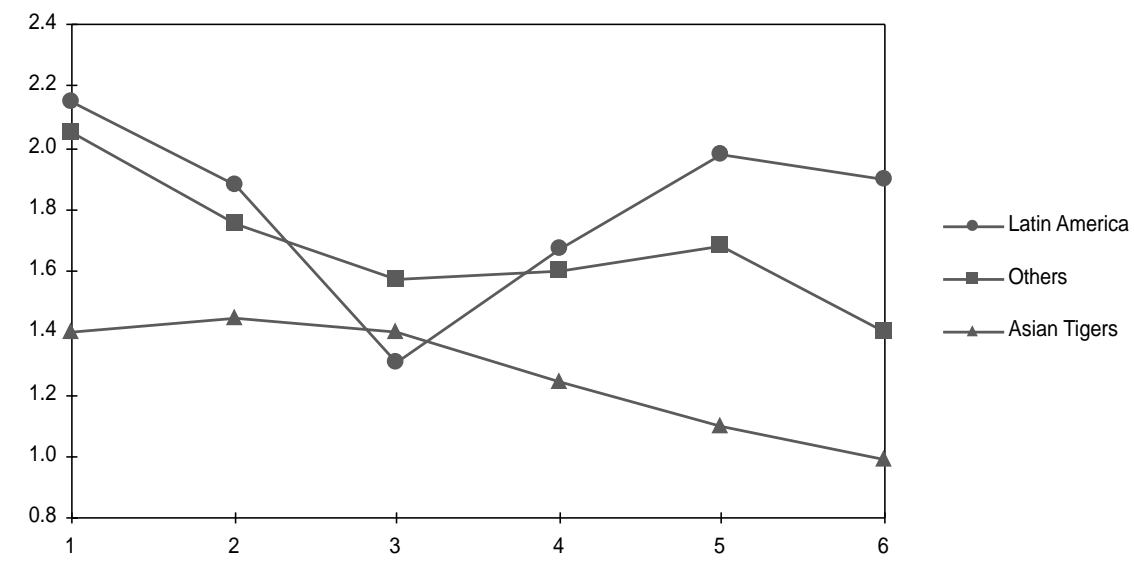

Source: Inter-American Development Bank (IDB), Economic and Social Progress in Latin America, 1998-1999 Report, Washington, D.C. (1998).

Thus, all the evidence points in the direction of a high skill differential in Latin America. It is high relative to other developing countries, and it rose in the 1990s in most of the cases for which survey evidence is available.

Efforts to explain these relative skill differentials naturally lead to questions about demand and supply. The demand for skills is not directly observable, but the supply is. Barro and Lee (1996) assemble a data set that gives the educational composition of the adult population for 138 countries. Using the profile of the adult males in that sample as a proxy for the labour force as a whole allows for an interesting comparison between Latin America and Asia. The question to keep in mind is whether differences in the educational profile between regions or countries help explain differences in relative wages (see figures III-2 and III-3).

The educational profiles in the two figures highlight the surprisingly large proportion of university graduates in Latin America and the small number of adults with no more than a high school education. Every country in the sample has a higher proportion of college graduates than Indonesia, and thirteen have more than Singapore. In contrast, no country in Latin America has as high a proportion of high school graduates as Malaysia, Korea or Taiwan. Thus, if skilled labour is equated with university graduates, Latin America has a higher proportion of skilled labour than all but two Asian countries (Korea and Taiwan). That being the case, the puzzle is why the rate of return to college 
Figure III-2

LATIN AMERICAN EDUCATIONAL PROFILE, MALES OVER 25, 1985

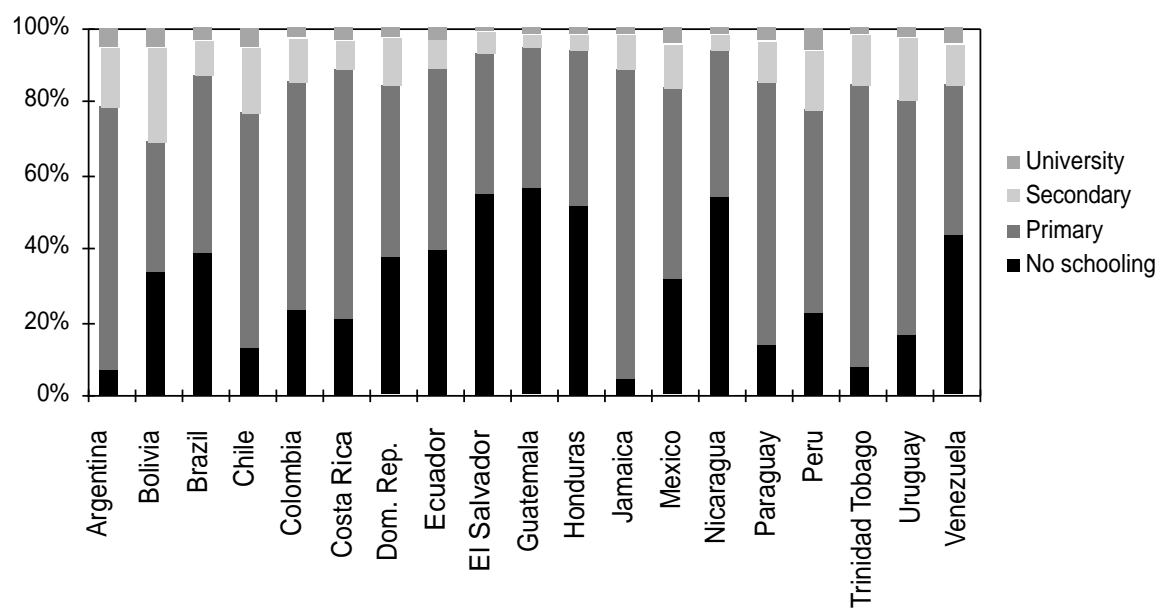

Source: Robert Barro and Jong-Wha Lee, "International measures of schooling years and schooling quality", American Economic Review Papers and Proceedings, vol. 86, No. 2 (1996).

Figure III-3

ASIAN EDUCATIONAL PROFILE, MALES, 1985

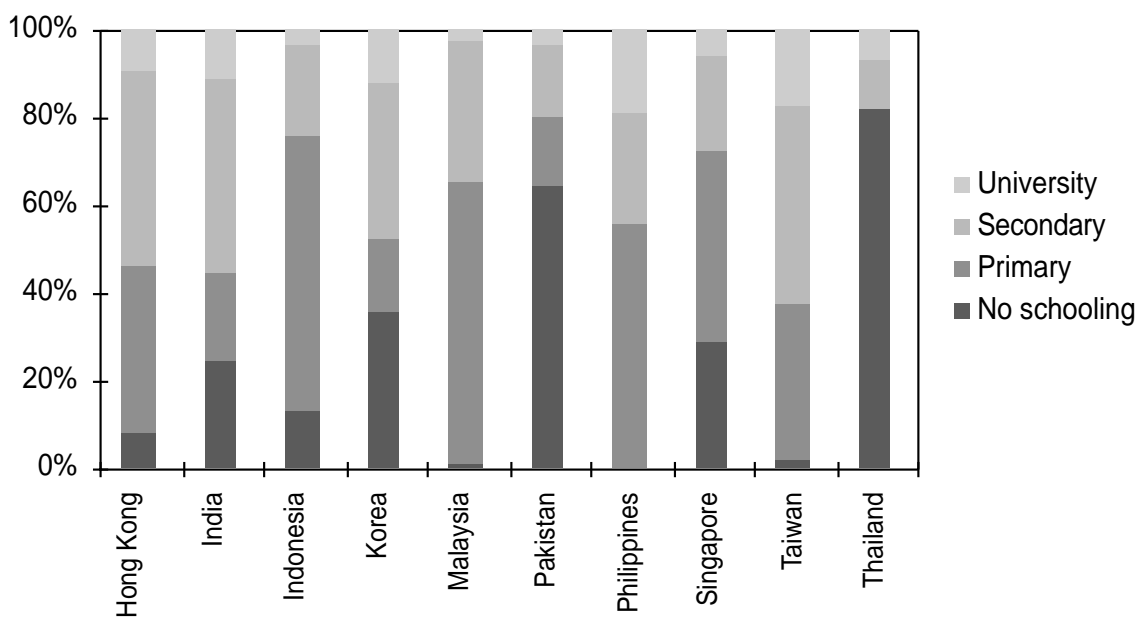

Source: Robert Barro and Jong-Wha Lee, "International measures of schooling years and schooling quality", American Economic Review Papers and Proceedings, vol. 86, No. 2 (1996). 
graduates is higher in Latin America than it is in Asia. Either demand must be very skill intensive in Latin America, or some other factor or factors must be at work.

It is possible that in developing countries, the pool of skilled labour includes both college and high school graduates. By that definition the four Tigers plus Malaysia have more skilled labour than most Latin American countries, which could help explain the white- versus blue-collar wage differentials. But the puzzle still remains about why the relative rates of return to university education in Latin America are so high compared to other areas.

The educational structure of the labour force in Latin America has undergone significant changes since 1970 (see table III-1). Most countries have succeeded in universalizing primary school education in the young cohorts entering the labour force. Over time this has reduced fairly sharply the percentage of the labour force without education, but too many are still dropping out after completing primary school in order to enter the labour market. This is particularly true in countries like Bolivia, Brazil, El Salvador, Guatemala and Honduras, where the education level of the 1970 labour force was relatively poor. In those countries, a good deal of the progress in reducing the group with no schooling has been offset by an expansion of the group with no more than primary education. In 1985 more than three-fourths of the adult males still had no more than primary schooling in eleven countries in the sample. Only three countries in the Asian sample demonstrate a figure that high. ${ }^{11}$

In the period since 1970, the Latin American experience differs most sharply from that of Asia in the rapid expansion of the university component relative to secondary education (see table III-2). In Asia both the secondary school and university component practically doubled between 1970 and 1985. That is not the pattern in Latin America, where the share of university graduates expanded twice as fast as high school graduates. Asia put a lot of its education dollars into eliminating the bottom tail of its educational distribution and universalizing secondary education. Latin America let most of its young cohorts leave school after the primary level, using the money instead to expand university coverage.

11 The data shown in table III-1 for 1995 are projections based on the observed changes in shares between 1960 and 1985, the last year for which Barro and Lee have internationally comparable firm observations. Thus, comparisons of Latin America with Asia are based on the 1985 observations rather than the projections. 


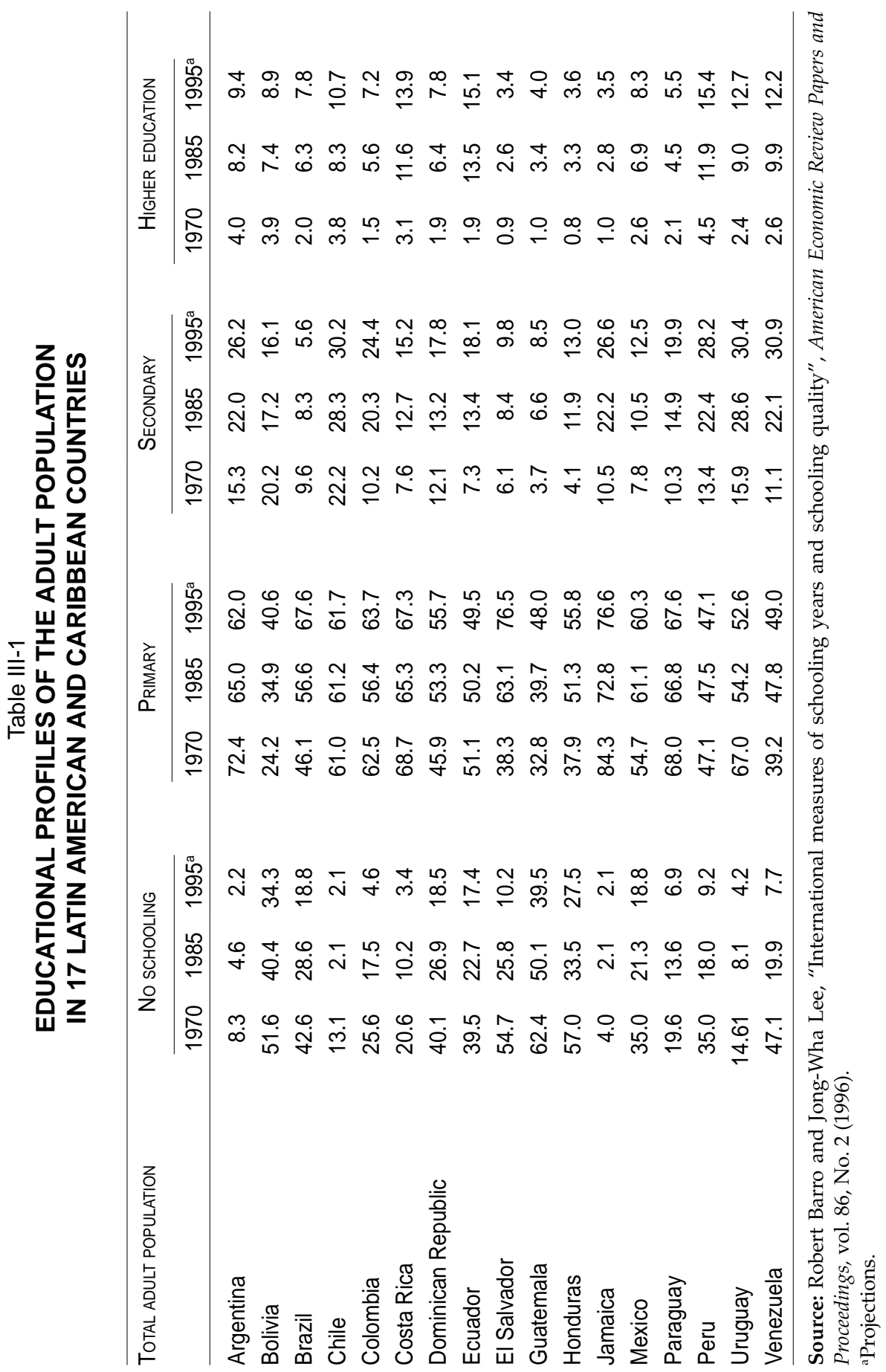


Table III-2

AVERAGE GROWTH BY LEVEL OF EDUCATION
IN LATIN AMERICA AND ASIA, 1970-1985

\begin{tabular}{lcccc}
\hline & No SCHOOLING & PrIMARY & SECONDARY & UNIVERSITY \\
\hline Latin America & 0.57 & 1.10 & 1.61 & 3.24 \\
Asia & 0.64 & 1.04 & 1.91 & 2.25 \\
\hline
\end{tabular}

Source: Robert Barro and Jong-Wha Lee, "International measures of schooling years and schooling quality", American Economic Review Papers and Proceedings, vol. 86, No. 2 (1996).

Two aspects of this difference between the two areas are important to this discussion. First, Latin America has expanded the supply of university graduates in the labour force faster than Asia. Therefore, rising relative wages or returns to university education in Latin America cannot be attributed to a failure to expand supply. Second, the university-intensive education strategy followed by Latin America has increased the variance in the ownership of human capital, or what could be called educational inequality. When any country begins a process of upgrading the education of its population, educational inequality increases as the educational level of the younger cohorts improves relative to older cohorts. That tendency is gradually reversed as older cohorts retire and are replaced by young cohorts who are better and more equally educated. The Latin American educational strategy has delayed this turning point. Not only is educational inequality still increasing in the region, but it is also increasing faster than would be expected compared with the experience of other countries. Londoño and Székely (1997) show the standard deviation of education rising along with education levels, from just over three years in the 1960s to over 4.5 years in the 1990s. That is over twice the increase in educational inequality that would be predicted from the increase in average educational level over the same period.

Comparative evidence within Latin America also shows that educational inequality increased in the 1990s. Table III-3 compares the average years of education of adults ( 25 years of age or older) at different income levels in the most recent household surveys with the same measure for 1989 for those over 18 years of age. Because of the difference in the definition of adults, the absolute values for the two years are not strictly comparable, but the ratio of the average education level of those in the top quintile to those in the bottom is comparable. This measure rises in every country but Brazil, meaning that the educational differences between the rich and the poor are rising in Latin America. So far, trends in educational inequality have not helped to reverse income inequality in the region. 
Table III-3

\section{EDUCATION BY QUINTILE}

\begin{tabular}{|c|c|c|c|c|c|c|}
\hline & \multicolumn{3}{|c|}{$\begin{array}{c}\text { AVERAGE EDUCATION IN MOST RECENT YEAR, } \\
\text { 25YEARS OF AGE OR OLDER }\end{array}$} & \multicolumn{3}{|c|}{$\begin{array}{c}\text { AvERAGE EDUCATION IN } 1989, \\
18 \text { YEARS OF AGE OR OLDER }\end{array}$} \\
\hline & $\begin{array}{c}\text { 1ST } \\
\text { QUINTILE } \\
(1)\end{array}$ & $\begin{array}{c}\text { 5TH } \\
\text { QUINTILE } \\
(2)\end{array}$ & $\begin{array}{l}\text { RatıO } \\
(2) /(1)\end{array}$ & $\begin{array}{c}\text { 1ST } \\
\text { QUINTILE } \\
(1)\end{array}$ & $\begin{array}{c}\text { 5TH } \\
\text { QUINTILE } \\
(2)\end{array}$ & $\begin{array}{l}\text { RAtio } \\
(2) /(1)\end{array}$ \\
\hline Argentina & 7.26 & 12.35 & 1.70 & 6.6 & 11.0 & 1.66 \\
\hline Bolivia & 6.20 & 11.75 & 1.89 & 7.0 & 10.4 & 1.48 \\
\hline Brazil & 2.23 & 8.98 & 4.01 & 2.1 & 8.7 & 4.14 \\
\hline Chile & 6.56 & 11.85 & 1.80 & 6.1 & 10.9 & 1.78 \\
\hline Costa Rica & 4.48 & 10.07 & 2.24 & 4.8 & 9.4 & 1.95 \\
\hline Ecuador & 3.89 & 10.51 & 2.70 & n.a. & n.a. & n.a. \\
\hline El Salvador & 1.88 & 8.69 & 4.61 & n.a. & n.a. & n.a. \\
\hline Honduras & 2.20 & 8.22 & 3.73 & 2.1 & 7.5 & 3.57 \\
\hline Mexico & 2.54 & 10.51 & 4.12 & 3.0 & 9.0 & 3.00 \\
\hline Panama & 4.83 & 12.22 & 2.52 & 5.1 & 11.7 & 2.29 \\
\hline Paraguay & 3.52 & 9.30 & 2.64 & 6.3 & 11.2 & 1.77 \\
\hline Peru & 4.02 & 9.92 & 2.46 & 7.1 & 11.1 & 1.56 \\
\hline Uruguay & 6.17 & 10.80 & 1.75 & 6.1 & 10.4 & 1.70 \\
\hline Venezuela & 4.80 & 9.69 & 2.01 & 6.3 & 9.9 & 1.57 \\
\hline
\end{tabular}

Source: Inter-American Development Bank (IDB), Economic and Social Progress in Latin America, 1998-1999 Report, Washington, D.C. (1998); A. Psacharopoulos and others, "Poverty and Income Distribution in Latin America: the Story of the 1980s", Technical Paper, No. 351, Washington, D.C., World Bank (1997).

Rising educational inequality in the region is partly a result of the Latin American educational strategy. On the one hand, the group with little or no education (the left hand tail of the distribution) was substantially reduced; that was helpful. On the other hand, the number of university graduates(the right hand tail of the distribution) expanded significantly. This increased educational inequality, given the relatively small size of the group at the beginning of the period. To put it another way, in Latin America the expansion in educational opportunities above the primary school level was limited to a small minority of new entrants. In contrast, the Asian strategy expanded the group in the middle -that is, those with high school education- relative to the top, and of course, a larger share of their labour force was in this group to start with. In variance terms, Asia reduced the left-hand tail and expanded the middle of the distribution, thus equalizing education over the labour force; 
Latin America did not. Eventually the educational inequality trends will reverse in Latin America, as they have in Asia, because intra-cohort inequality is now falling in almost all the countries in the region. However, the Latin American strategy of expanding primary and university education at the expense of secondary education has delayed the point at which overall educational inequality will begin to decline in the majority of countries in the region.

Within Latin America, there is a negative relation between the level and the variance of education. ${ }^{12}$ Countries such as Argentina, Chile and Uruguay have the highest average levels of education together with low levels of educational inequality. They also have the highest percentage of secondary school graduates in their labour forces. One of the reasons that educational inequality is still so high in the region is that the late educators, such as Brazil, El Salvador, Guatemala, Honduras and Mexico, have not followed this example. They still lose too many potential students before they get to the high school level.

The relevance of educational inequality to the distribution of income can be seen in figure III- 4 . The figure calculates the variance of education level for 14 countries by decile in Latin America using data from IDB (1998) and relates it to a recent Gini coefficient for each country. The relation between the two is not particularly close, but it is a clearly positive.

The distribution of income is related to both the return to and the variance of human capital. Both have increased in the last twenty-five years despite the sizeable investments in education that have been made in the region. So far, changes in the educational profile of the labour force in the region have not succeeded in reducing income inequality, and they may have actually increased it.

Two factors are at work here: the wage differential earned by better educated workers and the distribution or variance of education in the labour force. The two usually move together, that is, if the supply of the educated expands, the skill differential generally narrows. That did not happen in Latin America, however. To complicate matters further, it is quite possible for the wage differential to rise and earnings inequality to fall at the same time if there is a sufficient expansion in the numbers of the educated or a contraction in the numbers of the uneducated. The point here is that both of these factors matter, and they may not move together. Neither the distribution of education nor the wage differential by itself can sufficiently explain differences between countries in either the level or the trend of earnings inequality.

12 Using IDB data (1998, appendix table 1.2.3, p.30), a regression between the variance and level of education shows a significant (at the $10 \%$ level) negative relation. 
Figure III-4

\section{EDUCATION VARIANCE AND INCOME DISTRIBUTION}

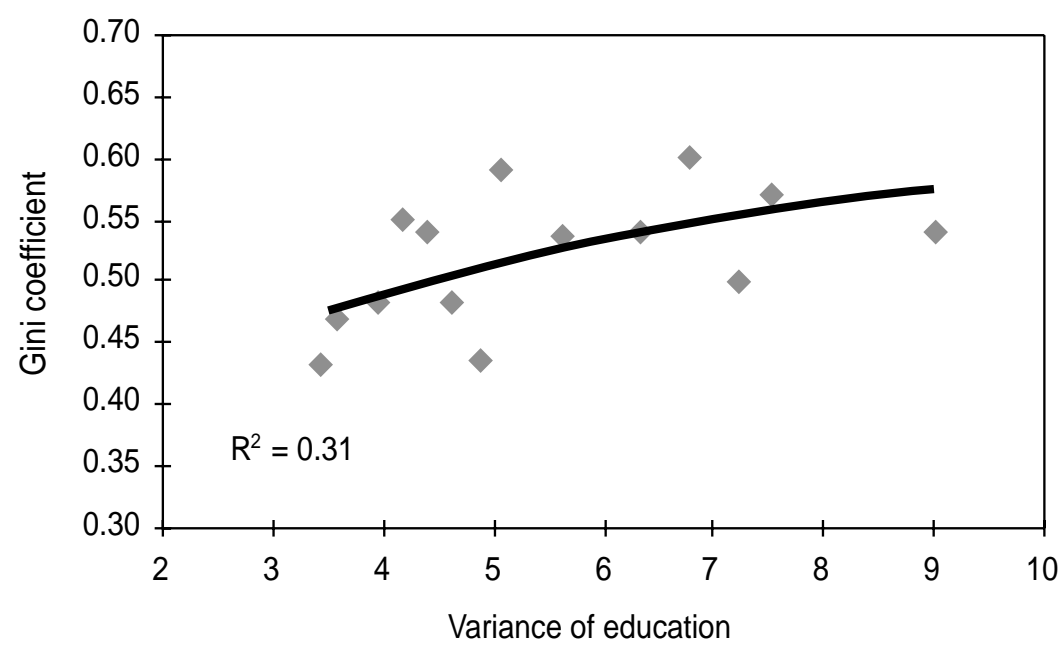

Source: Inter-American Development Bank (IDB), Economic and Social Progress in Latin America, 1998-1999 Report, Washington, D.C. (1998).

\section{B. Physical Capital}

The effect of physical capital or capital accumulation on distribution is ambiguous. The direct effect of increasing the stock of capital per worker should be progressive. Raising the supply of any factor relative to other factors theoretically should lower its rate of return. Since the ownership of capital is highly skewed in favour of the top of the distribution table, lowering the rate of return should reduce the relative income position of the rich.

This progressive direct effect of capital accumulation, however, may well be offset by the indirect effect on the wage differential. Physical capital can be either a substitute for or a complement to skilled and unskilled labour. Suppose it is a complement to skilled labour and a substitute for unskilled labour, as would be the case with construction machinery or computers. Capital accumulation will then tend to raise the demand for, and the wages of, skilled labour while lowering the wages of the unskilled. In this case capital accumulation raises the skill differential, which is likely to make the distribution of labour earnings less equal. This has two opposing effects, namely, the progressive direct effect of lowering the rate of return, and the regressive indirect effect of widening the skill differential. Which of these two effects is stronger, or indeed which factors are complementary to and which are substitutes for physical capital, is an empirical question which can only 
be decided by an examination of the data. The answer may well differ across countries.

In fact, recent estimates of the capital-labour ratio and the Gini coefficients for 14 Latin American countries suggest little if any relation between the two variables (see figure III-5). The regression line shown in the figure has a negative slope coefficient, but it is insignificant. Indeed, removing the outlier in the figure (Costa Rica) causes the relation to disappear altogether. This indicates that capital accumulation is unlikely to be a significant source of improvement in distribution. That would probably still be the case even if there were a strong negative relation with the Gini coefficient, because of the length of time that it takes for investment to significantly change the capitallabour ratio. Suppose that a country raised its investment ratio from $15 \%$ to $20 \%$. If the capital-output ratio is four, which is a reasonable estimate, at most this change in investment could raise the rate of increase in the capital-labour ratio by about $1 \%$ per year.

Figure III-5

\section{CAPITAL INTENSITY AND DISTRIBUTION}

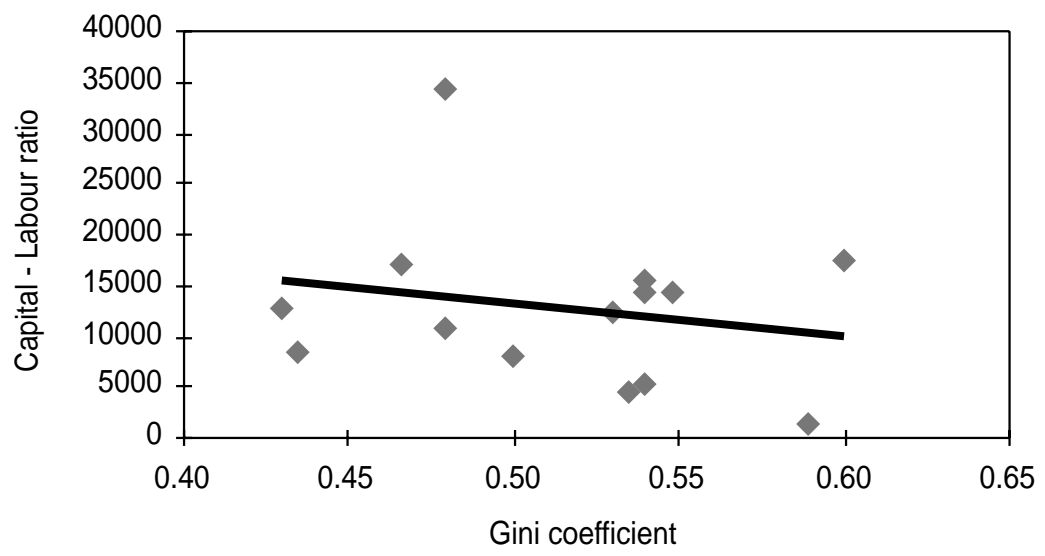

Source: Capital-labour ratios from Robert Summers and Alan Heston, The Penn World Tables: Version 5.6, diskette version (1995); Gini coefficients from appendix A-1 (this volume).

A comparison of the capital-labour ratios of Latin American and Asian countries suggests that low capital-labour ratios cannot be the source of Latin America's excessive inequality. The average capita-labour ratio for the 14 countries in figure III- 5 is 3.5 times that of the Philippines and more than twice that of Thailand. Indeed it is only $25 \%$ less than the capital intensity of Korea. 
The other possible role for capital in explaining excess inequality is if its rate of return or share of national income is significantly higher in Latin America than elsewhere. Unfortunately it is extremely difficult to get good comparable estimates of rates of return, particularly those corrected for risk. However, theory indicates that the removal of barriers to capital mobility that has accompanied globalization in recent years should tend to remove differences. Countries with high rates of return should be receiving capital inflows and seeing a decline in the profit rate as a result.

As to the share of capital in national income and its relation to capital intensity, the IDB comes to the optimistic conclusion that capital formation can be expected to increase the share of labour in national income (see IDB, 1998, figure 4-5). That conclusion, however, is based entirely on a cross-section which includes developed countries with high levels of capital per worker, high labour shares and a low level of inequality. Analysed separately, Latin America does not seem to demonstrate any relation at all between capital intensity and the labour share (see figure III-6). Nor does the average labour share in Latin America differ much from those countries in Asia for which data are available. ${ }^{13}$

Could Latin America's high inequality be the result of a higher profit share in the region? It is well known that the household surveys which serve as the basis for this project's measurement of inequality seriously underestimate total income from profits. Nonetheless, they do contain some income from that source, and, as would be expected, its distribution is far more skewed in favour of the rich than is labour income. For the twelve countries in the IDB study for which data are available in this respect, the average Gini for non-labour income was .64 compared to .53 for labour income alone (see IDB, 1998, appendix table 1.2.1). Because of under-reporting, however, the total amount of income from this source is too small to significantly change the distribution. The Gini for total income including distributed profits is less than one percentage point higher than the Gini for labour income alone. This fact leads to two important conclusions. First, the high inequality reported in household surveys in Latin America comes mainly from inequality in labour income, not profits. Second, because the surveys do not capture profit income, inequality in Latin America must be a good deal higher than would appear from the surveys.

13 The average labour share for 16 Latin American countries was .41 and for five Asian countries it was .43. The former is calculated from ECLAC's national accounts data, and the latter from United Nations, National Accounts Yearbooks. 
Figure III-6

\section{CAPITAL INTENSITY AND LABOUR SHARE}

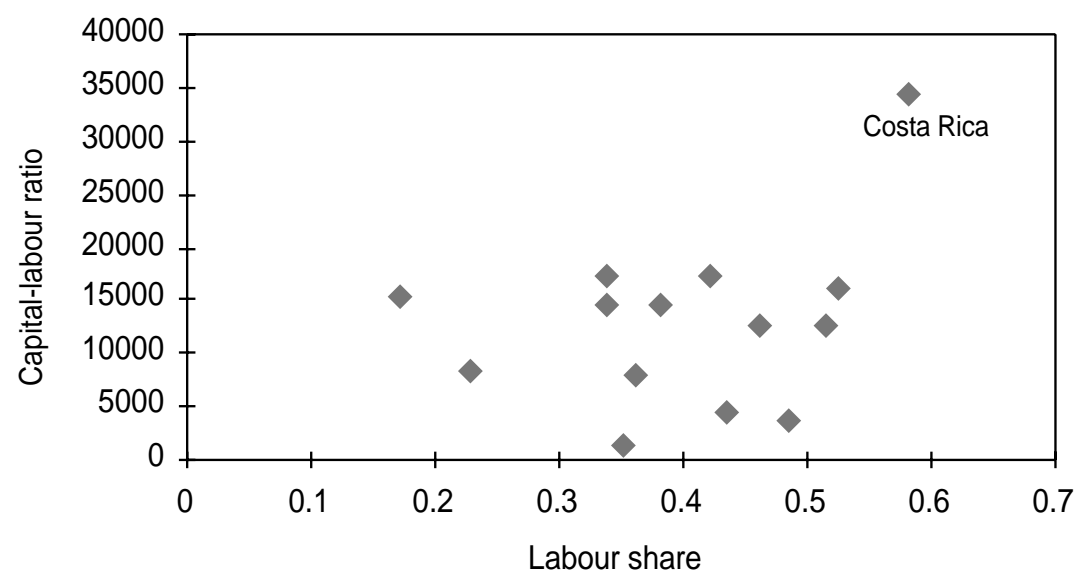

Source: Capital-labour ratios from Robert Summers and Alan Heston, The Penn World Tables: Version 5.6, diskette version (1995); labour share from Inter-American Development Bank (IDB), Economic and Social Progress in Latin America, 1998-1999 Report, Washington, D.C. (1998).

\section{The Distribution of Land and Unskilled Labour}

Latin America has always had the most unequal land distribution in the world. In a recent study of land distribution in developing countries, four countries in the region top the list, and 11 of the top 16 countries are in Latin America. No Latin American country is in the group of low or even medium inequality (Theisenhusen, 1995, p. 9). FAO estimates that around 1970 the largest $7 \%$ of land holdings in the region (those above 100 hectares) accounted for $77 \%$ of the land. At the other extreme, the smallest $60 \%$ had only $4 \%$ of the land. For Asia, holdings over 100 hectares comprised 1.6\% of all land, while $96 \%$ of farms had less than 10 hectares and accounted for $68 \%$ of all land (Cardoso and Helwege, 1992, appendix D).

At first sight it may seem surprising that the region's land distribution should be so unequal, since Latin America, like North America and Australia, had plenty of unowned land when settlement began. Had that land been made available to all comers, however, it would have been impossible to develop a landed aristocracy because the labour necessary to produce an exploitable surplus would not have been available. Obtaining such a surplus required workers who were willing or forced to work for less than their marginal product. When there is cheap or free land available, the wage cannot 
be less than what the workers could produce on their own farms, since otherwise they would start such farms. The availability of cheap land puts a floor under the wage for agricultural labour. Unless production entails significant economies of scale, it will be unprofitable to hire workers, and the typical farm will be a small one that can be farmed by a single family. That was the typical settlement pattern where free land was available in Australia, Canada and the western United States.

In Latin America the settlement patterns were completely different. In the first place, land was not made available to settlers, but rather was reserved by the State or given away in large tracts to a fortunate few. To assure a supply of labour at wages low enough to guarantee an exploitable surplus, some countries resorted to slavery, others to a variety of peonage systems which tied peasants to the land. In Central America, anti-vagrancy laws were passed, which forced peasants to donate a certain amount of labour to estate owners. These are examples of how a small group with political power was able to use the legal powers of the State to maintain its economic position.

The relevance of all this for income distribution is clear. Countries with a very unequal distribution of land tended to have a low reservation wage for unskilled labour in the countryside, particularly as population growth increased in the twentieth century. That condition also meant low wages for the unskilled in the cities because of rural-urban migration. A number of countries attempted to change this inequitable situation through land reform. Bolivia, Cuba, Mexico and Nicaragua are the most extreme examples, but reforms were also implemented in , Chile, Colombia, Costa Rica, the Dominican Republic, Ecuador, El Salvador Panama, Peru and Venezuela (Cardoso and Helwege, 1992, p. 261). In most cases these reforms did not cover a large proportion of landholdings, nor did they significantly equalize land ownership. The reformed land was either put into collective farms, as in the ejidos of Mexico, or later sold by the new owners. ${ }^{14}$

Rather than confronting the powerful landed oligarchs, the more typical solution was for the rural poor to escape to the cities through migration. The cities became the safety valve for the poor landless peasants from the countryside, which is just the opposite of the Turner hypothesis for the United States. By and large, this avoided violent confrontations, but at the cost of transferring inequality and low wages for the unskilled to the cities.

Blocking access to land for the unskilled has the same effect as lowering the supply curve or the reservation wage. This is why relative wages are so low in economies with a large supply of unskilled labour relative to the available supply of land. To make matters worse, the growth rate of the

14 A reform will not be effective in redistributing land unless small farms have a productivity advantage that raises the reservation price above what a large landowner is willing to pay; see Carter and Coles (1998). 
working age population has risen since 1950 because of the lagged effect of reductions in the death rate. In earlier periods the population growth rate was low because the high birth rate was counterbalanced by an equally high infant mortality rate and a short life span. The low growth equilibrium was broken first by a reduction in death rates, then later by a reduction in the birth rate, but there was a lag between the former and the latter. During the interval which demographers call the transition, population growth rate temporarily rises. That transition occurred in Latin America in the period between 1950 and about 1980, with differences across countries, such that the rate of growth of the labour force increased from $1.9 \%$ in the 1950 s to $2.3 \%$ in the 1960 s and $3.8 \%$ in the $1970 \mathrm{~s}$, then fell to $2.9 \%$ in the $1980 \mathrm{~s}$ (Weller, 2000). ${ }^{15}$ The schoolaged population (0-14) peaked as a share of the total population around 1970 (Duryea and Székely, 1998, figure 1).

This caused a quite large increase in the size of young age cohorts in the period after 1950. Those cohorts had to be either educated or absorbed into the labour force. As shown above, for the most part the education system did not expand enough to absorb them, and most entered the labour force with a low level of education and skills. The demographic transition thus increased the growth rate and supply of unskilled labour in a region where lack of access to land and other productive inputs meant that they would flood the cities and drive down the wage for unskilled workers.

To make matters worse, during that same transition period most of the countries in the region were pursuing a development strategy based on import substitution, which implied a rapid growth in the demand for skilled labour and capital rather than unskilled labour. The predictable result was a rise in informalization, stagnation in the real wages of the unskilled and a rise in the wage differential. Furthermore, a backlog or oversupply of poorly educated workers was created, which will have regressive effects on distribution until it is finally eliminated by a combination of more rapid and hopefully more labour-intensive growth, investments in education and a gradual reduction in population growth as the transition comes to an end.

\section{The Contribution of Inequality at the Top of the Distribution}

Another reason why the distribution of income is so unequal in Latin America is that the gap between the average incomes of the rich and those

15 Increases in the participation rate, particularly in the 1980s, affected the magnitude of the changes in the growth rate and moved the peak growth rate back to around 1980; see Weller (2000). 
further down the income pyramid is unusually large. The data show a segmentation between the rich and everyone else which is far greater than what exists in other countries. In other words, the rich in Latin America are much richer relative to the remainder of the population than they are elsewhere. Researchers at the IDB demonstrate this situation in two ways. First, they make a comparison of the differences in average income between adjacent deciles for countries in Latin America and the United States. Surprisingly, they find no significant difference between the inter-decile comparisons of Latin America and the United States except at the very top of the distribution (see IDB, 1998, figure 1.9b). There, however, the differences are very large. For example, the gap between the ninth and tenth deciles is 23 times as large in a typical Latin American country as it is in the United States.

The second method the IDB uses to highlight the significance for overall inequality of the high relative incomes of the rich is by calculating a Gini coefficient with and without the top decile (IDB, 1998, p.16). Obviously that results in a dramatic reduction in the Gini in all countries, but the reductions are much bigger in Latin America than in the United States. Eleven out of 17 countries have a total Gini that is at least twelve points higher than the Gini for the United States. For the $90 \%$ Gini, however, the maximum difference (that of Paraguay) shrinks to only eight points, and for seven Latin American countries it is actually lower than the $90 \%$ Gini for the United States. The excessive inequality in the region does not result from large gaps between those at the bottom and everyone else. Such gaps exist, but the differences between the typical Latin American country and the United States are not large in this respect. A search for the answer to excessive inequality should start with the top of the distribution.

These differences between the top two deciles have a strong positive relation with the Gini coefficient. Figure III-7 shows the relation between the relative incomes of the ninth and tenth deciles and the corresponding Gini for all the countries in the IDB sample; the year is around 1995. The implication of this positive relation is that high levels of inequality are almost always associated with high relative incomes at the very top of the distribution. The same positive relation holds within countries over time. Rising inequality is closely linked to increases in the relative income of the top decile. It would thus appear that a search for answers to excessive inequality in the region should start with a careful look at why those in the top decile are able to earn so much more in most Latin American countries than they can elsewhere.

If the main determinant of inequality is in fact the amount and distribution of assets, the sobering implication is that inequality is unlikely to change much without determined action by governments to change the asset distribution. Market forces alone, even if accompanied by modest improvements in education, will not do much. It takes time to create capital, either human or physical. Even a major effort to universalize primary education or expand the 
Figure III-7

\section{INCOME DIFFERENTIAL BETWEEN NINTH AND TENTH DECILES AND GINI COEFFICIENTS}

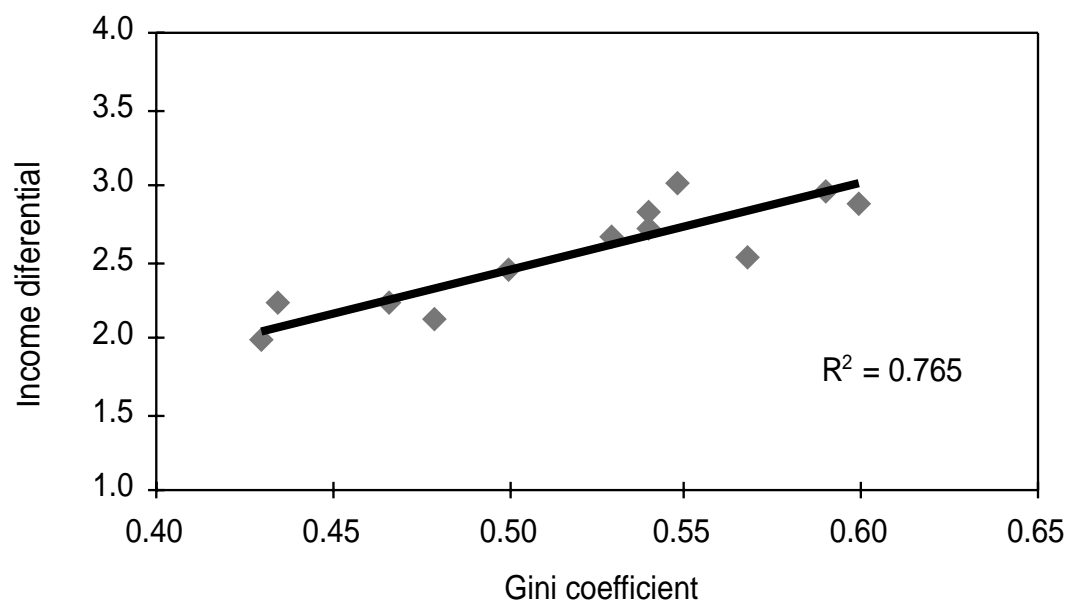

Source: Inter-American Development Bank (IDB), Economic and Social Progress in Latin America, 1998-1999 Report, Washington, D.C. (1998, appendix table 1.2.1).

coverage of secondary school education will take five to ten years to significantly upgrade the young cohorts entering the labour market. Since each cohort of new entrants only comprises $2-3 \%$ of the stock of labour, it takes even longer for educational improvements to make a noticeable dent in the amount or distribution of skills. More can be done, even in the short run, to improve the distribution of land or at least to broaden access to land. The excessive inequality currently found in Latin America is a heritage of past decisions which have left the region with an unequal distribution of assets. The most important of these assets is human capital. There is very little that a society can do in the short run to change that distribution. Latin America today is forced to live with the results of the inadequate education policies of the past. The current growth model or any feasible alternative cannot improve the distribution of earnings unless the quasi-monopoly of the skilled is broken by massive investments that broaden access to valuable skills and reduce the size of the unskilled labour pool. 

ChAPTER IV

\section{THE EFFECT OF REFORM AND GROWTH ON DISTRIBUTION OF FAMILY INCOME}

The previous chapters provided a preliminary look at the evidence on levels and changes in income distribution and proposed some hypotheses about causal relations with macroeconomic variables such as growth, inflation, reform policies and the distribution of assets, particularly land and education. This chapter reports on an econometric attempt to uncover systematic relations between all of these variables and the distribution of family income, using all the evidence that could be assembled from a pooled cross-sectional time series of 16 countries in the region.

Attempting to use pooled cross-sectional time-series evidence to capture a time-series relation for a single country clearly presents serious econometric difficulties. Essentially, it entails the assumption that the relation between distribution and income in today's high-income countries is similar to what the less-developed countries can expect when they reach the income level of the more advanced countries, that is, that unknown country-specific effects on the distribution are not sufficiently important to offset the effect of income growth. The analysis addresses this problem, first, by assembling a database with a relatively large number of time-series observations per country. Second, it incorporates factors other than income that vary across countries and that might be expected to have an impact on the distribution or on its responsiveness to changes in income. Third, a fixed-effects model is used, with country-specific constants to capture any unknown country-specific factors affecting the distribution relation.

Many previous studies attempt to econometrically estimate income distribution models. Most are estimations of the Kuznets relation, using crosscountry distribution and income data (Ahluwalia, 1976; Anand and Kanbur, 1993; Bruno, Ravallion and Squire, 1996; Clarke, 1995; Deininger and Squire, 
1996; de Janvry and Sadoulet, 1999; Fields, 1994; Ravallion and Chen, 1997). All but one of these studies use a worldwide sample of countries. The difficulty with that approach, as Fields (1994) points out, is that since Latin America is a middle-income region and has the highest inequality in the world, the simple choice of the sample can produce an apparent inverse U-shaped Kuznets curve. Fields finds that including a dummy for the Latin American observations causes the supposed relationship between income and inequality to disappear. Deininger and Squire (1996) produce exactly the same result. Bruno, Ravallion and Squire (1996) use data from 63 surveys covering 44 countries to test the Kuznets hypothesis for both levels and changes over time. In no case do they find evidence of an inverted $U$, and in no case is the relation between the distribution and income significantly different from zero. Ravallion and Chen (1997) regress changes in the Gini coefficients against changes in mean real consumption over 64 periods in 67 countries. They find a negative and significant relation between the two in the full sample. When they exclude the observations from Eastern Europe and Central Asia from the sample, however, the relation disappears.

The purpose in this chapter is somewhat broader than simply estimating a Kuznets curve. Rather, the goal is to fit a general model for the determinants of the distribution. Variables other than the level of income which could be expected to have an influence on the distribution are included in the estimation. Consequently, the database is much larger than that typically used in Kuznets curve estimation within the Latin American region. This has been made possible by pioneering work in data collection at the World Bank, the IDB and ECLAC, and by reports and analyses of recent household surveys in a large number of countries in the region. Two different samples are used, one for levels and the other for changes in the distribution. For the level, the sample consists of 262 observations in 16 countries from 1960 to 1997. No country is included in the survey unless it has at least four separate observations. The change sample comprises 124 observations over the same set of countries. Each observation in the change sample is based on a consistent set of estimates by the same researcher using the same methodology. Analysing changes in the distribution as a function of changes in income and other variables should reduce the effect of unspecified country-specific variables which may affect the level of the Gini, but not its responsiveness to changes in income.

Figure IV-1 plots the Ginis and income levels for all the observations in the sample. Many of the surveys obviously entail serious problems of comparability, which carry over to the distribution estimates that come from those surveys. Some of the surveys are based on the distribution of family income, others on family income per capita. Most of the surveys are based on income, but some use expenditure data. 
Figure IV-1

\section{GINI COEFFICIENTS VERSUS INCOME LEVEL}

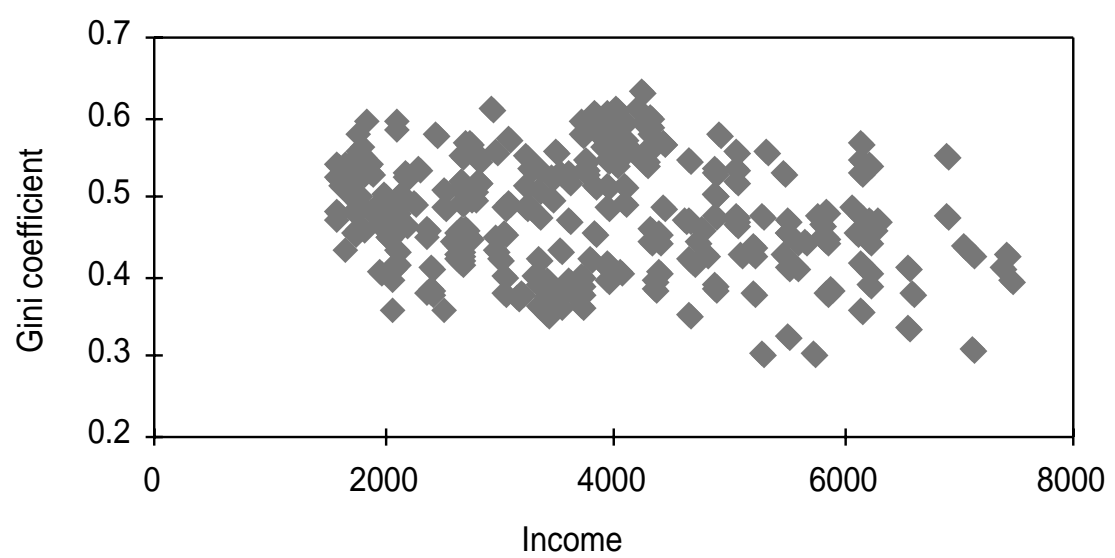

Source: Gini coefficients from appendix A-1 (this volume); income from Robert Summers and Alan Heston, The Penn World Tables: Version 5.6, diskette version (1995).

Another important distinction is between urban and nationwide surveys. Both Fields (1994) and Deininger and Squire (1996) have argued strongly that any analysis of the distribution of income should use only nationwide surveys. However, in many countries (e.g., Bolivia, Ecuador and Paraguay) urban surveys were all that were available until very recently, and in another two (i.e., Argentina and Uruguay) they are still the only surveys available. This presents the choice of either excluding these countries from any analytical work or attempting to control for systematic differences between urban and nationwide surveys by using dummy variables. This paper follows the latter strategy. Not only does this substantially expand the size of the sample, but it also permits the observation of any systematic differences in reaction to income or income growth between the urban sector and the nationwide surveys. The results for the urban and nationwide samples are displayed separately to verify the sensitivity of the estimates to this aggregation.

Because the distribution of assets should have an effect on the distribution of income measures are included for the distribution of land and the distribution of education. The first is a dummy variable which equals one for those countries with an unequal distribution of land. ${ }^{16}$ This variable has two

16 We were forced to use a dummy for this variable rather than a numerical estimate because the estimates for different countries are in some cases not available, and in others they appear to be based on different measures. 
variants, one which takes a value of one for all observations in the countries with an unequal land distribution, and the other with a value of one for the nationwide but not the urban observations. In the second variant, then, all the observations for Paraguay, for example, have a zero for this variable even though Paraguay has a very unequal distribution of land, because all the observations for that country are urban.

Several variables are used to measure the distribution of education, of which two are mentioned here. One is the ratio of the percentage of the adult labour force with university education relative to those with no schooling. This measure reflects the relative supply of skilled and unskilled labour. A second measure is simply the percentage of adults with university education or with no schooling. The rationale for this variant is that growth will have a different effect on inequality in economies in which skilled labour is scarce or abundant. In the former wage differentials should rise, whereas in the latter they may well be constant. That should have an effect on the observed relation between income or income growth and the Gini.

Another important variable which seems to have had a powerful effect on the distribution is inflation. Labour markets react fairly quickly to moderate but not to extreme rates of inflation. When the inflation rate is low, nominal wages adjust and the wage structure may change very little due to price changes. That does not happen in episodes of hyperinflation. Wage adjustments -particularly in the minimum wage-may lag behind the inflation rate. Even if nominal wages are raised by the full amount of inflation, it is still true that the average level of the real wage over the adjustment period is a negative function of inflation. This factor is not particularly important when the inflation rate is low, but it becomes exceedingly important when the rate is high, which is one of the reasons why the interval between wage adjustments gets shorter in periods of hyperinflation. The implication is that high inflation rates may have an impact on distribution. To test for this, the model includes an inflation dummy. In the level regressions, it takes a value of 1 for any year in which the annual inflation exceeded $1000 \%$. The change regressions use a dummy which takes a value of 1 when the inflation rate rises by more than $1000 \%$ and a value of -1 when it falls by more than $1000 \%$.

Finally the regressions incorporate a time trend to test whether there have been systematic changes in the Kuznets curve over time. Both the constant and the income term include a trend. The former tests whether the Kuznets curve has shifted up or down over time, and the latter tests whether the slope of the curve has changed.

\section{A. The Model for the Level of Distribution}

The general regression model for the level of distribution can be written as follows: 


$$
\mathrm{Gini}_{\mathrm{it}}=\mathrm{A}_{\mathrm{i}}+\mathrm{B}_{\mathrm{i}} \mathrm{Y}_{\mathrm{it}}+\mathrm{C}_{\mathrm{i}} 1 / \mathrm{Y}_{\mathrm{it}}+\mathrm{DZ}_{\mathrm{it}}+\mathrm{ER}_{\mathrm{it}}+\mathrm{FS}_{\mathrm{i}}+\mathrm{GT}_{\mathrm{t}} \mathrm{Y}_{\mathrm{it}}+\mathrm{HT}+\text { error }
$$

where i denotes the country and $t$ denotes the year.

A is a regression constant which may vary across countries but, in this model, not across years. $Y$ is income. $Z$ is a vector of variables such as inflation, land distribution and education, which are hypothesized to have an effect on the distribution. $\mathrm{R}$ is the index of reform, and $\mathrm{S}$ is a vector of dummies which reflect various sample characteristics (e.g., urban versus national surveys, household income versus income per capita, expenditure versus income). T is a trend variable.

If there are no country-specific effects, $A_{i}=A$ and $B_{i}=B$. If in addition there are no sample characteristics effects, $\mathrm{F}=0$ and all the countries in the sample are assumed to be on the same Kuznets curve. If there are no countryspecific effects, but sample characteristics are significant, then F is different from zero. Here the observed level of the Kuznets curve differs according to the type of survey, but the slopes are the same. Alternatively, this assumption can be tested by permitting $B_{i}$ to differ among countries and testing whether this alternative specification significantly improves the fit of the regression. The trend terms test for possible shifts in either the slope or the vertical position of the Kuznets curve over time.

Equation IV-1 provides a systematic way to determine whether income and the distribution are related (i.e., whether a Kuznets curve is present), holding other factors which might influence the distribution constant. At the same time it tests the supposed relation between education, land distribution, inflation and the distribution, and -central to the purposes of this bookexamines the effect of reform, holding all these other factors constant.

Tables IV-1, IV-2 and IV-3 estimate the determinants of the distribution of income. Table IV-1, using all of the available observations (the combined sample), shows four alternative regressions: three with fixed effects and one with random effects and a single intercept. The first two regressions use the exact same model and test whether cross-section weights or pooled least squares is the preferable specification. The third regression shows the effect of adding a trend to the constant terms. The fourth points to an explanation of differences between the constants across countries. Tables IV-2 and IV-3 repeat the basic regressions for the urban and nationwide samples considered separately, to see how much the aggregation affects the results. They use a single-intercept model.

Perhaps the most important result is that the general regression model fits the data well, explaining anywhere from $85 \%$ to $97 \%$ of the total variance in the Gini coefficient over time and across countries. In addition, the estimates and significance of the coefficient appear to be robust and consistent across 
the alternative fixed-effects regressions. Of the four specifications, those with fixed effects and cross-section weights (regressions 2 and 3) have the best fit. A Wald test on the sum of squared residuals of the fixed-effects and common constant (or single intercept) regressions (compare regressions 3 and 4) decisively rejects the hypothesis that a single Kuznets curve is common to the different countries. Unspecified country-specific factors significantly affect the level of inequality for a given level of income.

(i) Kuznets Curve. What do the results indicate about the existence or shape of the Kuznets curve? Look at the coefficients on income and the inverse of income. Both are negative and both are highly significant in all the fixedeffects specifications. This is also true in the separate regressions for the urban and nationwide samples shown in tables IV-2 and IV-3, with the exception of the 1 /income term in the urban sample. (This is the term that gives the positive slope to the curve at low levels of income) and the result suggests that in the urban sample the curve is downward sloping over the income range observed in the sample.) This result supports the hypothesis that there is a stable and identifiable relation between income and inequality in the region (a Kuznets curve), and that this relation has the same inverted-U shape that Kuznets found for Britain and the United States. Inequality rises at low levels of income, but at some income level there is an inflection point after which inequality begins to decline as income increases.

This is an important result, but it leaves open the question of whether there really is a single Kuznets curve for all the countries. To test that, I reran the model, this time permitting the coefficients $B$ and $C$ to differ across countries (results not shown). This significantly improves the fit of the regression, which means that the countries differ in the way that inequality reacts to changes in income. Even in this estimation, however, 12 out of $16 \mathrm{~B}_{\mathrm{i}}$ coefficients and 10 out of $16 \mathrm{C}_{\mathrm{i}}$ coefficients are negative, and only two countries (Bolivia and Paraguay) have a positive and significant $B_{i}$. It thus seems fair to conclude that while there are significant differences across countries, the average values of $B$ and $C$ shown in table IV-1 are quite representative of the typical or average relation between income and inequality in the region. It leaves open the question of whether there is a single curve representing both the urban and nationwide samples which is discussed below in the analysis of the urban surveys.

(ii) Education. Education is an important qualifier to this discussion of the Kuznets curve. The model includes three education variables: the percentage of the adult population with no schooling, the percentage with no more than primary schooling and the percentage with university education. A high percentage of poorly educated workers (the primary school variable) has quite a large and regressive effect on the distribution. ${ }^{17}$ According to regression 2 in

17 This finding is consistent with results from other cross-section studies; see Bruno, Ravallion and Squire (1996). 


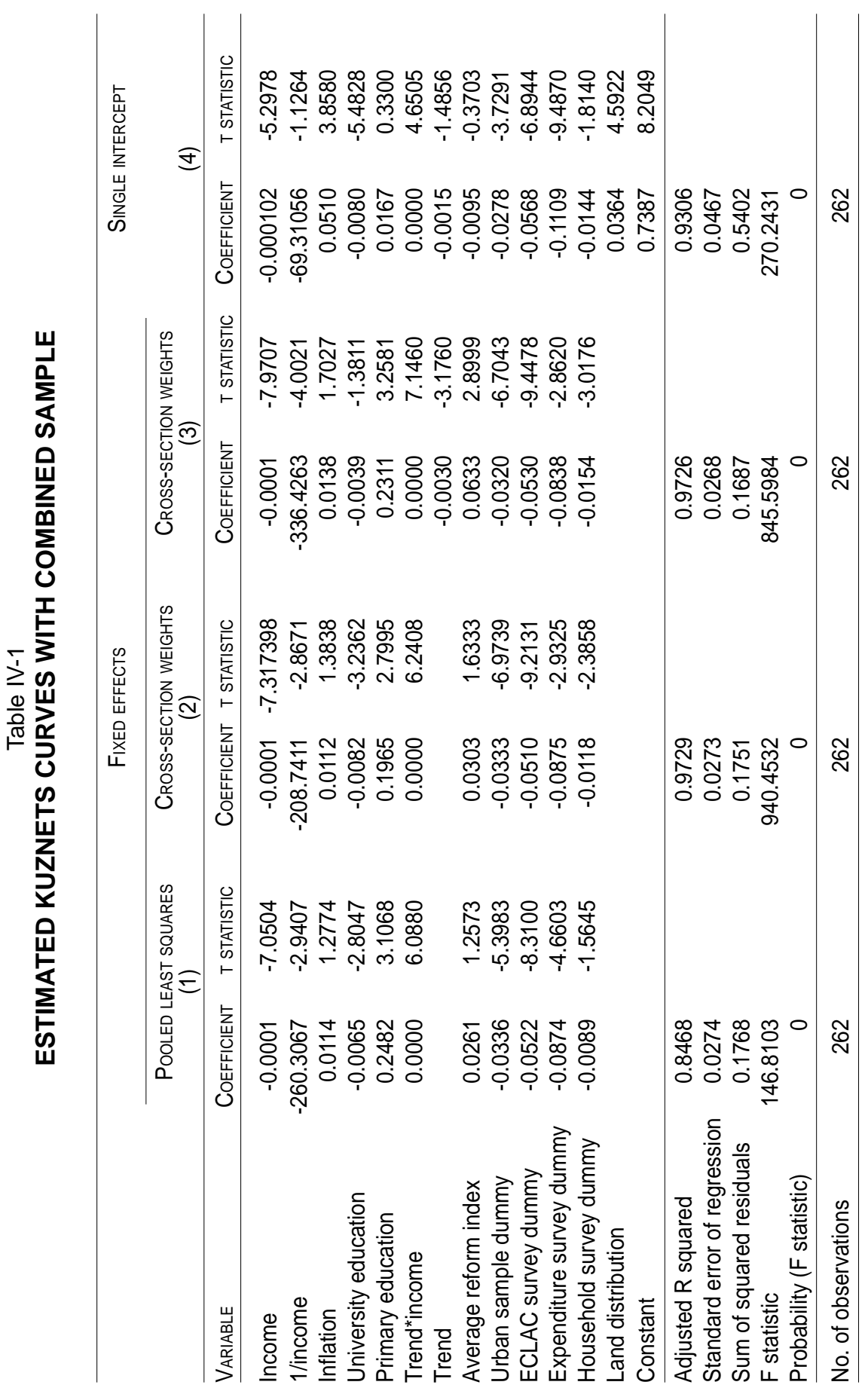




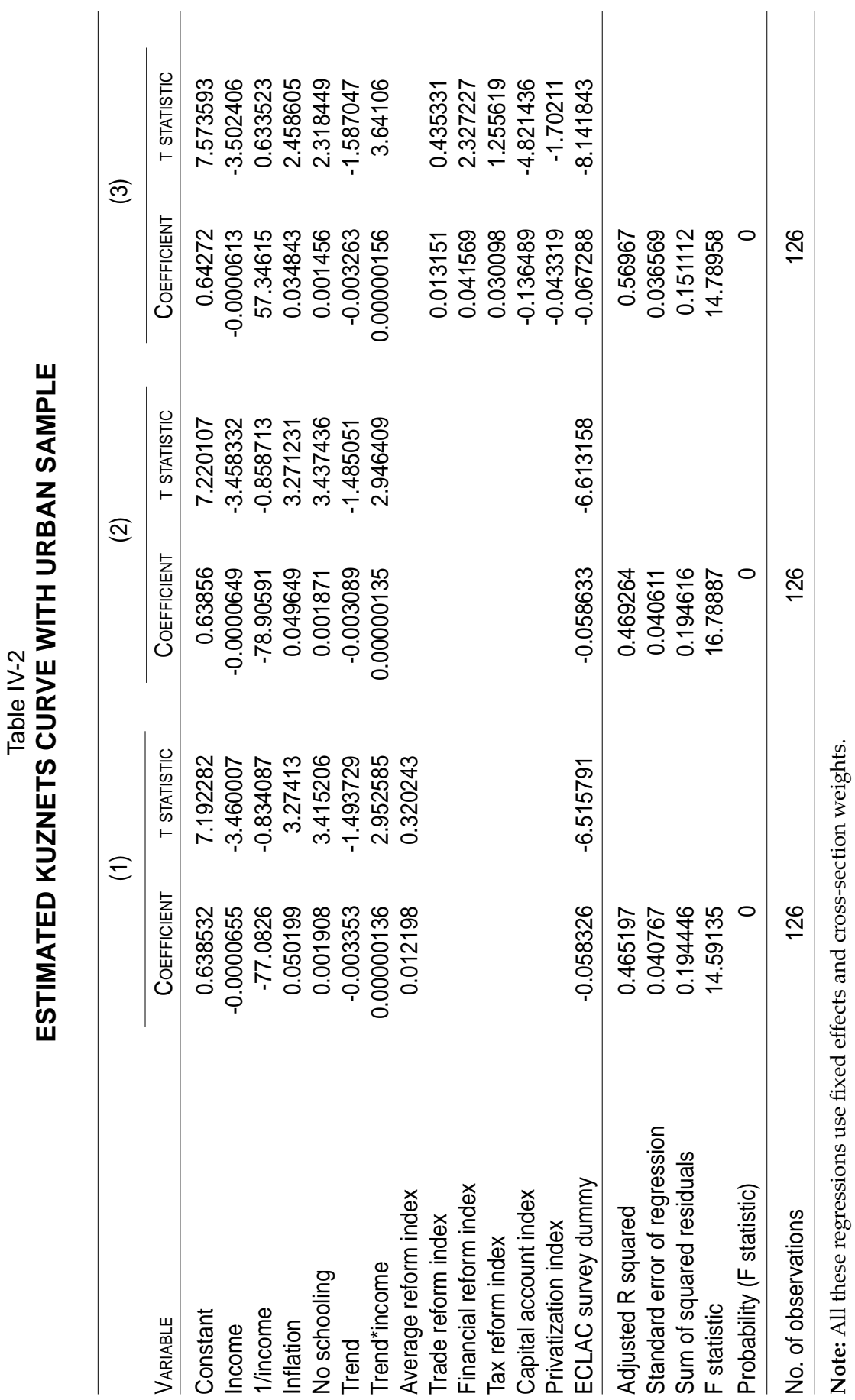




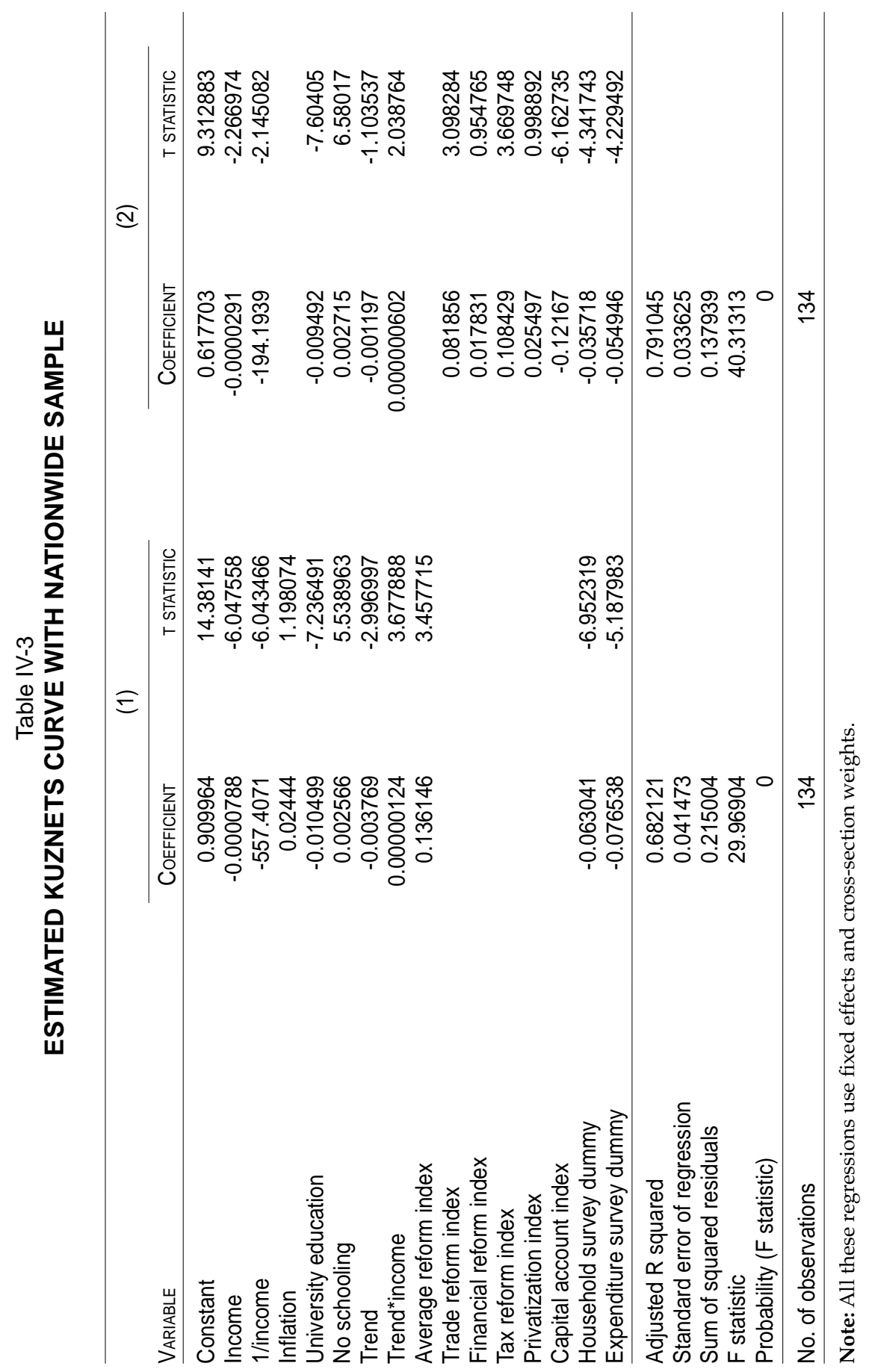


table IV-1, this improvement alone should have lowered the Gini coefficient by about three percentage points $\left(.197^{*} .17\right)$. At the same time, the negative coefficient for university education indicates that increasing the share of university graduates in the adult population is progressive (it shifts the Kuznets curve down). Note that the absolute size of the effect of expanding the proportion of university graduates is much smaller than the effect of reducing the share of the poorly educated, suggesting that a bigger distributional impact is obtained by spending money to reduce the size of the group with primary schooling or less than by expanding the coverage of high school education and universities. That is exactly the same message elicited by the comparison of education profiles between Asia and Latin America.

(iii) Inflation. As hypothesized, episodes of high inflation (more than $1000 \%$ per year in the model) are regressive. On average these episodes add about one percentage point to the Gini. This effect is robust to alternative estimation methods, but it is not significant in any regressions with an interaction term between the trend and income.

(iv) Urban-rural differences. In table IV-1 the urban dummy is negative, significant and robust. On average the Gini can be expected to be about 3 percentage points lower in the urban than in the nationwide surveys. Comparing the Kuznets curves implied by the regressions reported in table IV-1 with those for the separate urban and nationwide samples as reported in tables IV-2 and IV-3 shows that while the general form is the same (all three have an inverted-U shape), the coefficients and significance on the various income and trend terms are different. Figure IV-2 plots the curves from the three estimations.

As expected, the urban curve in figure IV-2 is lower than the nationwide curve over the relevant income range. It also peaks earlier and is slightly flatter than the nationwide curve. That is consistent with the rationale that Kuznets described for the relation. According to his analysis, the distribution changes with development because people move from the low-income rural sector to a higher-income urban sector. At low levels of aggregate income, the urban sector is small, so this change in structure increases inequality (i.e., the nationwide curve is upward-sloping). After a certain point, when the urban sector has grown enough, continued rural-urban migration reduces inequality because it shrinks the size of the group that is poor (i.e., after the inflection point, the curve turns down). Within the urban sector, however, there is much less reason to expect income growth to have these effects. The urban sector is more homogeneous, so the gains from income growth ought to spread through it more evenly. This implies that the urban Kuznets curve should be quite flat (flatter than the nationwide curve), which in fact it is.

(v) Other sample characteristics. All of the sample characteristics had a significant effect on the level of the Kuznets curve. Distribution measures based on expenditure rather than income have Ginis about nine percentage points 
Figure IV-2

\section{URBAN, NATIONWIDE AND COMBINED KUZNETS CURVES}

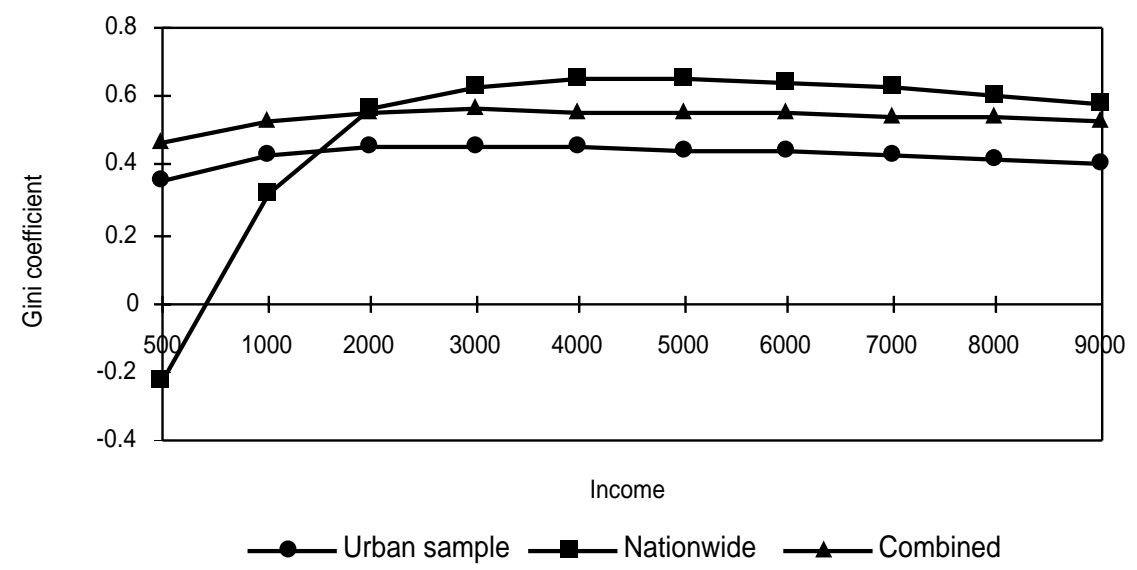

Source: Tables IV-1, IV-2 and IV-3.

lower than those based on income. They also have significantly flatter slopes, as indicated by the inclusion of an interaction term (not shown) in the regression. This is to be expected. To the extent that variations in income are temporary and not permanent, expenditures should reflect the latter more than the former. That implies that expenditures tend to change by less than measured income across different levels of income, so that the distribution of expenditure is more equal than the distribution of measured income.

Another sample characteristic is whether the distribution is based on family income or family income per capita (the per household dummy). Surveys based on family income have Ginis which are about one percentage point below those based on family income per capita, and this difference is significant. It reflects the fact that poor families tend to have more family members. Finally, the ECLAC distributions are systematically 5-6 percentage points more equal than the others because of their treatment of home consumption and other sources of under-reporting.

(vi) Reforms. This section examines the effects of the average reform index, deferring consideration of each of the subindexes. As is evident from the three tables, overall the reforms have a regressive effect on distribution. The coefficient is positive in all three samples, and it is significant in some of them. The effect, however, is relatively small. According to the reform coefficient on regressions 2 and 3 in table IV-1, increasing the average reform index by $10 \%$ can be expected to increase the Gini coefficient by between one-third and two- 
thirds of a percentage point. While this effect is not large, the sign does confirm the assertions of Berry (1998) and Bulmer-Thomas (1996), who used historical evidence up to the early 1990s for a small cross-section of countries to show that inequality had widened after the imposition of the reform package. The evidence here comes from a much larger cross-section of countries and a far longer time period, but it points to the same conclusion.

Two notes of caution: first, the effect of reforms is here taken to mean the direct impact apart from whatever effect the reforms may have had through inflation or growth in income. If the reforms increase the growth rate, or lead to lower inflation, as they seem to have done in some countries, the positive effect of those two factors may outweigh the direct regressive effect on inequality of the reforms themselves. ${ }^{18}$ Second, different reforms appear to have quite dramatically different and offsetting effects on distribution. Quite different conclusions may follow if the pattern of reform differs from the acrossthe-board change measured here.

(vii) Land distribution. Regression 4 of table IV-1 re-estimates the model with a single intercept and adds a measure of land distribution to see whether it helps explain why country-specific intercept terms differ. The land distribution variable is highly significant and positive, adding about 3.6 percentage points to the average Gini, which is a large effect. The change in model also affects the significance and size of some of the other variables, as well. Inflation, for example, becomes a larger and more significant factor. So do differences in the university education variable. All this suggests that differences in inflation, education profile and land distribution are among the reasons why income distributions differ across the countries in the region, but they are not the only differences. If they were, the fit of the model would not improve significantly with the use of country-specific intercepts.

(viii) Trend. The results indicate that the Kuznets curve shifts over time. The model captures this by introducing two trend terms, one in the constant (intercept term) and the other interacting with the income term. Regression 3 in table IV-1 puts the trend in the intercept term. It is negative and significant, suggesting a gradual reduction of inequality over time, other things being equal. But the interaction term tells a different story. It is positive and significant in all the regressions, including the one with the common intercept (regression 4 ), as well as in the regressions for the urban and nationwide samples considered separately. This indicates that the slope of the Kuznets curve changes over time. Since the coefficient is positive, the slope is gradually getting steeper to the left of the inflection point, where the curve is upward sloping. To the right of the inflection point, where the slope is negative, the trend makes

18 In a recent paper Escaith and Morley (2000) have estimated the effect of this same package of reforms on growth. Their results show that the average reform index did not have a significant effect on the growth rate because the various components of the reform package had different and offsetting effects. 
the slope gradually flatter. Furthermore, the interaction term gradually shifts the inflection point itself to the right over time, extending the range over which growth is regressive. Thus the trend terms tell two opposing stories. The trend term on the intercept is progressive, since it shifts the Kuznets curve down. But the interaction term is regressive, meaning that growth has become systematically less progressive than it used to be. To illustrate all this, figure IV-3 shows the Kuznets curves for Brazil for 1970, 1980 and 1996. For purposes of comparison, all the relevant variables other than trend are set at their 1996 values. The regression 3 coefficients are used for this calculation.

Figure IV-3

SHIFTING KUZNETS CURVES FOR BRAZIL

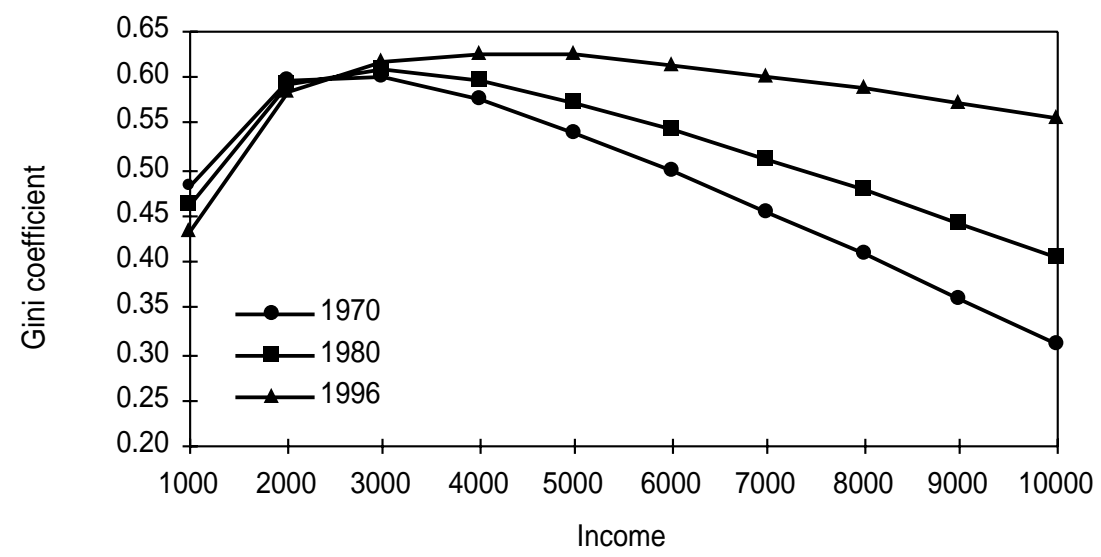

Source: Appendix table A-1.

The progressive shift downward in the intercept is increasingly dominated by the outward shift in the curve and its change of slope. Both of these changes make growth less progressive than it would otherwise be, for not only is the interaction reducing the slope of the curve, but the country is moving from one curve to another. That makes the improvement in inequality per unit of growth less than it would be if the country was moving down a stationary Kuznets curve. 


\section{B. The Effect of Growth on the Distribution: An Application of the Estimated Kuznets Curve}

One of the central questions regarding trends in distribution is the effect of future growth on inequality. Supposing that no policy changes occur other than growth, will Latin America become more equitable? Is high inequality nothing more than a phase which will be mitigated by growth?

The above regressions shed a good deal of light on this question. First of all, since the Kuznets curve has an inverted-U shape, some countries are undoubtedly to the left of the inflection point. For them growth is going to be inequitable. For the remaining countries, however, growth should improve distribution. The interaction between trend and income complicates the issue, because it makes the growth-equity relation steadily less progressive. This is partly because it moves the inflection point to the right and partly because it makes the curve itself steeper on the upward portion and flatter on the downward portion.

To see what the trend term implies for each country, the trend values for 1996 and 1970 were used to solve equation IV-1 (see table IV-4). The first three columns show how the inflection point moves to a higher income level over time as a result of the interaction of the trend and income. Columns four and five give the actual income level and the actual Gini for the most recent year for which a household survey is available. The sixth column shows the slope of the Kuznets curve, and the last two columns give the elasticity of the Kuznets curve at the income level given in column four for the 1970 and 1996 values of the trend variable. ${ }^{19}$

In 1996, the inflection point was just under US $\$ 4,000$ per capita. That means that all seven of the high-income countries in the region were beyond the inflection point (i.e., the value for dGini/dY, or the slope of the Kuznets curve, was negative) ${ }^{20}$ For them, growth is equalizing. The remaining nine were on the rising portion of the Kuznets curve. For them, the Gini rises with growth. The column showing the elasticity of the Gini with regard to income in 1996 indicates by how much the Gini could be expected to change with growth. For Argentina, for example, if per capita income grew by $5 \%$, the Gini should fall by about .6\% (5*.117), or from .486 to .483, which is not a large change. All this assumes, of course, that all the remaining variables stay at their 1996 levels. For the region as a whole, the simple average of the individual

19 The elasticity is the expected percentage change in the Gini coefficient per one percent change in income.

20 In the case of Colombia, the actual income listed in the table is for 1995; it is just below the inflection point. The dGini/dY was calculated on the basis of 1996 income, which was slightly higher. 


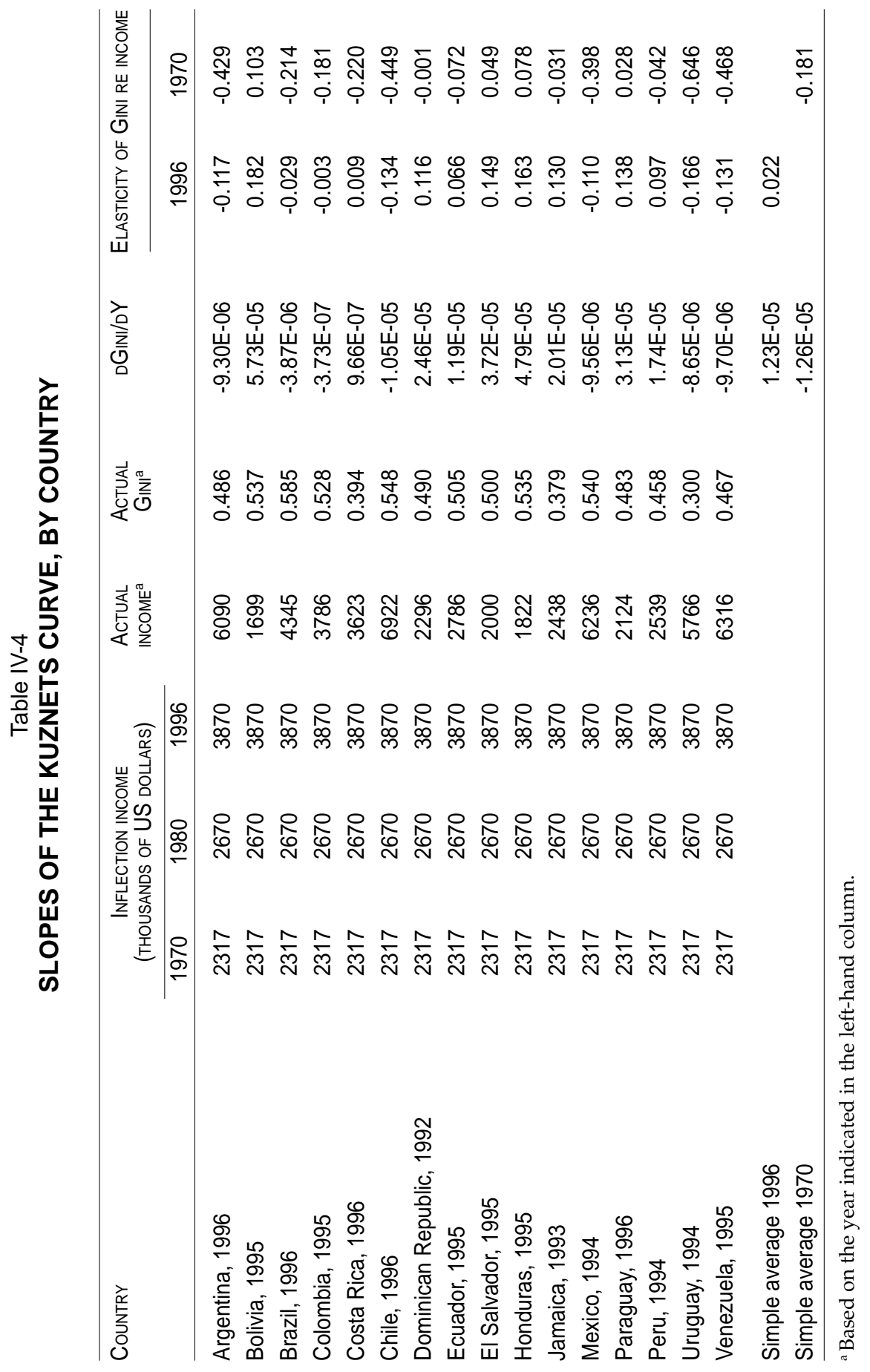


country elasticities demonstrates that if all countries grow by the same amount, the average Gini coefficient will rise slightly. Growth is not equalizing because the weight of the nine countries on the rising portion of the Kuznets curve is greater than the weight of those on the equalizing part of the curve. Weighting the elasticities by either population or income would reverse that conclusion, because all the big and relatively prosperous countries (i.e., Argentina, Brazil, Chile, Colombia, Mexico and Venezuela) are on the falling part of their curves.

Because of the trend term, the Kuznets curves for the high-income countries are tending to get flatter over time, and the low-income curves are getting steeper. That implies that growth is getting less and less progressive. This can be shown by recalculating the elasticities using the parameters of the 1970 Kuznets curve (see column 8 of table IV-4). With those parameters, only four countries demonstrate rising inequality, instead of the nine that actually had in 1996. As a result, the average elasticity of the Gini with respect to income would have been negative, which means that a growth rate that raised average inequality in 1996 would have lowered it in 1970 . This quite strongly suggests that if nothing else changes, the impact of growth on inequality in the future is likely to be more regressive than it is today.

Why the progressivity of growth is systematically reduced over time is not known. Probably it reflects rising skill intensity and the nature of technical change. Whatever the cause, the impact of growth on inequality is likely to be even more regressive in the future than it is today unless some deliberate actions are taken to counteract the trend.

\section{Subindexes of Reform}

This section disaggregates the average reform index to show the effect on equality of each of the separate reform components (see table IV-5). The regressions in table IV-5 use the same combined sample of urban and nationwide observations used for table IV-1. Table IV-6 summarizes the evidence from table IV-5 and from the urban and nationwide samples considered separately (from tables IV-2 and IV-3). The various reforms clearly have different and offsetting effects. In all the estimates of the Kuznets curve, some of the reforms have a significant regressive effect and some a significant progressive effect. That explains why the average reform indexes seem to have little effect on inequality.

Comparing the combined sample with the separate urban and nationwide regressions, the results for trade, capital and tax reform are a good deal more robust than the other two reforms. Trade reform has been regressive, more so in the nationwide than in the urban regressions. This suggests that the negative effect on agriculture of the loss of protection and price subsidies was more significant than the loss of protection in the manufacturing sector. The 


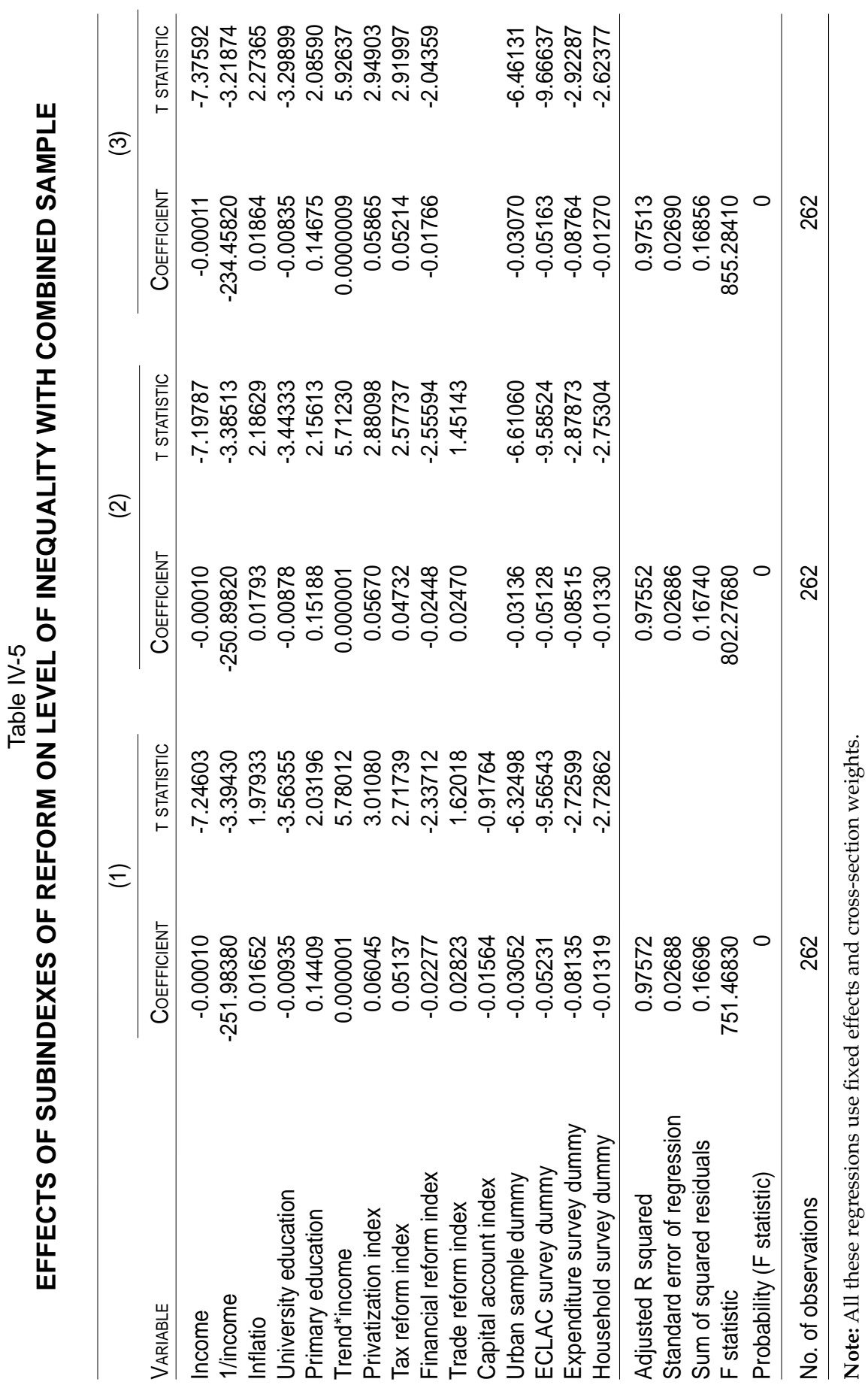


theoretical case for trade reform rested on the idea that increased openness should favour Latin America's abundant factor, which was expected to be unskilled labour. That should have improved the distribution, but the econometric evidence says that it did not work out that way in practice. If anything, the effect was the opposite.

This evidence is consistent with the findings of Donald Robbins (1996), who presents evidence that trade liberalization led to a widening of skill differentials. These results are somewhat stronger than those of Spilimbergo, Londoño and Székely (1997), who find that "trade openness also has a negligible effect over income distribution in Latin America," mainly because relative factor endowments in Latin America are very close to world averages weighted by population and openness (p. 30). The evidence presented here is not consistent with the work of Londoño and Székely (1997), who find a significant positive relationship between trade reforms in the period 19851995 and the income share of the bottom quintile for a panel of 13 countries in the region. However, their regressions do not include urban observations such as those for Argentina and Bolivia. Nor do they include any variables other than the reform indexes in the regressions. Thus the effects that they assign to the reforms may well be coming from other policies or variables.

In contrast to trade liberalization, opening the capital account has been progressive. Reducing barriers to capital mobility attracted a great deal of foreign capital to Latin America. Theoretically, this should have reduced profit rates and increased the demand for labour, all of which should be progressive. These results confirm that assertion. Tax reforms shift the Kuznets curve up towards more inequality. There are clear theoretical arguments why that might be the case. Switching from progressive income taxes to a flatter tax structure and substituting VAT or consumption taxes for income taxes and tariffs shifts the tax burden away from the rich. As for the other two reforms, the variations in the signs and significance of the coefficients on privatization and financial reforms suggest that the data are not good enough to give an unambiguous answer regarding their effect.

Table IV-6

\section{EFFECTS OF REFORMS ON THE KUZNETS CURVE}

\begin{tabular}{llll}
\hline & COMBINED & URBAN & NATIONWIDE \\
\hline Privatization & regressive & progressive & regressive \\
Financial reform & progressive & regressive & regressive \\
Tax reform & regressive & regressive & regressive $^{*}$ \\
Trade liberalization & regressive & regressive & regressive $^{*}$ \\
Capital account opening & progressive & progressive * & progressive $^{*}$ \\
\hline
\end{tabular}

Source: Table IV-5.

* Significant at $1 \%$ level 


\section{Results for the Model of Changes in Inequality}

The robustness of the model results was checked by collecting a pool of observed changes in Gini coefficients between two points in time and then rerunning the basic model to see whether the variables that enter into the level equations explain changes in inequality (table IV-7). The sample is drawn from the same set of observations used in the level regressions, except that here, in order to be included, each pair had to be consistent with respect to sample coverage, income definitions and sample design. That is, urban, household, expenditure and per capita income observations are paired to ensure that changes are not coming from a change in definitions. This procedure reduces the estimation bias that could be present in the level regressions, because those regressions combine surveys which may have been based on different definitions of income, different ways of handling under-reporting and so on. Each pair in this change database is internally consistent. The resulting pool has 122 observations over the same 16 countries used in the level regressions. To minimize the effect of sudden changes at the end points of periods, the observations represent two-year averages at end points whenever enough yearly distribution observations are available to make that possible.

There is a theoretical problem in estimating the change model, due to the fact that the original Kuznets curve is non-linear. The effect of changes in income on the distribution will depend entirely on whether the observations occur in countries to the left or right of the inflection point. To address that problem, the regression allows different slope coefficients by country (i.e., B is allowed to vary across countries). ${ }^{21}$

The model for determinants of changes in inequality is a hybrid in which the percentage change in the Gini is expressed as a function of changes in income and the levels of the sample characteristics, land distribution, the measures of education and the reform indexes. The choice is straightforward for sample characteristics such as household or urban, but for the education measures, it could be argued that if the educational profile helps to explain differences in the level of inequality, then changes in inequality should be related to changes in the education variables. The same argument could be made for the reform index. The problem with that reasoning is a practical one. The amount of change in the education and reform variables over the time periods for which most of the distributional changes were observed is so

21 In addition the regression incorporates a dummy variable which takes a value of one for those countries to the left of the inflection point where the relation between income growth and inequality should be positive. Putting this variable in the model permits the two groups of countries to have Kuznets curves with different slopes. However, this interaction is insignificant and is not shown in the table. 
small that it would have been meaningless to include it in the regressions. Therefore, the education and reform variables reflect the level observed at the start of the period for which the change is being measured. If education and reform have an effect in these regressions, it means that they affect the slope of the Kuznets curve. The same argument can be made for the sample characteristics (urban, household and expenditure). In the level equations, the sample variables help to determine the intercept or the degree of inequality. Here they determine the sensitivity of inequality to changes in income, or in other words, the slope of the Kuznets curve.

In the level regressions the inflation variable is a dummy which takes a value of one when the inflation rate for the year in question exceeded $1000 \%$. For the change regressions, the dummy takes a value of 1 when the increase in the inflation rate over the period was more than $1000 \%$ and a value of -1 when the inflation rate fell by $1000 \%$.

In addition to the variables that appear in the level regression equation, the change regression introduces the observed Gini coefficient at the beginning of the period. This is similar to the concept of convergence in the growth literature. The idea is that there is a long-run level of inequality. The further actual inequality is from this level, the bigger the change in inequality in response to income growth. Another way to think of this is to hypothesize that the Kuznets curve has a second inflection point on the downward sloping portion. Rather than have an increasingly negative slope with increasing levels of income, it has a slope that flattens out as the Gini approaches the long-run equilibrium or floor level. In the level regressions, the trend-income interaction term reflects this same idea.

With one significant exception, the results from the change regressions confirm the patterns uncovered in the level regressions. Variables have the same sign they had in table IV-1, and the results are quite consistent and robust to different estimation methods. As before, the model with cross-section weights appears to be superior to pooled least squares. While the fit of this model is not as good as the level regressions (as expected), it still explains quite a bit of the variation in distribution over the last 30 years in Latin America.

On average, changes in inequality are negatively related to changes in income. Inequality rises in recessions and falls in recovery, a finding that is consistent with previous work (Morley, 1995; Ravallion and Chen, 1997). The significance of this relation is questionable, however, because as might be expected in estimating a non-linear relation in levels, countries display big differences. When the model incorporates country-specific slope coefficients, the regression fit improves substantially and the slopes of different countries take on big differences (see regression 6). Eleven have a negative coefficient and five are positive. All seven of the countries to the right of the inflection point are in the negative coefficients group. Only one of the remaining countries (El Salvador) has the wrong sign and is significant. 


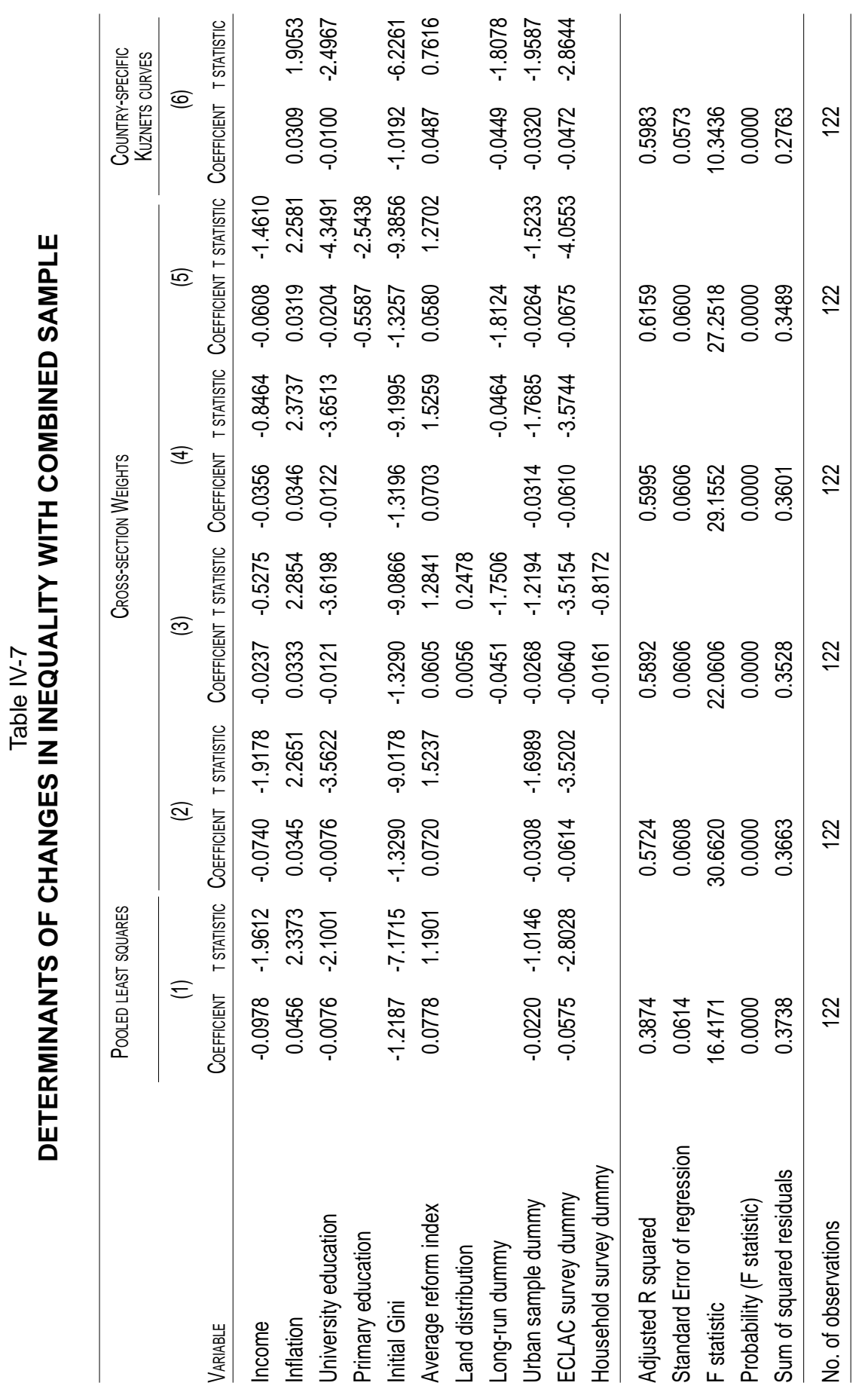


In the single-coefficient regressions (1-5), the significance of the slope coefficient is strongly affected by the presence or absence of a dummy variable (the long-run dummy), which takes a value of one for those changes observed prior to the debt crisis in the early 1980s. This long-run dummy has a consistently negative coefficient, suggesting that growth in the 1970s and before was more equitable than it has been subsequently. This is consistent with the trend-income interaction term in the level regressions. When the long-run dummy is in the regression, the Kuznets curve is essentially flat, which is consistent with the effect of the trend variable in the level regressions. In those regressions the trend interaction with income shifts the curves up and outward. Instead of moving down a single Kuznets curve, countries are moving from one curve to another, which reduces the observed effect of changing income on inequality.

The change regressions confirm the regressive impact of inflation on inequality. Here the dummy variable reflects the effect of both rising and falling inflation. The level regressions only pick up the impact of high rates of inflation. That equation does not distinguish between observations which had low and steady rates of inflation from others in which the low rate came after a high rate. The hypothesis about inflation is that changes in the rate matter as much as the rate itself. Thus the change model comes closer to testing this relation than does the level model. It is clear from the results that big changes in inflation do indeed matter, both positively and negatively. The poor are less able to defend themselves against very high inflation than are the rich. Therefore, the stabilizations successfully carried out in Argentina, Bolivia, Brazil and Peru had an important positive effect on equity. That is true even when those stabilizations were accompanied in the short run by recession, as was the case in Peru.

The sample characteristics (the per household and urban dummies) are less significant here than in the level regressions, although they both have the same negative sign. This indicates that there is not an important interaction between the sample characteristics and income. Urban income distributions are systematically more equal than nationwide distributions. They also tend to have slightly flatter Kuznets curves, but the differences are not significant. In other words, the distributional effect of income growth on the typical urban household does not appear to be significantly different from the effect on households for the country as a whole. The ECLAC observations (all of which are urban) have a significant negative coefficient in all of the regressions in table IV-7, as they do in the level regressions. This indicates not only that the level of inequality is lower in these observations, but that the reaction to income growth is also more progressive. Finally, as in the level regressions, land distribution has a significant regressive effect on the Kuznets curve, but only in a regression with a common intercept (not shown). Otherwise, its effect is incorporated in the country-specific constants. As in the level regressions, the effect of reform appears to be regressive, though not significantly different 
from zero. This results from offsetting effects among the different subindexes of reform (regressions not shown).

The university variable is progressive in these regressions, as in table IV1 , but that is not the case for the primary school variable. This is the only variable whose performance is completely different in the level and the change regressions. The level regressions demonstrate that the fraction with primary schooling or less has a regressive effect on inequality. Here, the effect of the variable is progressive. It should be recalled that these change regressions are measuring an interaction term with income. This result implies, therefore, that income growth has a more powerful and favourable effect on inequality in countries with a less educated labour force. In such countries, the Kuznets curve is higher, but its slope is flatter before the inflection point and steeper afterwards. This is a somewhat surprising result.

\section{E. Conclusions}

The econometric evidence suggests two main conclusions. First, the relation between the distribution and level of income appears to be robust and significant. It has the inverted U-shape that Kuznets predicted, but this relation has been shifting in a regressive direction over time. Growth is now a good deal less progressive than it used to be. In the aggregate, that means that further growth in Latin America is unlikely to improve the distribution much, if at all. Supplementary measures must therefore be taken. Among those suggested by the regressions are maintaining low inflation rates and investing in education. Giving new entrants to the labour force more education at any level is progressive, but countries will get a much bigger reduction in inequality if they start at the bottom, universalizing the coverage of primary education and then broadening the coverage of secondary and university education.

Second, in the aggregate the reforms appear to have a regressive effect on distribution, but this effect is both small and only marginally significant. The reason is that reforms in different areas have offsetting effects on equity. Trade reform is regressive in all of the specifications, but it is insignificant in all but the nationwide sample. Tax reform is unambiguously regressive, and opening up the capital account is unambiguously progressive. The results for tax reform and capital account liberalization are the most robust and significant of the set. For the other two reforms, the data are not good enough to give a clear answer. 



\section{Chapter V}

\section{EVIDENCE FROM COUNTRY CASE STUDIES}

Using a sample of nine countries in the region, this chapter draws a more detailed picture of the impact of the reforms and the main determinants that change the distribution in growing economies. The first indicator presented is simply a comparison of the family distribution of income per capita before and after the reforms. The chapter then moves on to an investigation of the primary earnings distribution, that is to say, the distribution of nationwide income among those who produce it. Given data constraints, in many countries the analysis is limited to the distribution of labour income because the household surveys have very little information on income from land and capital, particularly undistributed profits. This shift in focus to the primary distribution is justified because of its clear and close link with factor markets and economic processes. Understanding the channels by which the reforms affect income distribution requires starting with the distribution that depends directly on factor markets and factor prices. Large differences in trend between the two distributions would then point to the need to look for demographic or other explanations. Fortunately, the two distributions are closely related in most of the countries for which data are available, such that an analysis of how the reforms affect the primary earnings distribution can help predict how they affect the family distribution as well.

Two methodological points should be noted here. First, the fact that the distribution changed after the reforms is no proof that the reforms caused the change. Many other things that were going on at the same time could be responsible. Virtually all investigation of causal links in economics is open to this sort of criticism. The econometric analysis in chapter IV attempted to deal with the problem by including all the other factors that might be influencing the distribution. In time-series work, however, it is often difficult 
to separate different factors because of multicollinearity. Another way of investigating impact is to construct a general equilibrium model containing factor markets and behavioural equations, which can be used to simulate the response to reforms. The data requirements of such an exercise are large, however, and such an application is not attempted here. This leaves a methodology that makes the best case for causal links on the basis of an examination of relevant historical evidence, including factor prices, changes in factor supplies, rates of investment and changes in the composition of output, that could plausibly be related to reforms.

The second methodological issue involves the choice of dates for beforeand-after comparisons. That sounds fairly easy, but in fact it is quite difficult because the conclusions can be quite sensitive to these choices. For example, in the case of Mexico survey data are available for 1984, 1989, 1992, 1994 and 1996. The starting point should be a year prior to the adoption of the reforms, but the adoption of reforms is a fairly continuous process, with some reforms being adopted before others. In Mexico trade and financial reforms began around 1986 and were significantly extended after 1989. Inequality rose sharply in Mexico, but virtually all of it occurred between 1984 and 1989. Therefore, a 1984 starting point would likely lead to the conclusion that the reforms were regressive, whereas a 1989 date is more likely to indicate that they had no direct impact. ${ }^{22}$

The choice of starting and ending points should also be conditional on the absence of changes in other factors that are known to have a big impact on the distribution. Recession and inflation are the most obvious examples. The two points being compared should be at roughly the same point in the economic cycle, preferable one near full employment. It is also important to avoid points with very different rates of inflation. This is relevant in Argentina, where observations are available for 1974, 1980, 1986 and then yearly observations from 1989 on. The reform package under Menem, which started in 1990, was coupled with an orthodox stabilization programme that controlled hyperinflation. The 1991 observation comes right in the middle of that programme, so 1986 is taken as the starting point. As in Mexico, however, this choice has consequences, because the rise in inequality came between 1986 and 1989, and it seems to be due to hyperinflation. In 1991, thanks to the Menem stabilization programme, inequality was already falling, though it never recovered the 1986 level. Taking a 1989 observation as a starting point would undoubtedly lead to completely different conclusions about the impact of the reforms from those reached by starting in 1986.

22 Clearly, the reforms could have had an effect that was offset by other factors. This case is used simply to make the general point that whatever the direct or indirect effects are, they will be sensitive to the choice of starting and ending points. 
Turning now to the historical record, figure V-1 shows two consistent series of distribution measures: the distribution of family income per capita and the distribution of primary earnings, or in several cases labour earnings. ${ }^{23}$ The vertical line in the diagram marks the period when the biggest change in the reform indexes occurred. Admittedly, this dating is somewhat arbitrary, since the adoption of reforms was a continuous process. Whenever available, the Gini coefficients are used for the diagrams. In several cases only the Theil was available for the primary or earnings distributions.

The first thing to note about the figures is the relatively close correspondence between the trends in the primary and family distributions. Altogether there are 266 observed cases in the eight countries for which comparable estimates of changes in the household and the primary distribution are available. In all but six cases the direction of change is either the same or differs by an insignificant amount. Three of those six cases are from Argentina, where the estimate of the primary distribution is only for those who receive income. The difference between it and the family distribution undoubtedly reflects the impact of changes in unemployment, which was a critical feature of the labour market in Argentina in the 1990s. This evidence suggests that in most cases movements in the family distribution can be inferred from changes in the primary distribution. That helps establish an important link in figure $\mathrm{V}-1$ between what happens in the labour market and the distribution that is most closely related with social well-being. At the same time, given that most of the primary distributions (and the family distributions, too) reflect labour earnings and not profits, this analysis supplements the information from the household surveys with information on rates of return to capital and on factor shares from the nationwide accounts.

In three reforming countries (Argentina, Chile and Mexico), the distribution is clearly worse than it was before the reform process began. It would appear that in the 1990s these three countries reached a new equilibrium in which the distribution indexes stabilized, but at a much higher level of inequality than before. That is, the reform process seems to have permanently shifted the distribution toward higher inequality. In Peru the reverse seems to be true. Adopting the reform package and stopping hyperinflation shifted the inequality indexes down between 1985 and 1991, and the improvement continued at least until the last observation in 1996. ${ }^{24}$

In three of the remaining countries (Colombia, Costa Rica and Brazil), the changes between the pre- and post-reform distributions are insignificant. In one case, however, that conceals important sectoral changes: in Colombia 
Figure V-1

PRIMARY AND HOUSEHOLD DISTRIBUTIONS PER CAPITA IN NINE COUNTRIES
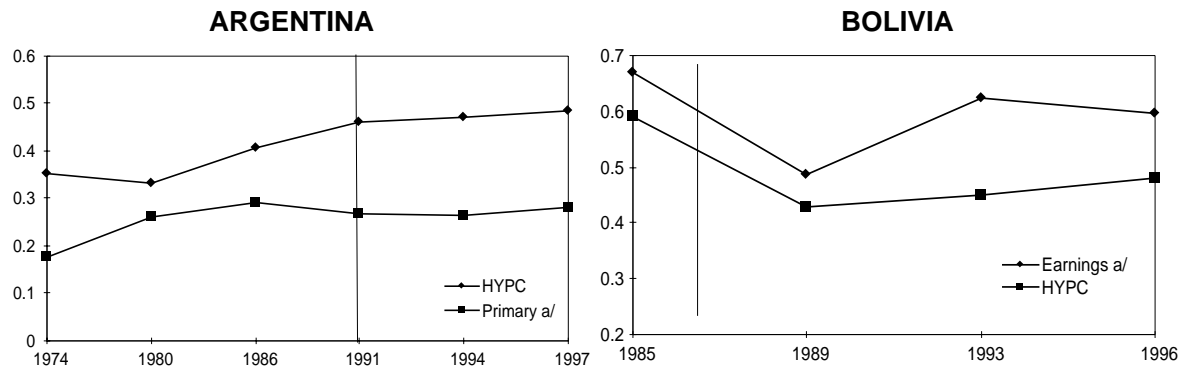

BRAZIL
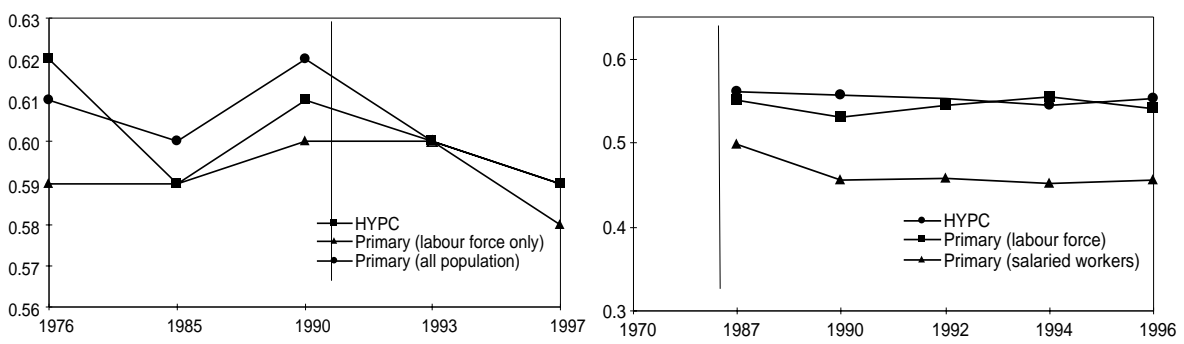

COLOMBIA

COSTA RICA
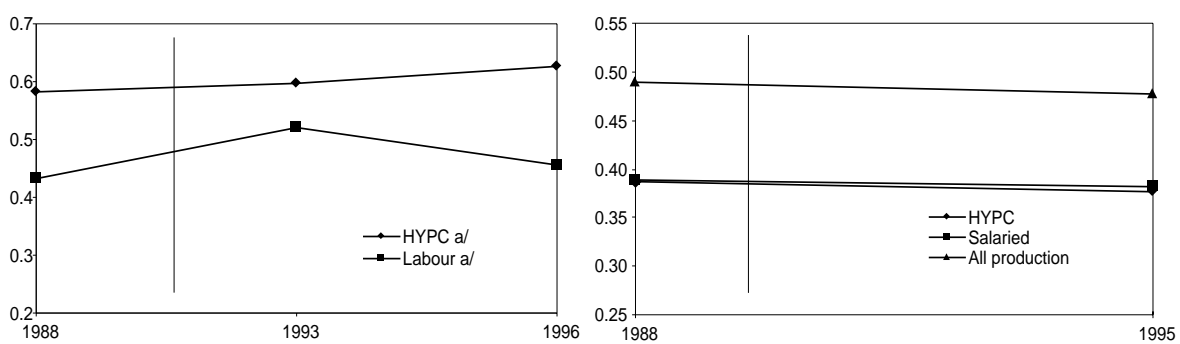
JAMAICA

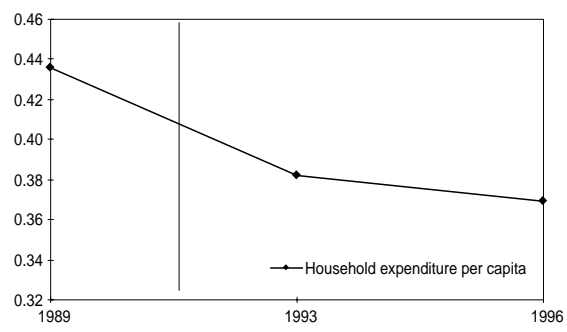

MEXICO

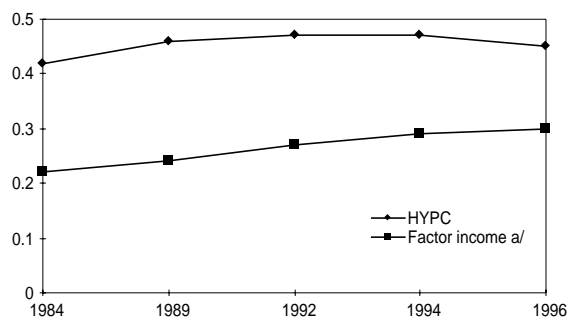

PERU

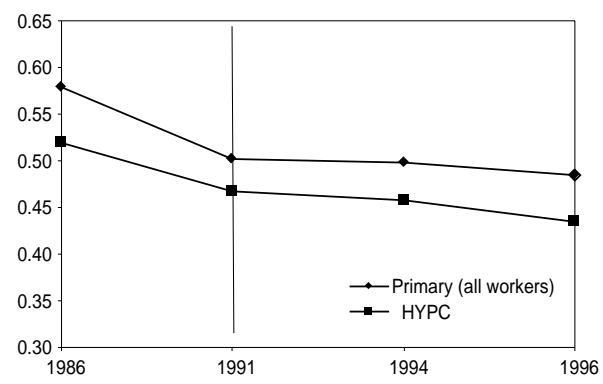

Source: Consultant reports.

aTheil index instead of Gini.

HYPC $=$ Household income per capita

the urban distribution deteriorated significantly, but this was offset by improvements in the rural distribution. That is at least in part a result of significant rural-urban migration in the 1990s, which is a good argument for studying nationwide as opposed to urban distributions. In Costa Rica the overall distribution was remarkably stable after the late 1980s, despite both the adoption of reforms and a fairly unstable macroeconomic growth environment. Brazil, too, registered little change in its household distribution after the mid-1980s, but it is not certain that the country is on a stable, postreform growth track. Not only is Brazil one of the most recent of the reformers, but its distribution record in the 1990s is blurred because of the simultaneous adoption of reforms and the control of inflation. Nonetheless, as for Costa Rica, the data for Brazil exhibit a distribution that is very stable, despite big changes in underlying conditions. 
The remaining two countries, Bolivia and Jamaica, call for special comment. Bolivia did not undertake rural surveys until 1996, so it is not possible to track levels of inequality at the nationwide level. For the urban economy, the distribution improved significantly after 1985, but it worsened after 1990. Most of the reform package was adopted between 1985 and 1987, but at the same time a successful stabilization programme stopped hyperinflation. Consequently, the big reduction in inequality is not attributable to the reform package alone; some or all of it may instead be due to the successful stabilization programme. Bolivia thus has neither data on trends in the nationwide distribution nor evidence of what the distribution was like in a low-inflation environment prior to reform. It is clear, however, that after the reforms, in the most recent period, inequality rose significantly, at least in the urban economy. Bolivia is one of the only two countries where that has happened (the other is Colombia). Jamaica is different from the other countries because its adoption of reforms has been gradual and intermittent and because it did not grow in the 1990s. To complicate matters, it was forced to adopt contractionary macroeconomic policies to stop rising inflation. Despite all this, its distribution improved after 1989, although only in relative terms in an economy in decline.

Six of the countries thus demonstrate rigidity or stability in distribution in the post-reform period. With the possible exception of Bolivia, there is no case in which inequality displayed an upward trend in the 1990s, and it decreased in at least two (Peru and Jamaica). For the rest, the distribution was virtually unchanged over the decade, despite growth and despite structural change and reform. In several countries, however, this overall distributional stability masks important sectoral changes. In Colombia and Mexico, and possibly also Bolivia, the urban and rural distributions moved in opposite directions. In Mexico and Chile, changes in the distribution of labour income were offset by changes in the share of profits. Argentina, Chile and Mexico experienced a one-time upward shift in inequality, but there, too, the distributions remained approximately unchanged after the early 1990s.

Here, then, are the puzzles examined in this chapter, using evidence from factor markets, factor supplies and breakdowns of the inequality indexes of the primary distribution:

(i) What explains the one-time rise in inequality during the implementation of reforms in Argentina, Chile and Mexico? What is different about these three cases? Why did that same shift not happen in other countries when they adopted reforms?

(ii) Why was the distribution so rigid or stable in the 1990s? The econometric analysis provides strong evidence that the Kuznets curve is shifting over time and therefore that growth is systematically less progressive than it once was. For all the countries to the right of the inflection point, that would be consistent with moving to higher, flatter Kuznets curves over time or to a constant Gini coefficient. The econometrics is unable to tell us why the Kuznets curve is shifting, however. 
(iii) What has been the impact of changes in sectoral growth patterns due to the reforms? Trade reform, in particular, hurt some sectors and helped others. Privatization and financial reform presumably encouraged investment, which also changed patterns of growth. All of this must have affected the relative demand for factors. The changes may have made growth either more or less skill intensive, and that should have affected the earnings distribution. What does the historical evidence suggest in this regard?

(iv) What is the role of changes in unemployment, wage differentials and job creation in changes in the earnings distribution?

\section{A. Historical Evidence on Factor Prices and Relative Factor Supplies}

The investigation begins with a look at the historical evidence on factor supplies and factor prices (see table V-1). The first indicator is relative capital intensity, measured by the capital-labour ratio $(\mathrm{K} / \mathrm{L})$. Capital is the nonresidential capital stock measured in constant 1985 purchasing power dollars; it is taken from the Penn tables, with an upgrade to 1996 from ECLAC data (see Summers and Heston, 1995). Labour is defined as the employed labour force. The second indicator is the skill differential, a key element in the analysis. Countries differ somewhat in how they measure this variable, but it is generally defined as the ratio of wages of university graduates to those with no more than primary education. Whenever possible, this information is drawn directly from the household surveys. The third measure is the Theil index of inequality for the primary distribution. This measure is used in the breakdowns of inequality or changes in inequality later in this chapter. Finally, the Gini coefficient is used to measure the distribution of family income per capita. This is the distribution used above for the empirical statements about preand post-reform trends.

The income share of better-educated labour rose in every country. In some countries, the wage differential for the better educated went up as well. Such countries are here labelled skill intensive, meaning that the increase in demand for better-educated labour was greater than the increase in supply. On the basis of that classification scheme, the countries with skill-intensive growth (i.e., an increase of more than 5\% in the skill differential) are Argentina for the entire period since 1974, Bolivia, Brazil, Mexico and Peru. In Chile the differential widened between 1968 and 1987, but then fell back sharply to below its initial level. ${ }^{25}$ It is the only country in which the skill differential fell

25 Comparable evidence for the entire period comes only from Greater Santiago. The evidence from the CASEN surveys from 1987 to 1996 also shows a narrowing of wage differentials, but it is much less pronounced than the narrowing for Greater Santiago (wage work sheets from Weller, 2000). 
Table V-1

TRENDS IN CAPITAL-LABOUR RATIOS, SKILL DIFFERENTIALS AND INEQUALITY

\begin{tabular}{|c|c|c|c|c|}
\hline \multirow{2}{*}{$\frac{\text { COUNTRY AND INDICATOR }}{\text { Argentina (urban) }}$} & \multicolumn{4}{|c|}{ VaLue } \\
\hline & 1974 & 1986 & 1991 & 1996 \\
\hline Capital-labour ratio & 9060 & 11869 & 10953 & 10617 \\
\hline Skill differential & 78 & 98 & 94 & 116.5 \\
\hline Primary distribution (Theil) & 0.176 & 0.293 & 0.268 & 0.283 \\
\hline Family distribution (Gini) & 0.354 & 0.407 & 0.461 & 0.486 \\
\hline Bolivia (urban) & 1985 & 1989 & 1996 & \\
\hline Capital-labour ratio & 6987 & 5946 & 5196 & \\
\hline Skill differential & 100 & 146.9 & 202.4 & \\
\hline Primary distribution (Theil) & 0.668 & 0.486 & 0.595 & \\
\hline Family distribution (Gini) & 0.59 & 0.43 & 0.48 & \\
\hline Brazil & 1976 & 1985 & 1990 & 1997 \\
\hline Capital-labour ratio & 10765 & 16007 & 17290 & 17511 \\
\hline Skill differential & 100 & 98.5 & 93.9 & 107.8 \\
\hline Primary distribution (Theil) & 0.83 & 0.68 & 0.7 & 0.71 \\
\hline Family distribution (Gini) & 0.62 & 0.59 & 0.61 & 0.59 \\
\hline Chile & 1968 & 1987 & 1996 & \\
\hline Capital-labour ratio & 5840 & 7527 & 14269 & \\
\hline Skill differential & 100 & 123.8 & 97.8 & \\
\hline Primary distribution (Theil) & & 0.653 & 0.636 & \\
\hline Family distribution (Gini) & & 0.56 & 0.553 & \\
\hline Colombia (urban) & 1988 & 1993 & 1995 & 1996 \\
\hline Capital-labour ratio & 12919 & 12554 & 12343 & 12180 \\
\hline Skill differential & 71.5 & 73.3 & 75.2 & 76.6 \\
\hline Primary distribution (Theil) & 0.432 & 0.522 & & 0.457 \\
\hline Family distribution (Theil) & 0.582 & 0.596 & & 0.625 \\
\hline Costa Rica & 1988 & 1995 & & \\
\hline Capital-labour ratio & 29777 & 34547 & & \\
\hline Skill differential & 88.9 & 86 & & \\
\hline Primary distribution (Theil) & 0.49 & 0.478 & & \\
\hline Family distribution (Gini) & 0.387 & 0.377 & & \\
\hline
\end{tabular}




\begin{tabular}{|c|c|c|c|c|}
\hline COUNTRY AND INDICATOR & & & & \\
\hline Jamaica & 1989 & 1993 & 1996 & \\
\hline Capital-labour ratio & 3424 & 3505 & 3682 & \\
\hline Skill differential & 100 & 101.9 & 102 & \\
\hline Family distribution (Theil) & 0.313 & 0.258 & 0.252 & \\
\hline Family distribution (Gini) & 0.436 & 0.382 & 0.369 & \\
\hline Mexico & 1984 & 1989 & 1994 & 1996 \\
\hline Capital-labour ratio & 14357 & 12963 & 14304 & 14849 \\
\hline Skill differential & 100 & 122.1 & 138.7 & \\
\hline Primary distribution (Theil) & 0.21 & 0.24 & 0.29 & 0.30 \\
\hline Family distribution (Gini) & 0.42 & 0.46 & 0.47 & 0.45 \\
\hline Peru & $1985-86$ & 1991 & 1996 & \\
\hline Capital-labour ratio & 9480 & 8651 & 8151 & \\
\hline Skill differential & 100 & 94.8 & 142.9 & \\
\hline Primary distribution (Theil) & 0.579 & 0.502 & 0.485 & \\
\hline Family distribution (Gini) & 0.519 & 0.467 & 0.435 & \\
\hline
\end{tabular}

Source: Consultant reports.

Note: All family distributions are family income per capita, except for Mexico, which is family income, and Jamaica, which is family expenditure per capita. The last Theil observation for Argentina is 1997. The Chilean relative wages are averages over groups of years: $1968=1964-1969$, 1987=1987-1990, and 1996=1991-1996. For Jamaica under-reporting of income makes the household surveys unreliable as a source of average wages; a proxy is therefore used, namely, the average wage of the financial sector relative to construction as reported by the establishment surveys.

significantly in the 1990s. In Colombia the differential narrowed from 1976 to about 1990, and then increased slightly. In the two remaining countries (Costa Rica and Jamaica) the post-reform skill differential was roughly equal to what it was in the pre-reform observations.

As for capital intensity, only three countries (Chile, Costa Rica and Mexico) demonstrate a significant increase in the capital-labour ratio, whether preand post-reform or in the 1990s. In Brazil, Colombia and Jamaica, the ratio was roughly constant, while in Argentina, Bolivia and Peru it clearly fell. In short, the skill differential was either constant or growing in eight out of nine countries, but capital intensity rose in only three out of nine.

A relation between changes in capital intensity and the skill differential might be expected, since skilled labour and capital are generally considered to be complementary, but the table does not demonstrate that pattern. For the five countries with widening skill differentials, capital intensity increased significantly in only one, namely, Mexico. Actually the proportion of rising 
capital intensity is larger in the four countries without an increase in the skill differential. Costa Rica and Chile, in particular, need to be examined further because they combine a rapid increase in capital intensity with constant or declining wage differentials.

\section{B. Factor Shares and the Rate of Return to Capital}

As is well known, the household surveys on which the distribution statistics are based do not adequately reflect the income from capital. To some extent that is simply because of conscious under-reporting, but in addition a large part of that income is not distributed as profits and thus never appears in the surveys. It is possible to correct for the under-reporting of profit income by inflating whatever profits and interest income is reported, using the differences between the reported total and the nationwide accounts. ECLAC attempts to do this in its analysis of the surveys. However, the distribution statistics in table V-1 do not include that sort of correction. The survey distribution evidence must therefore be supplemented with information on factor shares as estimated and reported in the national accounts. Unfortunately, the breakdowns by factor incomes in the national accounts are unable to attribute to labour or capital the income that is generated in the informal sector or by self-employed workers. In table V-2, that component of national income is combined with capital. ${ }^{26}$ The table thus presents the income from salaries and wages as a fraction of total income at factor cost.

The surplus clearly fell between the pre- and post-reform periods in Bolivia, Colombia and Costa Rica, and it increased in Peru. It also rose during the first stage of reforms in Mexico (1984-1989), Chile (1970-1987) and Argentina (1974-1986), which corresponds exactly with the one-time shift up in inequality. Subsequently, the labour share recovered in all three countries, but only in Chile did it return to its pre-reform level. Thus, a shift from labour to capital in the distribution would appear to be an important component of the one-time upward shift in inequality between the pre- and post-reform periods in these three countries.

Information on the rate of return is only available for five of the countries, and it is sketchy even there. Each nationwide series is constructed with a different definition and is therefore useful only for intra-country comparisons over time. Note, in particular, that for Costa Rica the figures listed are an index of the rate of return. The available data indicate that the rate of return was either constant or declining over the period of the reforms. It was constant

26 The exception is Argentina, where the labour component of the informal sector was separately estimated and added to wage income. 
Table V-2

FACTOR SHARES AND RATE OF RETURN TO CAPITAL

\begin{tabular}{|c|c|c|c|c|c|}
\hline Argentina & 1974 & 1980 & 1986 & 1991 & 1997 \\
\hline Labour/GDP & 45 & 34.3 & 28 & 33.3 & 32 \\
\hline Surplus/GDP & 55 & 65.7 & 72 & 66.6 & 68 \\
\hline Rate of return & n.a. & n.a. & n.a. & n.a. & n.a. \\
\hline Bolivia & 1985 & 1989 & 1996 & & \\
\hline Labour/GDP & 35.6 & 39.4 & 39.8 & & \\
\hline Surplus/GDP & 64.4 & 60.6 & 60.2 & & \\
\hline Rate of return & 13.7 & 13.4 & 14.6 & & \\
\hline Chile & 1970 & 1987 & 1996 & & \\
\hline Labour/GDP & 47.8 & 42.9 & 48.0 & & \\
\hline Surplus/GDP & 52.2 & 57.1 & 52.0 & & \\
\hline Rate of return & n.a. & 15.1 & 15.4 & & \\
\hline Colombia & 1988 & 1993 & 1995 & & \\
\hline Labour/GDP & 42.7 & 45.0 & 46.3 & & \\
\hline Surplus/GDP & 57.3 & 55.0 & 53.7 & & \\
\hline Rate of return & 31 & 22.1 & 23.3 & & \\
\hline Costa Rica & 1988 & 1995 & & & \\
\hline Labour/GDP & 56.3 & 60.1 & & & \\
\hline Surplus/GDP & 43.7 & 39.9 & & & \\
\hline Rate of return & 101.9 & 91.2 & & & \\
\hline Jamaica & 1989 & 1993 & 1996 & & \\
\hline Labour/GDP & 51.2 & 50.9 & 50.6 & & \\
\hline Surplus/GDP & 48.8 & 49.1 & 49.4 & & \\
\hline Rate of return & n.a. & n.a. & n.a. & & \\
\hline Mexico & $1982-87$ & 1989 & 1994 & 1995 & 1996 \\
\hline Labour/GDP & 46.6 & 35.3 & 42.6 & 37.4 & 35.7 \\
\hline Surplus/GDP & 53.4 & 64.7 & 57.4 & 62.6 & 64.3 \\
\hline Rate of return & 14.5 & 12 & 10 & 7.5 & 7.5 \\
\hline Peru & 1985 & 1991 & 1994 & 1996 & \\
\hline Labour/GDP & 30.5 & 24.9 & 24.4 & 23.0 & \\
\hline Surplus/GDP & 69.5 & 75.1 & 75.6 & 77.0 & \\
\hline Rate of return & n.a. & n.a. & n.a. & n.a. & \\
\hline
\end{tabular}

Source: Consultant reports.

Note: The 1974 observation for Argentina is taken from Luis Beccaria, “Distribución del ingreso en la Argentina: explorando lo sucedido desde mediados de los setenta", Desarrollo económico, vol. 31, No. 123, (October-December 1991, table 1). That source gives a value for the labour share for 1980 of $35 \%$, which is comparable to the remainder of the series. 
in Bolivia and Chile after 1987, while it fell in Colombia, Costa Rica and Mexico. At the very least, there is no evidence of any increase in the return to capital.

Taken together, the available evidence from the factor markets indicates that growth has been more skill intensive during the post-reform period, but not necessarily more capital intensive. In fact, trends in capital intensity and the skill differential show very little relation. Furthermore, the rate of return to capital and possibly the share of capital in national income appear to have fallen, although the evidence is incomplete and unsatisfactory. If true, that pattern is consistent with the clear message of the previous chapter on the progressive effect of capital account liberalization. It is also consistent with trade reform having reduced monopoly profits in protected sectors, as pointed out by Londoño and Székely (1997).

\section{The Link between Labour Market Performance and Inequality}

Public discussions of performance under the new economic model repeatedly cite low rates of employment creation and a mismatch between jobs and skills as two of the main culprits for rising inequality in the region. The argument is that because of skill-intensive growth, not enough jobs are being created in most countries, and what jobs there are require too much skill. Unemployment has therefore risen, putting downward pressure on wages for the least skilled, while strong demand for skills has pushed up wages for the more educated. This hypothetical description is logically consistent, but it does not adequately reflect what has actually been happening in many, if not most, of the nine countries in the sample.

This section presents a number of indicators of labour market performance, and then looks for a relation between changes in those indicators in the post-reform period and changes in the primary distribution of earnings. This analysis is based on the distribution across those who earn income (the primary distribution) rather than the household distribution (see table V-1).

How should labour market performance be measured? One indicator is the growth in the total number of jobs, but that measure suffers from differences across countries and over time in the growth rate of the labour force. It is possible to correct for that by calculating the occupation rate, which is the percentage of those of working age who actually hold jobs. That is surely a better indicator of performance than the growth rate of jobs, but it is affected by changes in the participation rate. In several of the countries in the sample (Argentina being the most obvious example), job growth was faster than the growth of the working-aged population, so that the occupation rate increased. That would appear to be positive, but large increases in the participation rate, particularly for women, caused the unemployment rate to rise at the same 
time, since job creation was not fast enough to keep pace with the growth rate of the labour force. An economy should get positive marks if it can raise its occupation rate. For those interested in the distribution of earnings, however, unemployment is also relevant, since a rise in the unemployment rate will probably exert downward pressure on the wages of unskilled and hence upward pressure on the skill differential. Countries in which the unemployment rate rises should get a negative mark, even if they have rapid job creation at the same time. Finally, a measure of the skill intensity of the jobs being created would be valuable. Possibilities include the percentage of professionals among the new jobs, jobs in the so-called informal sector, the proportion of salaried jobs among the new jobs and the wage differential itself. Each of these may have some relation to wage inequality.

Table V-3 gathers together some of these indicators for the post-reform period. Whenever possible, the starting and ending dates for the tables below coincide with the observed data on the primary earnings distribution shown in table V-1.

Judging by the growth rate of employment, the unemployment rate and the occupation rate, Bolivia, Chile and Peru are the clear leaders in labour market performance, while Brazil, Colombia and Jamaica are the clear laggards. In all three of the leaders, the growth rate of jobs exceeded by a wide margin the growth rate of both the working-aged population and the labour force. Economic growth was translated into falling unemployment and rising real wages. The three lagging countries had exactly the opposite situation. They had low growth in jobs, rising unemployment and, except for Colombia, falling participation rates. However, these three countries also enjoyed healthy increases in the average real wage -not as large as the leaders, but not insignificant either.

Clearly, differences in overall economic growth rates are the main reason for the difference in performance between the leaders and laggards. In the three leaders, GDP grew by an average of $6.2 \%$, while in the laggards it grew by only $3.3 \%$. This does not mean that the leaders' success derived from labourintensive growth. That is true for Bolivia where, if the numbers are reliable, employment grew $50 \%$ faster than output, but it is not true for either Chile or Peru. Job growth was rapid because economic growth was rapid. In the laggards, low overall economic growth was complicated by the lowest employment-output elasticities in the sample. In Brazil and Colombia, what little growth occurred was labour saving.

The remaining three countries are harder to classify. Argentina, Costa Rica and Mexico all had employment growth rates close to the growth rate in their working-aged populations. The difference between them and the leaders or laggards hinges more on their participation rates than on the growth rate of employment. Argentina, for example, experienced a serious rise in unemployment during the 1990s, but that does not reflect a lack of job creation. 
Table V-3

INDICATORS OF LABOUR MARKET PERFORMANCE

\begin{tabular}{|c|c|c|c|}
\hline COUNTRY & PERIOD & INITIAL YEAR & FINAL YEAR \\
\hline \multicolumn{4}{|l|}{ Argentina } \\
\hline Occupation rate & $1991-97$ & 59.8 & 62.6 \\
\hline Unemployment rate & $1990-97$ & 7.5 & 16.1 \\
\hline Growth rate of jobs & $1990-97$ & & 1.7 \\
\hline Average real wage & $1990-97$ & 100.0 & 100.2 \\
\hline Primary distribution & $1991-96$ & .268 & .283 \\
\hline \multicolumn{4}{|l|}{ Bolivia } \\
\hline Occupation rate & $1989-96$ & 52.8 & 56.4 \\
\hline Unemployment rate & $1989-96$ & 9.5 & 4.2 \\
\hline Growth rate of jobs & $1990-97$ & & 6.6 \\
\hline Average real wage & $1990-97$ & 100.0 & 123.0 \\
\hline Primary distribution (urban) & $1989-96$ & .486 & .595 \\
\hline \multicolumn{4}{|l|}{ Brazil } \\
\hline Occupation rate & $1992-97$ & 61.5 & 60.1 \\
\hline Unemployment rate & $1990-97$ & 4.3 & 5.8 \\
\hline Growth rate of jobs & $1990-97$ & & 1.2 \\
\hline Average real wage & $1990-97$ & 100.0 & 106.0 \\
\hline Primary distribution & $1990-97$ & .700 & .710 \\
\hline \multicolumn{4}{|l|}{ Chile } \\
\hline Occupation rate & $1990-96$ & 51.6 & 54.4 \\
\hline Unemployment rate & $1987-97$ & 11.9 & 7.2 \\
\hline Growth rate of jobs & $1990-97$ & & 2.5 \\
\hline Average real wage & $1990-97$ & 100.0 & 132.0 \\
\hline Primary distribution & $1987-96$ & .653 & .636 \\
\hline \multicolumn{4}{|l|}{ Colombia } \\
\hline Occupation rate & 1988-95 & 56.8 & 58.1 \\
\hline Unemployment rate & $1990-97$ & 10.3 & 13.2 \\
\hline Growth rate of jobs & $1990-97$ & & 1.4 \\
\hline Average real wage & $1990-97$ & 100.0 & 110.0 \\
\hline Primary distribution (urban) & $1988-96$ & .432 & .457 \\
\hline
\end{tabular}




\begin{tabular}{|c|c|c|c|}
\hline COUNTRY & PERIOD & INITIAL YEAR & FINAL YEAR \\
\hline \multicolumn{4}{|l|}{ Costa Rica } \\
\hline Occupation rate & $1990-96$ & 53.5 & 52.2 \\
\hline Unemployment rate & $1988-96$ & 6.3 & 6.6 \\
\hline Growth rate of jobs & $1990-97$ & & 2.7 \\
\hline Average real wage & $1990-97$ & 100.0 & 110.0 \\
\hline Primary distribution & 1988-95 & .490 & .478 \\
\hline \multicolumn{4}{|l|}{ Jamaica } \\
\hline Occupation rate & $1989-96$ & 69.8 & 68.4 \\
\hline Unemployment rate & & & see note \\
\hline Growth rate of jobs & $1990-97$ & & 1.2 \\
\hline Average real wage & $1990-97$ & & see note \\
\hline Family distribution & $1989-96$ & .313 & .252 \\
\hline \multicolumn{4}{|l|}{ Mexico } \\
\hline Occupation rate & $1991-96$ & 53.6 & 55.4 \\
\hline Unemployment rate & $1989-96$ & 2.9 & 5.5 \\
\hline Growth rate of jobs & $1990-97$ & & 2.9 \\
\hline Average real wage & $1990-97$ & 100.0 & 101.0 \\
\hline Primary distribution & $1989-96$ & .270 & .290 \\
\hline \multicolumn{4}{|l|}{ Peru } \\
\hline Occupation rate & $1991-97$ & 58.0 & 67.8 \\
\hline Unemployment rate & $1990-96$ & 8.3 & 7.9 \\
\hline Growth rate of jobs & $1990-97$ & & 3.8 \\
\hline Average real wage & $1990-97$ & 100.0 & 110.0 \\
\hline Primary distribution & $1991-96$ & .502 & .485 \\
\hline
\end{tabular}

Sources: Unemployment from ECLAC, Social Panorama of Latin America, Santiago, Chile (various years); primary distribution from table V-1; other data from Jürgen Weller, Reformas económicas, crecimiento y empleo: los mercados de trabajo en América Latina, Santiago, Chile, ECLAC and Fondo de Cultura Económica (2000).

Note: Exact numerical estimates are not available for unemployment and the real wage for Jamaica, but Weller notes that the real wage rose in the 1990s and unemployment was constant.

The growth rate of jobs was just about equal to the growth rate of the workingaged population $(1.7 \%$ compared to $1.8 \%)$. Instead, it reflects a significant increase in the participation rate, particularly among women. Despite rapid growth, the Argentine economy was unable to create enough jobs to absorb these new entrants into the labour force. Costa Rica and Mexico display a 
similar situation. They both had good growth rates of employment, higher in fact than Chile's. However, a combination of rising participation rates and relatively rapid growth rates of the working-aged population increased the unemployment rate in both countries.

Which countries had relatively skill-intensive growth? Weller (2000) compares the change in the share of each education group in total employment to the change in the share of the same education group in the potential labour force. If growth is skill intensive, the change in the share of the more educated in employment should exceed the change in the potential labour force. The opposite should be observed for the less educated. That is exactly the pattern Weller observes for Argentina, Brazil, Chile, Colombia and Costa Rica, where employment growth was relatively skill intensive. The opposite was true, however, for two of the three successes namely, Bolivia and Peru. In both of those countries, employment growth for the less educated exceeded the growth of the potential labour force, and yet these two countries display the most rapid growth in the skill differential (see table V1). For some reason, skill intensity does not seem to be closely associated with changes in the skill differential.

Weller's approach is also useful for investigating the relation between the labour market data and the primary earnings distribution, by grading the performance of the labour market according to four characteristics that ought to have an impact on the distribution. Weller assigns a value of one to favourable changes over the period of analysis, zero to an insignificant change and minus one to an unfavourable change. The four characteristics chosen here are the changes in the unemployment rate, the occupation rate, the growth in real wages and the growth in salaried employment (a proxy for good jobs). The overall ranking is the simple sum of the four. This is admittedly a somewhat arbitrary selection and weighting, but it gives a rough quantification of the performance of the labour market (see table V-4).

Figure V-2 graphically represents the relation between the "totals listed in table V-4 and the change in the primary distribution shown in table V-3.

Clearly there is not a particularly close relation between the performance index and changes in the primary distribution. In particular, there are two outliers: Bolivia and Jamaica. In the case of Jamaica, the data are not really comparable with that of the other countries for two reasons: first, it is based on per capita expenditure distribution rather than the primary earnings distribution, which is not available, and it is the only economy in which per capita income was declining. The Jamaican economy did not have a positive reaction to the reform package. In the case of Bolivia, very rapid employment growth -the fastest in the sample- was coupled with falling unemployment and rising real wages. In terms of distribution, however, this favourable climate was offset by a very rapidly rising wage differential in favour of skilled labour, in spite of the fact that growth was not particularly skill intensive. It seems that the very rapid overall employment growth raised the wage differential for skilled labour, even in the absence of rising skill intensity, perhaps because 
Table V-4

INDICATORS OF LABOUR MARKET PERFORMANCE IN THE 1990s

\begin{tabular}{lccccc}
\hline Country & Unemployment & $\begin{array}{c}\text { Occupation } \\
\text { RATE }\end{array}$ & $\begin{array}{c}\text { SALARIED } \\
\text { EMPLOYMENT }\end{array}$ & REAL WAGES & TOtAL \\
\hline Argentina & -1 & 1 & 1 & 0 & 1 \\
Bolivia & 1 & 1 & -1 & 1 & 2 \\
Brazil & -1 & -1 & 0 & 1 & -1 \\
Chile & 1 & 1 & 1 & 1 & 4 \\
Colombia & -1 & 1 & -1 & 1 & 0 \\
Costa Rica & -1 & -1 & 0 & 1 & -1 \\
Jamaica & 0 & -1 & 1 & 1 & 1 \\
Mexico & -1 & 1 & 1 & 0 & 1 \\
Peru & 1 & 1 & -1 & 1 & 2 \\
\hline
\end{tabular}

Source: Author's calculations based on methodology in Jürgen Weller, Reformas económicas, crecimiento y empleo: los mercados de trabajo en América Latina, Santiago, Chile, Economic Commission for Latin America and the Caribbean (ECLAC) and Fondo de Cultura Económica (2000). There are some differences in periods covered.

Figure V-2

\section{LABOUR MARKET PERFORMANCE AND PRIMARY DISTRIBUTION}

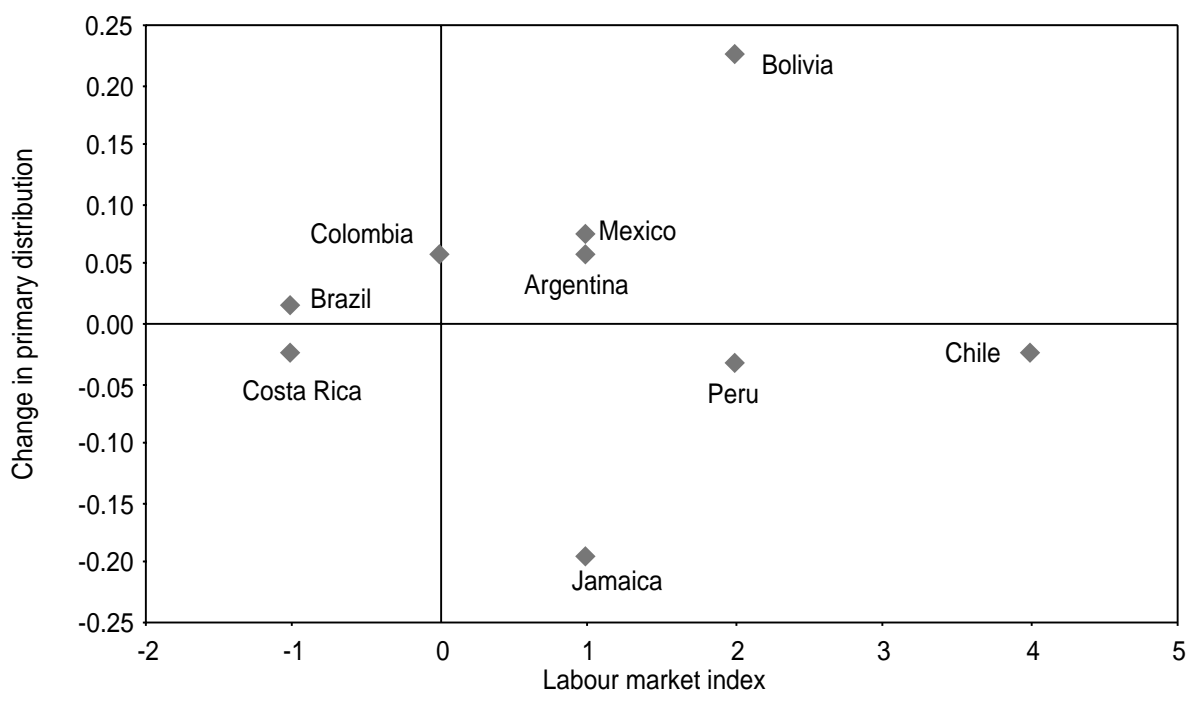

Source: Tables V-3 and V-4. 
of the rising premium paid to the combination of education and experience in buoyant labour market conditions.

The remaining seven countries seem to demonstrate a roughly negative relation between labour market performance and inequality. The more jobs are created, the more unemployment declines, and the more real wages go up, the more likely it is that earnings inequality will decline. Obviously many factors other than labour market conditions influence the earnings distribution, but the evidence here suggests that adequate employment growth and rising real wages have an important levelling effect.

\section{Patterns of Sectoral Growth in the 1970s and 1990s}

One of the ways by which the reforms could be expected to affect the earnings distribution would be if they particularly favoured those sectors that are big users of either skilled or unskilled labour. That is, reforms could affect the sectoral composition of demand, and that, in turn, could affect the relative skill intensity of labour demand. The evidence does not support that hypothesis, however. For the most part, the same sectors that were leaders in the 1970s before the reforms were still the leaders in the 1990s, and the same is true of lagging sectors.

To demonstrate this, the sector growth rates at the one-digit level were collected for the 1970s and 1990s in eight of the countries. Table V-5 classifies all these sectors into four groups: those that led in both periods (leaders), those that lagged in both periods (laggards), those that led in the 1970s but lagged in the 19990s (losers) and those that lagged in the 1970s but led in the 1990s (winners).

It seems clear from the table that the reforms have not led to dramatic changes in the sectoral characteristics of growth. Those sectors that had above or below average growth rates in the 1970s tended to continue the same pattern in the 1990s. The finance, electricity, transportation and communications sectors were generally leaders in both periods, while agriculture and housing were laggards. Altogether, sectors switched position in only 27 cases, compared to 49 cases in which the sector kept the same classification.

After the reforms, countries were more open, but for the most part they did not switch towards the tradable goods sectors (i.e., agriculture, mining and manufacturing). Indeed, looking at the winners and losers columns, more of the losers than the winners come from these three sectors. That becomes even more obvious on considering that agriculture in Brazil and Mexico, which accounts for two of the winners in column four, actually switched positions because the overall growth rate fell sharply in both countries between the 1970s and the 1990s, not because agriculture itself grew more rapidly. Indeed, its growth rate fell in both cases, but not as much as the growth rate of the 
Table V-5

\section{LEADING AND LAGGING SECTORS IN THE 1970s AND 1990s}

\begin{tabular}{|c|c|c|c|c|}
\hline & LAGGARDS $^{a}$ & LEADERS $^{\text {a }}$ & LOSERS $^{a}$ & WINNERS $^{\text {a }}$ \\
\hline ARGENTINA & $\begin{array}{l}\text { AgRICULTURE, } \\
\text { GoVERNMENT }\end{array}$ & $\begin{array}{c}\text { Finance, EleCtricity, } \\
\text { Commerce, Construction }\end{array}$ & Servilies & $\begin{array}{l}\text { Manufacturing, } \\
\text { TRANSPORT } \\
\end{array}$ \\
\hline BoLIVIA & Mining, Commerce & $\begin{array}{c}\text { FinanCe, Transport, } \\
\text { Manufacturing, } \\
\text { ElECtRICITY }\end{array}$ & $\begin{array}{c}\text { GovernMent, Services, } \\
\text { Agriculture }\end{array}$ & CONSTRUCTION \\
\hline BRAZIL & - & $\begin{array}{l}\text { TranspoRT, } \\
\text { MaNuFACTURING, } \\
\text { ELECTRICITY }\end{array}$ & Mining, Construction & $\begin{array}{l}\text { AgRiculture, } \\
\text { COMMERCE }\end{array}$ \\
\hline CHILE & $\begin{array}{l}\text { Manufacturing, } \\
\text { GovernMENT }\end{array}$ & $\begin{array}{c}\text { Electricity, Construction, } \\
\text { CommerCE, Transport, } \\
\text { FinanCE } \\
\end{array}$ & $\begin{array}{c}\text { Agriculture, Mining, } \\
\text { SeRvices }\end{array}$ & - \\
\hline Colombia & $\begin{array}{l}\text { Agriculture, Mining, } \\
\text { FinAnCE, Housing }\end{array}$ & $\begin{array}{l}\text { Commerce, Transport, } \\
\text { Government, Services }\end{array}$ & $\begin{array}{l}\text { ManufaCtuRING, } \\
\text { ELECTRIIITY }\end{array}$ & Construction, Finance \\
\hline Costa Rica & $\begin{array}{l}\text { AgRiCuLTuRe, } \\
\text { HOUSING }\end{array}$ & $\begin{array}{c}\text { FinanCE, Transport, Co } \\
\text { ELECTRICITY, } \\
\text { ManUfaCtURING }\end{array}$ & $\begin{array}{c}\text { Construction, GoVernMent, } \\
\text { Services }\end{array}$ & Commerce \\
\hline MeXICO & - & $\begin{array}{c}\text { Mining, ManufaCtuRING, } \\
\text { ELECTRICITY, CoMmerCE, } \\
\text { TRANSPORT, CONSTRUCTION }\end{array}$ & - & AgRICULTURE \\
\hline Peru & $\begin{array}{l}\text { AgRICULTURE, } \\
\text { Housing }\end{array}$ & $\begin{array}{c}\text { FinANCE, TRANSPORT, } \\
\text { CoMmERCE, CONSTRUCTION, } \\
\text { ELECTRICITY }\end{array}$ & $\begin{array}{l}\text { GoVernNmeNT, } \\
\text { SERVICES, } \\
\text { MinING }\end{array}$ & MANUFACTURING \\
\hline TOTAL & 14 & 35 & 17 & 10 \\
\hline
\end{tabular}

Source: ECLAC, Economic Survey of Latin America and the Caribbean, Santiago, Chile (various years). ${ }^{\text {a }}$ See text for definitions.

whole economy. The only clear switches among the tradable goods sectors are the post-reform gains in manufacturing in Peru and Argentina and the loss in Colombia. The government sector provides another example of the effect of the adoption of reforms. Of the six countries for which data are available, government is a clear loser in three reforming countries and a laggard in two others. Only in Colombia is government a leading sector in both periods.

The relative stability in patterns of growth implied in table V-5 may seem surprising, but in fact it illustrates an important feature of any growth process. Most of the demand for sectoral output is induced through the multiplier effects of exogenous spending, which could come from exports, government spending, the replacement of imports or investment. Whatever the source, differences in sectoral income elasticities and backward linkages to intermediate products almost guarantee that manufacturing, finance, transportation and some services will be leaders, that agriculture will be a laggard and that commerce and services will reflect the overall growth rate of 
the economy. In other words, the effects of any change in exogenous conditions will be less marked by the time they work their way though a country's inputoutput table and its demand system. Even when the reform process triggers rapid growth in some export commodities, the factors that produce those exports are likely to spend their income in about the same way as the factors in some previous leading sector. The result of all this is a relatively stable pattern of sectoral growth rates. This, in turn, implies a relatively stable pattern of growth rates in the demand for skilled and unskilled labour.

Generally speaking, growth was relatively skill intensive: the wage differential in favour of university graduates widened in every case but Chile. However, that could not have been caused by changes in sectoral growth rates due to the reforms. It is more likely to have been the result of the pressures of competition in the more open economy, overall trends in the nature of technology and the effects of restructuring during privatization. These regressive trends raised the skill differential, but they were not sufficiently abrupt to offset the beneficial effects of reducing the share of unskilled labour. As a result, the overall earnings distribution in most countries did not change much over the course of the 1990s.

\section{E. What Explains the Big Increases in Inequality in Chile, Argentina and Mexico?}

Obviously, none of the above discussion implies that income distributions are always constant. Rapid changes have frequently occurred over quite short periods. Three episodes, in particular, demand an explanation because they are not cyclic: Chile in 1970-1987, Argentina in 1974-1986 and Mexico in 19841989. These significant, one-time upward shifts in inequality have never been reversed. If distributions tend to be constant apart from variations over income cycles, what factors explain these three exceptions, and are they linked to the adoption of reforms?

Both Argentina and Chile implemented a significant part of their reform programmes prior to the mid-1980s. Chile's aggregate reform index rose from .32 in 1973 to .72 in 1987, making Chile the second most reformed country in the region. Argentina did less, but its index rose from .41 in 1976, when the reforms started, to .61 in 1986 and to .81 in 1990 (Morley, Machado and Pettinato, 1999). In both countries, commercial, financial and tax reforms were the central components of the early reform programme. Mexico, in contrast, began its trade and financial reforms in the 1985-1987 period by eliminating quantitative import restrictions and narrowing tariff differentials. The changes it implemented were far less dramatic than those in the Southern Cone, partly because Mexico had always had lower tariffs than Argentina and Chile (Ros, 1999). The policy change took place during the long downturn that followed 
the 1982 debt crisis in Mexico, a period in which real wages contracted, the skill differential widened and the factor distribution shifted towards profits (Székely, 1998, pp. 64-67; Ros, 1999, table 5). ${ }^{27}$

All three countries suffered macroeconomic instability and inflation during the relevant periods. Chile went through two severe recessions between 1973 and 1987, and Argentina had three between 1976 and 1990, though none were quite as severe as the 1982-1983 downturn in Chile. Mexico also experienced recession or stagnation conditions in the 1984-1989 period, with output per capita $6 \%$ lower in 1989 than it had been five years earlier.

Another factor that characterizes Chile and Argentina, but not Mexico, is a change in the treatment of labour accompanying a change of political regime. The two reforming military governments effectively curtailed unions, increased labour market flexibility and generally reduced the bargaining power of labour vis-à-vis management. ${ }^{28}$ In Chile the military government reduced the coverage of the minimum wage, relaxed conditions for dismissal of workers, suspended labour unions, closed the labour courts, limited the permissible activities of labour unions and encouraged the organization of competing labour unions within enterprises (Ffrench-Davis and Raczynski, 1990, p. 8.). In Argentina under the military regimes between 1976 and 1983, union activities were prohibited and wage increases were set by the government. This new labour market regime, combined with rising inflation and the drastic recession after 1982, led to a sharp decline in real wages between 1976 and 1983 (Beccaria, 1991; Altimir and Beccaria, 1999a).

It is impossible to determine what role each of these three factors played in rising inequality, but the combination of recurrent recession, commercial liberalization and a change in the treatment of labour best explains the onetime upward shift in inequality in these three countries.

Why didn't the other countries in the region have the same experience that Chile and Argentina did with reforms? First of all, all the other countries adopted the reforms in the 1990s, a period that was relatively free of the violent fluctuations observed in the 1980s. This helped avoid significant increases in inequality, because recessions typically have a strong negative impact on the distribution of income (Morley, 1995; Ravallion and Chen, 1997). Colombia and Costa Rica carried out their reforms gradually and without serious recessions. In that environment, the reforms had little effect on distribution. Bolivia and Peru made sudden, quite drastic reforms, but they both did so as

27 In addition, the guaranteed price for maize and beans declined sharply, and the per hectare yield fell by 25\% between 1984 and 1989 (Székely, 1998, p. 69).

28 These two cases seem somewhat similar to Brazil in the 1963-1980 period. Brazil had a reforming military government that sharply curtailed labour bargaining power in the context of a successful inflation control programme and a first round of tariff reductions. The result was a long period of rapid growth, wage stagnation and a one-time upward shift in inequality, which has so far not been reversed. 
part of a broad stabilization package that stopped hyperinflation. Any regressive impacts of reforms were more than offset by the favourable impact of stopping hyperinflation.

Whenever there were large shifts in distribution, they accompanied big changes in wage differentials or real wages and in the share of profits, which took place during periods of high inflation, recession, very rapid growth or changes in regime. But the 1990s were not marked by very rapid growth, except perhaps in the case of Chile. Nor were there cases of hyperinflation or deep recessions (up to 1998) of the sort that would cause the sudden sharp swings in wage differentials or the profit share that would swamp the longrun effects of changes in the education structure. And in these changes, the progressive and regressive components seem to just about cancel each other out. 


\section{CHAPTER VI \\ THE COMPONENTS OF INCOME INEQUALITY}

So far, this book has examined the determinants of inequality and the impact of reform by constructing an econometric model of the distribution of family income and by comparing inequality before and after the reforms. Another way to better understand the determinants of inequality is to look more closely at the inequality indexes themselves, searching for clues as to what is making them change as they do, or in some cases not change in spite of events that might be expected to cause changes. This chapter and the next conduct an exercise of this sort. While such an exercise does not directly measure the impact of growth or reform on inequality, it highlights the role of education, skill, experience, sector and gender as contributors to both the level and the type of change in inequality.

The exercise starts by separating the total population into a number of groups, by education, location, sector, occupation, age and gender, and then calculating an inequality index and average income for each group. These inequality indexes are indicators of how much of overall inequality is due to differences in the mean income between the various groups and how much comes from inequality within the groups. The greater the proportion of inequality explained by the differences in mean income between the groups, the more significant is this particular characteristic of the population as a source of inequality.

This sort of decomposition is particularly useful for understanding changes in the level of inequality. By carrying out the decomposition at different points in time, it is possible to measure how much of the change in inequality comes from changes in average income between the groups and how much from change in inequality within the groups. This methodology is used here to measure how far changes in wage differentials between education classes 
have contributed to changes in inequality during the post-reform period. The next chapter uses the same technique to study those at the top of the income distribution as a source of inequality.

The decomposition of inequality has been slowed down by the widespread use of the Gini coefficient, which does not decompose easily. An alternative measure that does is the Theil index shown in equation VI-1. The Theil index is defined as the weighted average of the log of the relative income of each member of a population, where the weights are in the income share of each individual.

$$
\begin{aligned}
& \mathrm{T}=\sum_{\mathrm{i}} \mathrm{y}_{\mathrm{i}} \ln \left(\mathrm{y}_{\mathrm{i}} / \mathrm{p}_{\mathrm{i}}\right) \\
& \mathrm{y}_{\mathrm{i}} \text { is the income share of the ith individual } \\
& \mathrm{p}_{\mathrm{i}} \text { is the population share of the ith individual }
\end{aligned}
$$

The Theil index varies between zero, for perfect equality, and the log of the number of individuals in the population, for perfect inequality. It may seem odd that the index is sensitive to the size of the sample, but this characteristic reflects the idea that the amount of inequality should be higher when there are more individuals with no income relative to those with income. Following Theil (1972), imagine a society with two individuals, one of whom has all the money. The Theil in this case is log2. If 999,998 individuals are added to the group without income, there are now one million individuals in all, one of whom has all the money. Inequality is surely greater in the second society than the first, and this is reflected in the value of the Theil, which rises from $\log 2$ to $\log 10^{6}$.

Equation VI-1 can be rewritten to show how the overall index can be decomposed or expressed as a sum of two individual components, one expressing differences in average incomes between subgroups, and the other differences of income or inequality within each subgroup. After first dividing the population into the groups of interest, equation VI-1 can be rewritten as follows:

$$
\begin{aligned}
& \mathrm{T}=\sum_{\mathrm{i}} \mathrm{y}_{\mathrm{i}} \ln \left(\mathrm{y}_{\mathrm{i}} / \mathrm{p}_{\mathrm{i}}\right)+\sum_{\mathrm{i}} \mathrm{y}_{\mathrm{i}} \mathrm{T}_{\mathrm{i}} \\
& \mathrm{y}_{\mathrm{i}} \text { is the income share of the ith group } \\
& \mathrm{p}_{\mathrm{i}} \text { is the population share of the ith group } \\
& \mathrm{T}_{\mathrm{i}} \text { is the Theil index for the ith group }
\end{aligned}
$$

The first term on the right hand side of the equation is a weighted average of the differences in average incomes among the various subgroups. It is natural to call this component the "between groups" component of total inequality. The second term on the right hand side is a weighted average of the Theil index for each subgroup, where the weight is the share of the group in total income. It measures the amount of inequality within each of the 
subgroups and is therefore called the "within group" component. This breakdown is used in the following tables to help identify sources of inequality and changes in inequality.

\section{A. Decompositions of Inequality}

The decomposition shown in equation VI-2 were performed on the sample of nine countries, using sub-groups based on education, occupation, age, gender and location. The results are displayed in tables VI-1 to VI-4.

The left-hand columns are the indexes themselves. In most cases they are the same values shown earlier in table V-1. The columns labelled "variation within groups" show the proportion of inequality coming from differences in income among the members of each of the groups. The "variation between groups" columns show the fraction due to differences in average incomes between the different groups. With that as an introduction, what do the tables suggest about the sources of inequality in the nine-country sample?

Differences between mean incomes across different education levels are the single most important determinant of inequality. According to table VI-1, variation between groups explains anywhere from a fifth to a third of inequality in the primary distribution. ${ }^{29}$ Furthermore, that proportion increased in every country except Brazil and Chile. In some cases, such as Bolivia and Peru, the differences between the pre- and post-reform surveys are very large. This evidence is consistent with the evidence on trends in the skill differential, except for Jamaica and Costa Rica (see table V-1). It suggests that differences in education, which have always been an important factor in the distribution, have become even more important in recent years. As for Costa Rica, the measure of the skill differential is dominated by the relative income of university graduates. A separate decomposition for Costa Rica shows an almost constant betweengroup contribution to total inequality for university graduates alone.

Differences in average income across occupations are the second largest source of inequality after education, accounting for anywhere from $20 \%$ to $38 \%$ of the total (see table VI-2). Each survey features a different breakdown of occupations, but the typical one includes employees, informal sector or self-employed, owner or employer and in some cases government and agriculture. In the nationwide surveys, a good part of the inequality must have come from the low wages of agricultural labourers. As in the case of education, the proportion of total inequality accounted for by interoccupational differences in average incomes generally increased.

29 In the case of Jamaica, the contribution of education is less, but this survey refers to family expenditure per capita and is therefore not really comparable to the primary distributions of the other eight surveys. 


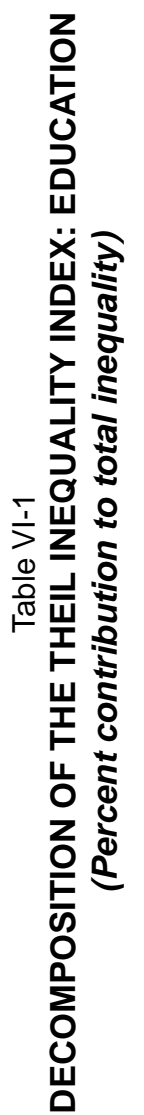

命 户் б.

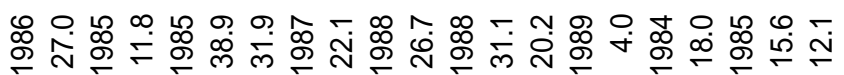
ஜํำ

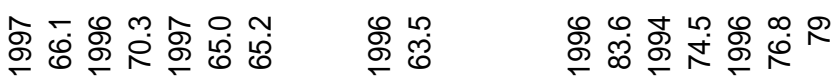
б ூ

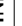

이 ᄂ

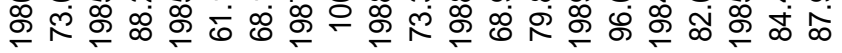
ஜ 요

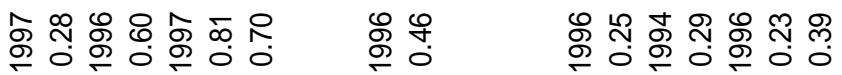
岌

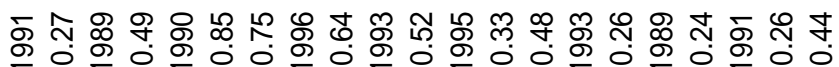
은

ஜ ำ O 0 O

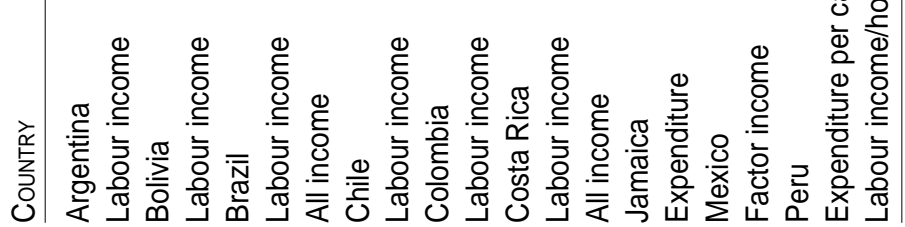

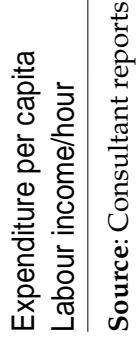




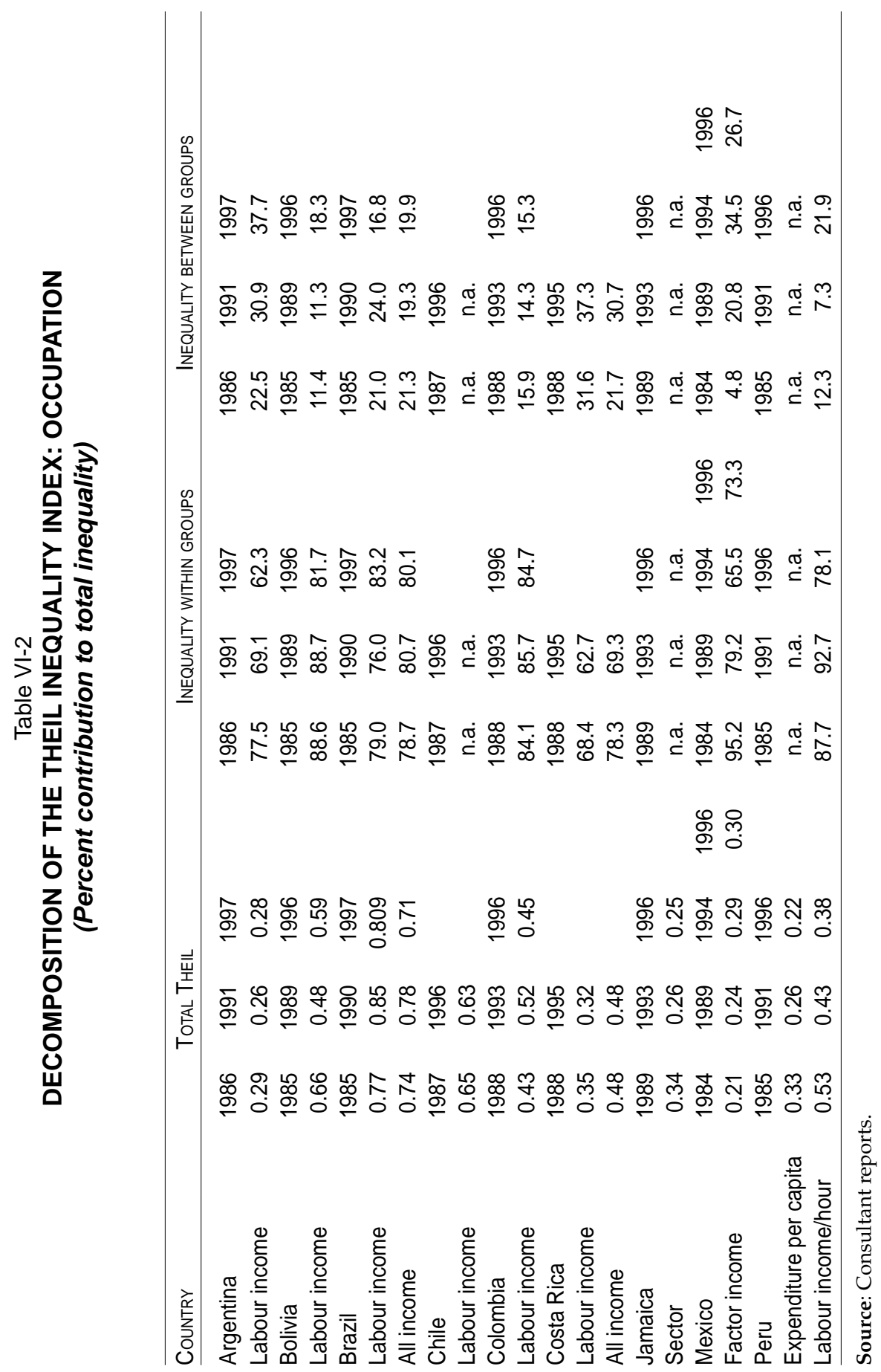




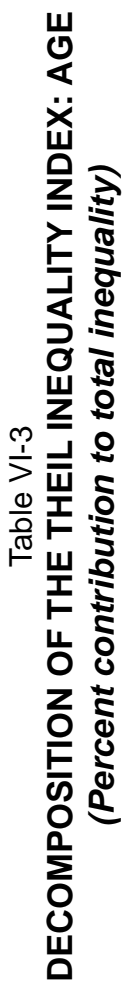

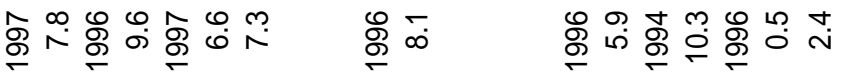

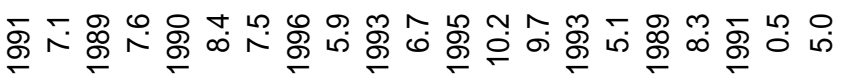
舟 ஜ ஜ

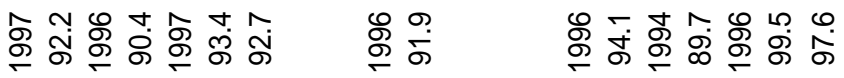

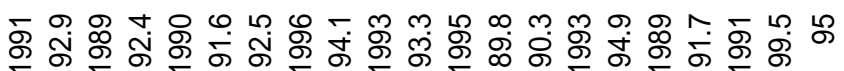
荘

ஜ บ ᄂ

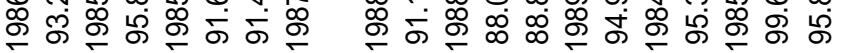

ஜํㅇ

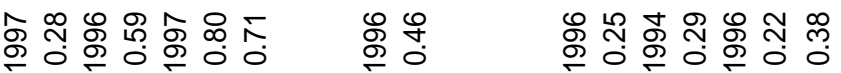

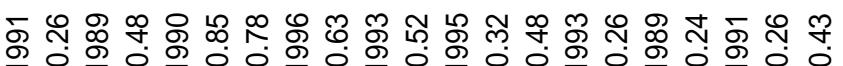
危

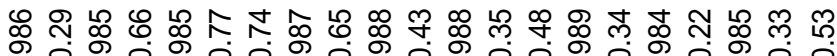

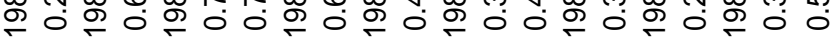

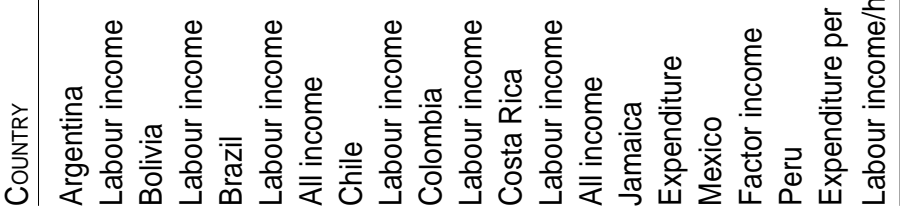

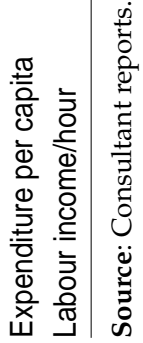




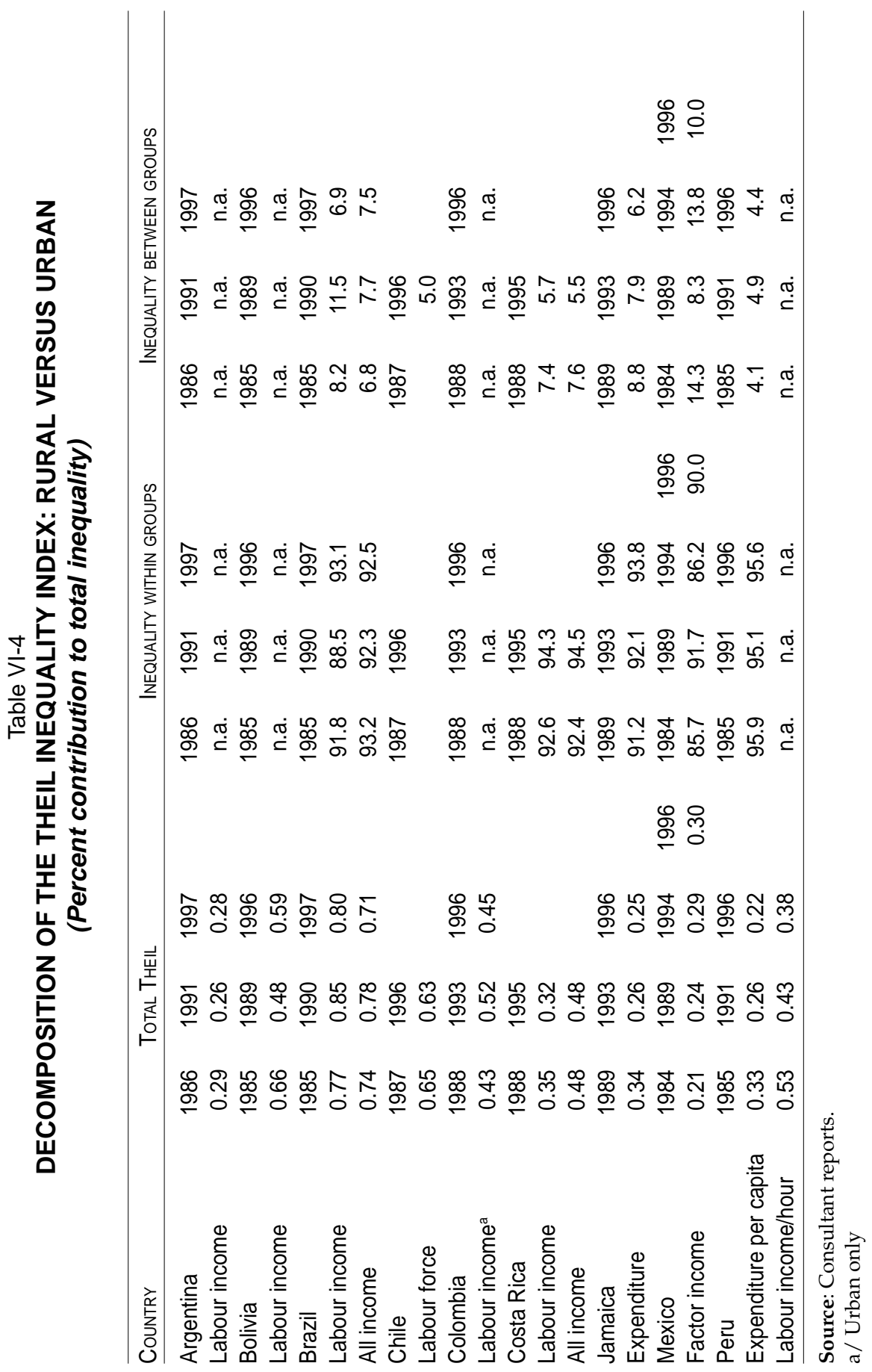


Neither age nor gender appears to be important sources of inequality. Breaking down the population into age groups shows that differences in average incomes between cohorts constitute no more than $5-10 \%$ of total inequality, and no significant change occurred between the pre- and postreform situations, except possibly in the case of Bolivia (see table VI-3). The case of gender, which is not shown in the tables, requires explanation. According to the decompositions, the between-group contribution of gender never reaches more than $5 \%$ of total inequality, although that does not mean that there is no inequality in earnings between men and women. According to IDB cross-country data the gender earnings differential varied from $5 \%$ in Paraguay to $35 \%$ in Brazil (IDB, 1998, table 2.5). That is only one of the factors determining the between-group Theil index, however. In the Theil formula, the between-group component is the sum of the logs of relative incomes weighted by the relevant income share. Consequently, the smaller the proportion of women to men in the labour force, the smaller is the between-group Theil, holding relative average incomes constant. One of the reasons gender differences do not generally contribute much to overall inequality is that the size of the female labour force is small relative to the male. To put it another way, most of the income is earned by males, partly because they earn more, but mainly because there are so many more of them in the labour force. Therefore, inequality within the male group is the main contributor to total inequality.

Finally table VI-4 shows a rural-urban disaggregation. Rural-urban income differentials are large, so it is somewhat surprising to see that they have such a small effect on national inequality. As in the case of gender, the reason is not that income differences do not exist, but rather that the population classified as living in the rural sector is not very large. In Brazil (the only study for which detailed information is available), the rural population was only $23 \%$ of the total (in 1997). Thus, even though rural average income was less than half the corresponding urban figure, the smallness of the rural population reduces the impact of these differences to only $7.5 \%$ of total inequality. Indeed, eliminating the difference between the rural and national average income would only reduce inequality by 2.3 percentage points, or about $4 \%$. In other words, to reduce inequality in Brazil, or almost anywhere else in Latin America, efforts must focus on the areas that encompass most of the people and income, and these are in the urban sector.

Another interesting result arises from the comparison of the rural-urban differential before and after the reforms. There is a good deal of evidence that the rural sector did not do as well as the urban sector in the 1990s. The data here do not show that, except for Mexico in 1994. In all the other countries, the between-group contribution of rural-urban differentials fell in the 1990s.

This first look at the decomposition data points to two conclusions. First, education and occupation are the only two characteristics for which betweengroup differences in average income really matter. Second, most of the inequality comes from within the groups, not between them. Even for 
education and occupation, the between-group fraction of total inequality is less than one-third in all but a few cases. Personal characteristics other than level of education or position held are still the main sources of inequality in the region, despite the rise in the skill or occupation income differentials in the post-reform period.

\section{B. The Effect of Changes in Education and Skill Differentials}

One of the puzzles that requires an explanation is why the overall distribution is so rigid in so many countries despite rising wage differentials and skill-intensive growth. Wage differentials increased in eight of the nine countries, yet in four of these (Argentina, Brazil, Costa Rica and Jamaica) the distribution hardly moved at all in the 1990s. In Chile, the distribution was similarly constant, but the wage differential decreased slightly. Only Peru demonstrates an unambiguous trend, and it is progressive in spite of a significant rise in the skill differential. Mexico and Colombia are special cases in that the aggregate distribution data conceal significant shifts among the component parts (a fall in the profit share offsetting rising wage inequality in Mexico and a fall in rural inequality offsetting rising urban inequality in Colombia). In Bolivia, inequality is lower now than it was in 1985, but it is higher than in 1989. Why doesn't earnings inequality follow the trend of wage inequality?

A number of different factors affect the education decomposition in any analysis over time. These include changes in relative incomes between groups, changes in inequality within groups and, most important, changes in the sizes of the groups. Some of these factors are equalizing and some are disequalizing. Their various effects seem to be largely mutually offsetting in the nine countries studied here. The important implication is that rising wage differentials do not necessarily imply rising earnings inequality. More often than not, reductions in within-group income variance and changes in population weights offset the disequalizing effect of widening skill differentials.

Since the proportion of between-group inequality increased in every case but Brazil, it follows that within-group inequality must have fallen either relatively or even absolutely in those cases where overall inequality declined. A closer look at the countries for which detailed information is available indicates that the reduction in within-group inequality occurred among those with primary education or less. Those at the top of the education pyramid saw an increase in within-group inequality, but it did not offset the reduction in inequality among those at the bottom. For example, in Costa Rica the withingroup contribution of those with incomplete primary schooling fell by five points between 1988 and 1995, while it rose by two points for the university graduates (Trejos, 1999, table B-11). In Colombia the within-group Theil for 
those with less than five years' schooling fell 3.4 points, just about offsetting a rise of 2.6 points for university graduates (Cárdenas and Bernal, 1999, table 1). That suggests that the post-reform economies have either equalized incomes for workers at the bottom or reduced the size of the group while creating special earnings opportunities for an expanding sub-group of winners at the top. In most cases, the gains in equity among the poor are bigger than the losses of equity among the rich, such that overall within-group inequality has declined, either relatively or absolutely.

On balance, it seems that in most countries (even those with rising wage inequality) these various effects just about cancel each other out and the distribution appears to be roughly stable. To show how this process works numerically, tables VI-5, VI-6 and VI-7 present detailed country cases using actual data from Brazil, Argentina and Peru. In all three cases, the aggregate inequality indexes are roughly constant or declining (except for Argentina between 1976 and 1980), yet their wage differentials and between-group inequality are generally rising.

Table VI-5

BRAZIL: EFFECT OF CHANGES IN EDUCATION STRUCTURE

\begin{tabular}{|c|c|c|c|c|c|c|}
\hline LEVEL OF SCHOOLING & $\begin{array}{l}\text { POPULATION } \\
\text { SHARE }\end{array}$ & $\begin{array}{l}\text { INCOME } \\
\text { SHARE }\end{array}$ & THEIL & $\begin{array}{l}\text { CONTRIBUTION } \\
\text { OF INEQUALITY } \\
\text { WITHIN GROUPS }\end{array}$ & $\begin{array}{c}\text { CONTRIBUTION } \\
\text { OF INEQUALITY } \\
\text { BETWEEN } \\
\text { GROUPS }\end{array}$ & TOTAL \\
\hline \multicolumn{7}{|l|}{1976} \\
\hline 0 years & 0.2458 & 0.0997 & 0.4600 & 0.0459 & -0.0900 & \\
\hline $1-4$ years & 0.4377 & 0.3215 & 0.5700 & 0.1833 & -0.0992 & \\
\hline $5-8$ years & 0.1824 & 0.1940 & 0.6700 & 0.1300 & 0.0119 & \\
\hline $9-12$ years & 0.0892 & 0.1612 & 0.5500 & 0.0887 & 0.0954 & \\
\hline $13-16$ years & 0.0417 & 0.1964 & 0.3500 & 0.0687 & 0.3045 & \\
\hline$>16$ years & 0.0032 & 0.0272 & 0.3600 & 0.0098 & 0.0585 & \\
\hline Total & 1.0000 & 1.0000 & & 0.5263 & 0.2811 & 0.8074 \\
\hline \multicolumn{7}{|l|}{1997} \\
\hline 0 years & 0.1339 & 0.0490 & 0.4900 & 0.0240 & -0.0493 & \\
\hline $1-4$ years & 0.3365 & 0.1999 & 0.5700 & 0.1140 & -0.1041 & \\
\hline $5-8$ years & 0.2445 & 0.1812 & 0.5400 & 0.0978 & -0.0543 & \\
\hline $9-12$ years & 0.1978 & 0.2460 & 0.5400 & 0.1328 & 0.0536 & \\
\hline $13-16$ years & 0.0789 & 0.2672 & 0.5000 & 0.1336 & 0.3258 & \\
\hline$>16$ years & 0.0083 & 0.0567 & 0.4100 & 0.0232 & 0.1086 & \\
\hline Total & 1.0000 & 1.0000 & & 0.5255 & 0.2803 & 0.8058 \\
\hline \multicolumn{7}{|l|}{ Simulations } \\
\hline 76p97y & & & & 0.5250 & 0.2379 & 0.7629 \\
\hline $76 y 97 p$ & & & & 0.5083 & 0.3020 & 0.8104 \\
\hline
\end{tabular}


Table VI-6

\section{ARGENTINA: EFFECT OF CHANGES IN EDUCATION STRUCTURE}

\begin{tabular}{|c|c|c|c|c|c|c|}
\hline LEVEL OF SCHOOLING & $\begin{array}{c}\text { POPULATION } \\
\text { SHARE }\end{array}$ & $\begin{array}{l}\text { INCOME } \\
\text { SHARE }\end{array}$ & THEIL & $\begin{array}{l}\text { CONTRIBUTION } \\
\text { OF INEQUALITY } \\
\text { WITHIN GROUPS }\end{array}$ & $\begin{array}{c}\text { CONTRIBUTION } \\
\text { OF INEQUALITY } \\
\text { BETWEEN } \\
\text { GROUPS }\end{array}$ & TOTAL \\
\hline
\end{tabular}

\section{4}

$\begin{array}{lcccccc}\text { Less than primary } & 0.2682 & 0.2047 & 0.1248 & 0.0256 & -0.0552 & \\ \begin{array}{l}\text { Primary and } \\ \text { incomplete secondary }\end{array} & 0.5322 & 0.5065 & 0.1548 & 0.0784 & -0.0251 & \\ \begin{array}{l}\text { Secondary and } \\ \text { incomplete university }\end{array} & 0.1706 & 0.2226 & 0.1315 & 0.0293 & 0.0593 & \\ \text { University } & 0.0290 & 0.0661 & 0.1774 & 0.0117 & 0.0545 & \\ \text { Total } & 1.0000 & 1.0000 & & 0.1450 & 0.0334 & 0.1784\end{array}$

1980

$\begin{array}{lcccccc}\text { Less than primary } & 0.1969 & 0.1335 & 0.1339 & 0.0179 & -0.0519 & \\ \begin{array}{l}\text { Primary and } \\ \text { incomplete secondary }\end{array} & 0.5728 & 0.4868 & 0.1926 & 0.0938 & -0.0792 & \\ \begin{array}{l}\text { Secondary and } \\ \text { incomplete university }\end{array} & 0.1862 & 0.2600 & 0.1975 & 0.0513 & 0.0867 & \\ \text { University } & 0.0444 & 0.1201 & 0.1972 & 0.0237 & 0.1194 & \\ \text { Total } & 1.0000 & 1.0000 & & 0.1867 & 0.0750 & 0.2617\end{array}$

1997

\begin{tabular}{|c|c|c|c|c|c|c|}
\hline Less than primary & 0.0698 & 0.0406 & 0.1207 & 0.0049 & -0.0220 & \\
\hline \multicolumn{7}{|l|}{ Primary and } \\
\hline incomplete secondary & 0.4920 & 0.3459 & 0.1433 & 0.1496 & -0.1219 & \\
\hline \multicolumn{7}{|l|}{ Secondary and } \\
\hline incomplete university & 0.3287 & 0.3670 & 0.1996 & 0.0733 & 0.0405 & \\
\hline University & 0.1096 & 0.2465 & 0.2427 & 0.0598 & 0.1999 & \\
\hline Total & 1.0000 & 1.0000 & & 0.1876 & 0.0965 & 0.2841 \\
\hline
\end{tabular}


Table VI-7

\section{PERU: EFFECT OF CHANGES IN EDUCATION STRUCTURE}

\begin{tabular}{|c|c|c|c|c|c|c|}
\hline LEVEL OF SCHOOLING & $\begin{array}{l}\text { Population } \\
\text { SHARE }\end{array}$ & $\begin{array}{l}\text { INCOME } \\
\text { SHARE }\end{array}$ & THELL & $\begin{array}{l}\text { CONTRIBUTION } \\
\text { OF INEQUALITY } \\
\text { WITHIN GROUPS }\end{array}$ & $\begin{array}{c}\text { CONTRIBUTION } \\
\text { OF INEQUALITY } \\
\text { BETWEEN } \\
\text { GROUPS }\end{array}$ & TOTAL \\
\hline \multicolumn{7}{|l|}{1985} \\
\hline No schooling & 0.0435 & 0.0210 & 0.4732 & 0.0100 & -0.0153 & \\
\hline Primary & 0.3213 & 0.2285 & 0.5257 & 0.1201 & -0.0778 & \\
\hline Incomplete secondary & 0.1704 & 0.1352 & 0.5106 & 0.0690 & -0.0313 & \\
\hline Complete secondary & 0.2646 & 0.2819 & 0.5076 & 0.1431 & 0.0179 & \\
\hline \multicolumn{7}{|l|}{ Non-univ. higher } \\
\hline education & 0.0548 & 0.0771 & 0.3167 & 0.0244 & 0.0263 & \\
\hline University & 0.1455 & 0.2562 & 0.4127 & 0.1058 & 0.1451 & \\
\hline Total & 1.0000 & 1.0000 & & 0.4724 & 0.0649 & 0.5372 \\
\hline \multicolumn{7}{|l|}{1996} \\
\hline No schooling & 0.0197 & 0.0093 & 0.1203 & 0.0011 & -0.0070 & \\
\hline Primary & 0.2103 & 0.1477 & 0.3316 & 0.0490 & -0.0522 & \\
\hline Incomplete secondary & 0.1587 & 0.1169 & 0.2686 & 0.0314 & -0.0357 & \\
\hline Complete secondary & 0.3075 & 0.2548 & 0.2699 & 0.0688 & -0.0479 & \\
\hline \multicolumn{7}{|l|}{ Non-univ. higher } \\
\hline education & 0.1259 & 0.1343 & 0.2691 & 0.0361 & 0.0087 & \\
\hline University & 0.1779 & 0.3369 & 0.3505 & 0.1181 & 0.2151 & \\
\hline Total & 1.0000 & 1.0000 & & 0.3045 & 0.0810 & 0.3855 \\
\hline
\end{tabular}

The left-hand columns of the tables show the population and income shares and the within-group Theil for each year in each country. The right hand columns, namely, the contribution of inequality within and between groups, show the components of equation VI-2. Those components sum to the within and between figures for the entire sample that are shown in the total. In Argentina in 1974, for example, the group with less than primary education comprised $27 \%$ of the labour force and earned $20 \%$ of total income. Their Theil was .1248. According to the formula, the within-group component of total inequality is the income share times the group's Theil, or $.205^{*} .1248=.0256$. The level of detail in these tables is perhaps tedious, but it is only by looking at the details that one can really understand at a statistical level what is changing the distribution. In particular, the stastistics can trace the impact of changes in education structure and inequality within each group 
to changes in aggregate inequality.

A word of caution is in order with regard to the entries for the contribution of inequality between groups. Those entries are defined as the income share of the group multiplied by the log of the relative income share of the group $\left(\mathrm{y}_{\mathrm{i}} / \mathrm{p}_{\mathrm{i}}\right)$. As for within-group contribution, these components sum to the between-group Theil. However, unlike the within-group components, one cannot read any significance into the individual elements in the table. In particular, they do not represent the contribution of the sub-group to betweengroup inequality.

All three countries feature a significant upgrading of the educational profile of the labour force. For Peru the population share of the group with primary education or less fell from $36 \%$ to $22 \%$ between 1985 and 1996, while for Argentina it fell from 27\% to 7\% between 1974 and 1997. Since the skill differential also increased in those two countries, the between-group Theil went up too (from .145 to .187 in Argentina and from .065 to .081 in Peru). In Brazil the between-group Theil also fell, reflecting a reduction in the gap between the earnings of the two bottom income groups.

Together, the trends in inequality within each group and the relative level of inequality between groups drive the distribution over time. In Brazil and Peru intra-group inequality is higher for the less educated. Other things being equal, in these two countries upgrading the education structure of the labour force tends to reduce within-group inequality because it expands the groups with relatively lower intra-group inequality. That factor, however, may be offset or augmented by the trends in intra-group inequality themselves. In Peru the two effects are complementary. Not only did the change in structure move people into lower-variance education classifications, but the variance itself was falling. The net effect was a very large reduction in within-group inequality (from .47 to .30), which overshadowed the two-point rise in the between-group Theil due to rising wage differentials. Contrast that with Brazil. There, the progressive effect of the move into lower-variance education classes was completely offset by the rise in the intra-group inequality of the better educated.

In contrast to Brazil and Peru, the Theils in Argentina are higher for the educated. That means that changes over time in education structure tend to increase within-group inequality. In particular, the trend was for inequality to increase among those with secondary or university education. Total withingroup inequality rose both because more people were in the high-variance education groups and because the income variance in those groups rose.

The next step is to use the disaggregated data to look more closely at the three cases. For Brazil, the question is how the distribution could have been so stable over so long a period of time despite a big change in educational structure and a rise in the wage differential. Brazil's Theil was essentially constant between 1976 and 1997. How did that happen?

First, the educational structure changed considerably over the period (see 
table VI-5). The proportion with four or fewer years of education fell from $68 \%$ of the labour force to $47 \%$, while the group with more than high school rose from $4.4 \%$ to $8.6 \%$. As mentioned above, however, the within-group Theils show that in both years the variance for the poorly educated was greater than for the university and high school groups. Finally, the variance at the top increased sharply over the period. This last point is crucial to understanding why the distribution stayed constant.

Two simple simulations are displayed at the bottom of table VI-5. The row labelled 76p97y calculates what the distribution would have been if the 1976 population had had the 1997 income structure, holding the within-group Theils constant. A comparison of this simulated distribution with the actual 1976 distribution shows that the changes in relative incomes was progressive (i.e., the 1976 Theil of .807 falls to .763 in the simulation). That is mainly because the between-group Theil falls in the simulation. This may seem odd, given that Brazil showed a rising wage differential between university and primary school graduates in table V-1, but that is because the wage differential narrowed between those with primary schooling and those with no education. This simulation demonstrates that overall, the trend in wage differentials was progressive in Brazil between 1976 and 1997 even though the wage ratio of university graduates relative to workers with only primary schooling rose from 8 to 9 over the period.

The second simulation (76y97p) shows the effect of raising the educational level of the labour force between 1976 and 1997 while holding relative incomes constant at their 1976 levels. In this case, the distribution is slightly less equal (the Theil rises from .807 to .810 ). The between-group Theil rises a bit, but that is offset by a fall in the within-group Theil. Keep in mind that the intra-group Theils have not changed in this simulation. Rather the reduction comes from reducing the share of the low-education groups which have the highest intragroup income variance. In particular, the bottom two groups had high withingroup Theils in 1976, and the simulation dramatically lowers the weight of these two groups in the total. Indeed, this shift is big enough to offset the regressive effect of population shifts on the between-group Theil.

Gains at the bottom should have been enough to reduce inequality in Brazil. That did not happen because of the interaction of improvements in education with increasing variance for the top two education groups. The high school graduates' within-group Theil rose from .35 to .50 , and for college graduates it rose from .36 to .41 . When that increase is combined with the rise in the proportion of the labour force in those two groups, the regressive interaction is just sufficient to offset the positive effect of changes in income and educational structure considered separately. This interaction is consistent with the shifts in the Kuznets curve due to the trend term in the chapter IV regressions.

Tables VI-6 and VI-7 present details of the education breakdowns for 
Argentina and Peru. Each gives the income and population shares plus the within-group Theils for each education group. That information pinpoints why the distribution has or has not changed over time. For Argentina, inequality rose sharply between 1974 and 1980, and remained roughly constant since that time despite rising skill differentials. For Peru, the distribution improved in spite of rising wage differentials.

Consider first the case of Argentina between 1974 and 1980, when the country experienced a big jump in inequality that has never been reversed (the Theil rose by 8.4 points or almost $50 \%$, according to the last column in table VI-6). Exactly half of that rise came from the between-group component and the other half from the within-group element. The skill differential rose sharply (see Table V-1), which increased the between-group Theil by 4.2 points (from 3.3 to 7.5). At the same time, the variance of income increased in all of the education groups and the population shifted toward the university and secondary groups, which have a higher variance. That increased the withingroup Theil by 4.2 points. Both rising wage differentials and increasing differences in income within all educational groups contributed to the big jump in inequality.

Between 1980 and 1997, inequality increased further; virtually all of this rise was attributable to the between-group component. Inequality also widened for the two highest education classes, but this is just offset by reductions at the bottom. Most of the increase in the between-group Theil came from growth of the population in the high-income group, and not from a widening of wage differentials, which actually fell over the period.

For Peru, table VI-7 indicates how the distribution improved between 1985 and 1996 in spite of a big increase in the skill differential. All of the improvement was generated by a very big reduction in the variance in all income classes, particularly the least educated. The rise in wage differentials is reflected in a rise in the between-group component from 6.5 to 8.1, but that is swamped by the fall in the within-groups component by 16.8 points.

\section{Conclusions}

The cross movements can be summarized as follows. Improvements in education have moved people up the distribution, which is progressive because a smaller fraction of the labour force is in the left-hand tail. This is reinforced by the fact that the variance of income among the less educated is often bigger than it is for the more educated. Thus reducing the size, or more accurately the proportion, of the labour force with low education reduces total within-group variance in the Theil decompositions at the same time that it reduces between-group variance. Both of these effects are progressive. For example, in Peru the reduction in the relative size of the group with no more 
than primary education between 1988 and 1995 reduced the within-group Theil by 8 points, more than offsetting the regressive effect of rising wage inequality (Saavedra and Diaz, 1999, p. 69). In Costa Rica the weighted withingroup Theil fell by 3.5 points, which was almost enough to offset all the other factors that were pushing up inequality (Trejos, 1999, table B-10).

Offsetting this progressive change, however, is the fact that improving education increases the right-hand tail of the distribution at the same time that it reduces the left-hand tail. That tends to make the distribution less equal. In addition, skill-intensive growth in the 1990s increased the variance of incomes among the educated. That is, post-reform growth created opportunities that were primarily open to the best educated, which increased within-group variance at the top of the education pyramid. When this is combined with the expansion in the fraction of the labour force at the top, the result is increased overall inequality. That is what happened in Argentina. The Kuznets curve estimations in the previous chapter uncovered this same interaction effect.

Observed changes in wage differentials were almost never big enough to cause a significant change in inequality. This is partly because of offsetting changes at the top and the bottom of the education pyramid, but another reason is simply that almost two-thirds of total variance is explained by intragroup inequality (within-group Theil) and not by average wage differentials (between-group Theil). Within-group inequality either dampened, or in some cases (such as Peru) even offset, the effect of widening wage differentials. 


\section{CHAPTER VII \\ THE RICH AND THE POOR IN THE POST-REFORM PERIOD}

The previous chapters use aggregate indexes to measure and analyse changes in the distribution of income. The discussion now turns to two key groups: those at the very top and those at the very bottom of the distribution. The relative position of those at the top is one of the principal reasons why the Latin American income distributions are so unequal compared to other countries. This chapter examines who the members of this favoured group are, where they work, and how much the group has contributed to changes in inequality during the post-reform period.

Evidence on relative wages and the decompositions in the last chapter suggest that another key group in determining trends in inequality is university graduates. In this chapter, the labour force is divided into university and nonuniversity groups in order to measure the contribution of the university group to the level and changes in inequality. If skill-intensive growth is an important reason why inequality is not generally falling in the region, this decomposition should reflect that.

At the other end of the distribution are the poor, another group of interest to anyone concerned with equity. There was little significant change in income distribution in the post-reform period, but the reduction in poverty was significant. Any evaluation of the impact of the reforms on social welfare should take that into account. Since poverty generally responds to growth, it is useful to compare the reductions in poverty with reductions during previous growth periods. In other words, holding growth constant, has poverty performance under the new economic model been better or worse than it was before? 


\section{A. A Profile of the Rich}

This section opens the discussion with a closer look at the characteristics of those in the top income-earning classes. Most of the surveys used for this analysis capture labour earnings, not the full return to capital. Consequently, no matter how skewed the measured distributions might be, the total distribution including profits would be far more skewed. For simplicity this group is labelled as the rich, but this is a misnomer. The group that is here called the rich is in reality the group with the highest earnings from their own labour. That group may be far from the richest in the country; it just happens to be the only group for which any information is available.

Table VII-1 summarizes the available information. The data in the table come both from a number of special country studies and from the worksheets of a forthcoming IDB study. ${ }^{30}$ The individual country papers for this project track changes in the profile of the rich over time, whereas the IDB study gives the most recent profile only. For the most part, the data refer to the characteristics of the head of household or the individual who receives the bulk of income in the household.

The biggest educational group among the rich is the most educated, yet it is surprising how small the proportion is. University and high school graduates might be expected to constitute at least $75 \%$ of rich heads of households, but this is not the case in Argentina, Bolivia, Costa Rica or Peru. One-third of the rich in Argentina and almost half in Peru have less than secondary education. This reinforces the point made in the previous chapter that education is not the only determinant of earnings. In fact, the data in the table show why income varies so much among the poorly educated in many countries: the economy creates opportunities and winners in all education groups.

The intertemporal evidence is somewhat fragmentary, but it suggests that growth in the post-reform period was not necessarily biased in favour of the better educated. In Costa Rica and Mexico, the share of secondary and university graduates among the rich rose considerably, but that was not the case in Brazil or Chile. Growth may have been skill intensive, but that did not mean that increased wealth was confined to the top of the education pyramid.

Another interesting question is where the rich work. According to the table, between $50 \%$ and $60 \%$ are formal-sector employees, and those numbers appear to be quite stable over time. A surprisingly high number are in the informal sector (from one-fourth in most countries to $46 \%$ in Peru). That reflects the heterogeneity of the sector. In the table the informal sector includes all 


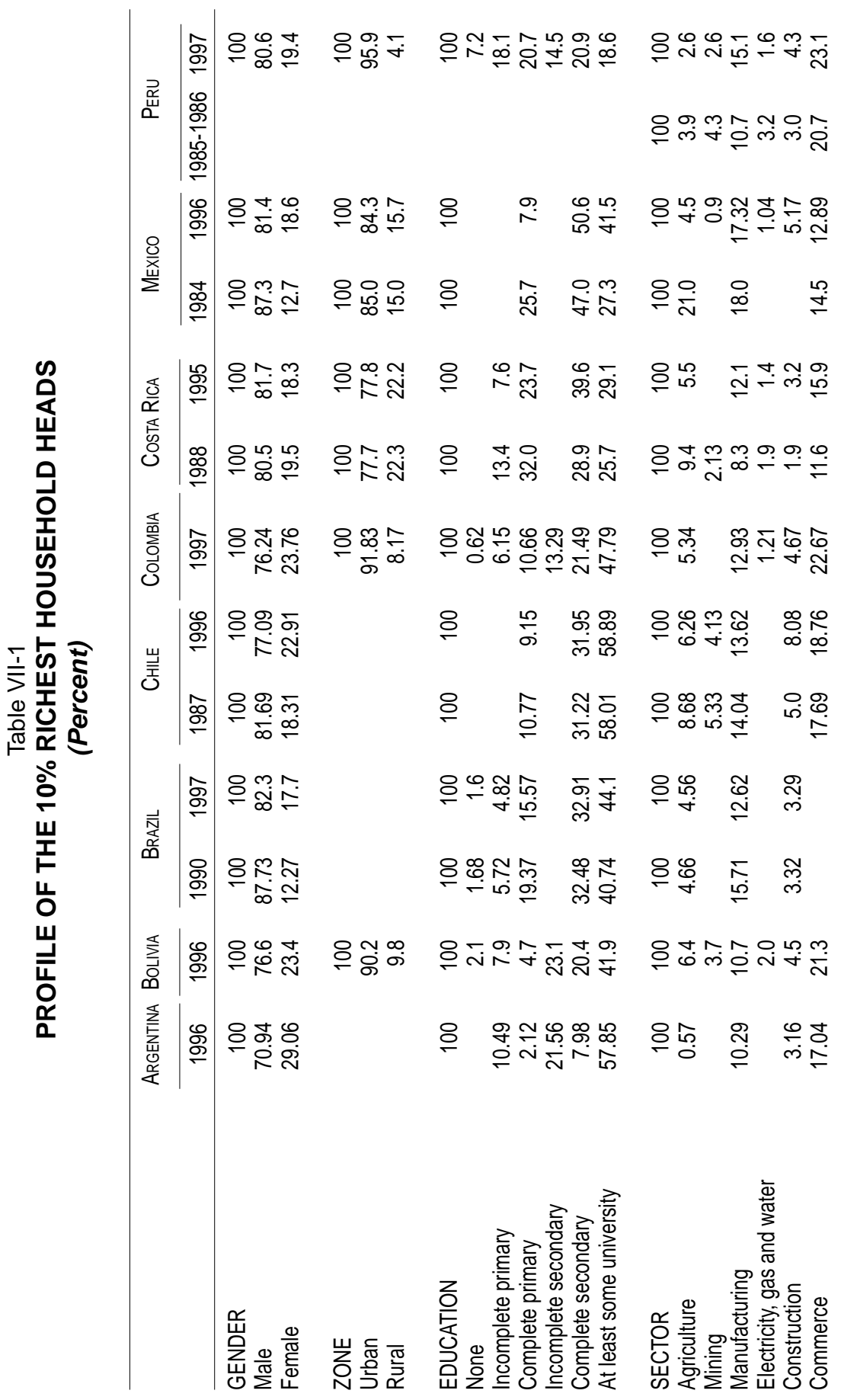




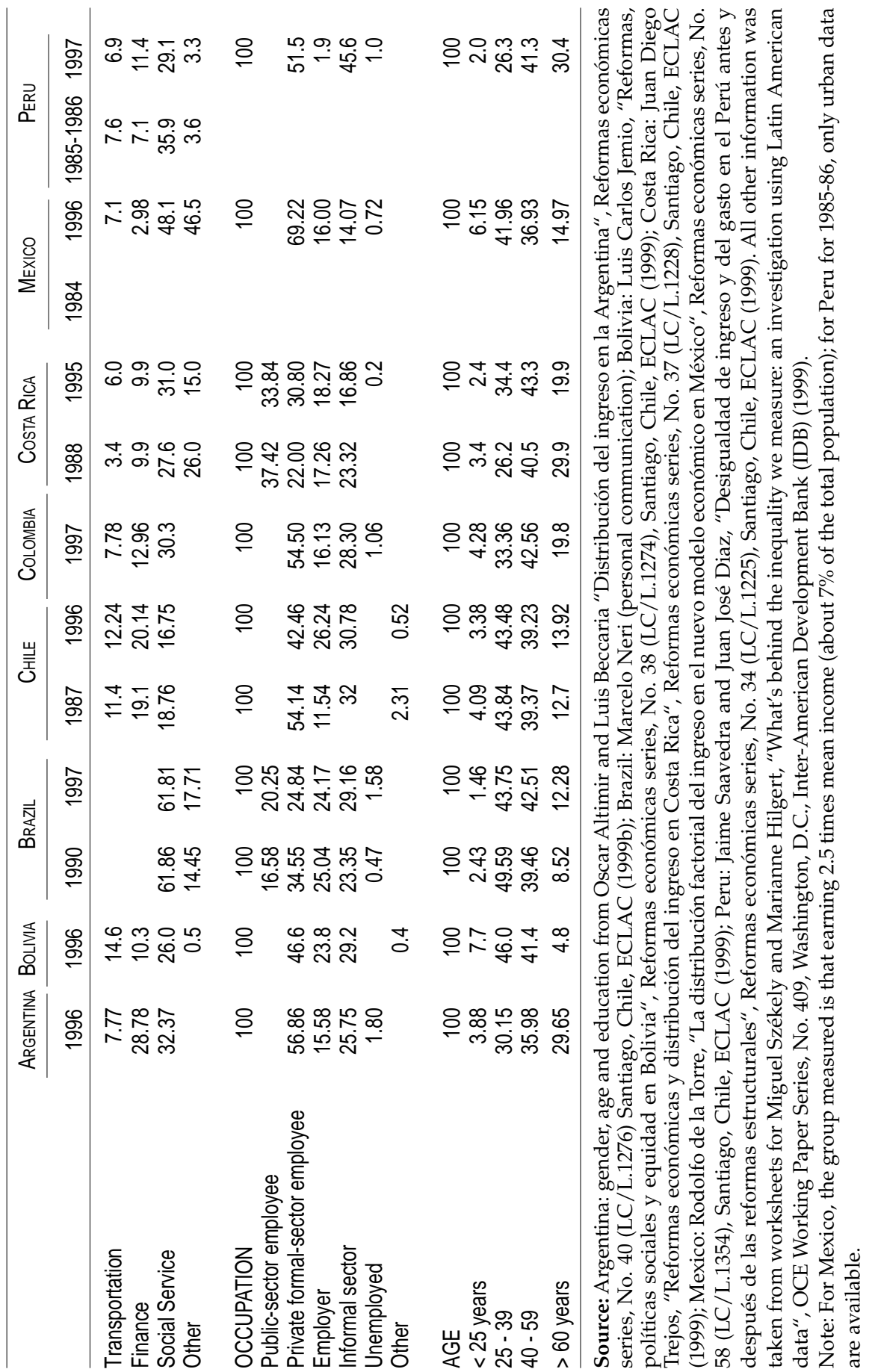


independent (self-employed) workers, such that it covers consultants as well as street sellers. In any case, owners or employers comprise a relatively small proportion of the group, which mainly reflects the fact that the surveys do not capture very much of the income from capital. Finally, it is somewhat surprising to find a significant number of public-sector employees in this favoured group for the few countries for which we have this information (see in particular Costa Rica).

As to sector of activity, the bulk of the rich work in the services sector, broadly defined, rather than in manufacturing and agriculture. That mainly reflects the employment patterns of the labour force as a whole, which is also concentrated in services. Finance is the one sector with a disproportionate number of the rich compared with its share in the overall labour force. In Argentina, for example, $12 \%$ of all household heads are in finance, but $29 \%$ of the rich are in that sector. The comparable figures for Colombia are $5 \%$ overall compared to $13 \%$ of the rich. Most other countries have equally large differences. The only significant trend over time in sector shares is a fall in the share of social services in the majority of countries for which data are available.

A surprisingly high proportion of the rich are in female-headed households, although only in Argentina, Mexico and Peru is this percentage higher than the proportion of female-headed households in the entire population. The proportion has, however, increased over time in every country with corresponding data, except Costa Rica.

\section{B. Contribution of the Rich to Total Inequality}

Recent work at the IDB highlights the special importance of the rich in inequality in Latin America. In an analysis of the distribution of the bottom 90\% of the population for 17 Latin American countries, seven are lower than the same distribution in the United States (IDB, 1998, p. 16). This section expands on this analysis by using the Theil index in place of the Gini. As mentioned above, the great advantage of the Theil is that it is decomposable, which allows the researcher to calculate exactly how much of total inequality comes from income differences between the top $10 \%$ and everyone else, as well as how much comes from income differences within the top $10 \%$. In addition, for those countries with the necessary data, the Theil can be used to calculate how much of the change in inequality between pre-reform and postreform periods comes from changes at the top of the distribution.

Table VII-2 shows a breakdown of earners into two groups: the top $10 \%$ and the bottom $90 \%$. In the case of Mexico the top group is that earning more than 2.5 times the mean income (around $7 \%$ of the population). Where available, each table shows the population and income shares and the withingroup Theil coefficients. These three components can be used to break the 
overall Theil down into its within-group and between-group elements, as in the previous chapter. Column 7 in the table shows the percentage contribution of the top $10 \%$ to total inequality; this is defined as the total between-group Theil plus the within-group Theil for the rich, expressed as a percentage of the total Theil index. Thus, for example, for Chile in 1996, the percentage contribution of the top $10 \%$ is $(.402+.121) / .63=82.8 \%$. Where the within-group Theils are not available (Argentina, Jamaica and Peru), the contribution is just the between-group Theil. Finally, column 8 in the table shows the income of the top $10 \%$ relative to the remaining $90 \%$ of the population. Comparisons of these relative incomes between countries give a pretty good indicator of relative levels of inequality. Within each country the calculation across years gives a rough measure of how favourable to the rich the post-reform period has been.

What is immediately apparent is the very large proportion of total inequality explained by the top $10 \%$, varying between $60 \%$ and $90 \%$ for all the countries in our sample except Jamaica, where the inequality indexes are based on expenditure rather than income. This strongly confirms the evidence on the $90 \%$ Ginis analysed in IDB (1998). An analysis of inequality in Latin America must start with the rich, asking how it is that the group is able to capture such a large share of total income. The high share of this group is particularly puzzling given that most of the data in the surveys refer to labour income, not profits.

Both differences in average income between the rich and everyone else (the between-group component) and differences in income within the top group are important sources of inequality. Of the two, the between-group component is far and away the most important. For example, in Brazil in $1997,65 \%$ of total inequality came from this source and only $17 \%$ from inequality within the top $10 \%$. Percentages are similar in other countries, with the notable exception of Uruguay, which has the lowest differential in the region. These very high income differentials between the top $10 \%$ and the rest of the population are the main source of Latin America's high income inequality.

While the absolute contribution of the rich to total inequality is extremely high, it did not increase over the period of the reforms, with the significant exception of Argentina and Mexico. In Chile the within-group Theil rose slightly, but it is offset by a reduction in the relative income of the rich (the between-group Theil fell by about the same amount that the within-group Theil of the rich increased). Roughly the same pattern can be seen in Costa Rica for receivers of income from production. In Peru and Brazil both components fell over time.

A glance at the trend in income differentials in Argentina and Mexico shows why the share of between-group inequality rose in these two countries. The gap between the top $10 \%$ and everyone else widened in exactly the same 
Table VII-2

\section{PERCENTAGE OF TOTAL INEQUALITY DUE TO THE RICH}

\begin{tabular}{|c|c|c|c|c|c|c|c|c|}
\hline & $\begin{array}{l}\text { Population } \\
\text { SHARE } \\
\text { (1) }\end{array}$ & $\begin{array}{l}\text { INCOME } \\
\text { SHARE } \\
(2) \\
\end{array}$ & $\begin{array}{c}\text { Thell } \\
\text { SHARE } \\
\\
(3) \\
\end{array}$ & $\begin{array}{c}\text { CONTRIBUTION } \\
\text { OF INEQUALITY } \\
\text { WITHIN GROUPS } \\
(4) \\
\end{array}$ & $\begin{array}{l}\text { CONTRIBUTION OF } \\
\text { INEQUALITY } \\
\text { BETWEEN } \\
\text { GROUPS } \\
(5)\end{array}$ & $\begin{array}{l}\text { TOtAL } \\
\text { THELL } \\
\\
(6) \\
\end{array}$ & $\begin{array}{c}\text { SHARE OF } \\
\text { TOTAL } \\
\text { INEQUALITY } \\
\text { FROM TOP 10\% } \\
\quad(7) \\
\end{array}$ & $\begin{array}{c}\text { INCOME OF TOP } \\
\text { 10\% RELATIVE } \\
\text { TO BOTTOM } \\
90 \% \\
(8) \\
\end{array}$ \\
\hline $\begin{array}{l}\text { Argentina } \\
1974\end{array}$ & \multicolumn{8}{|c|}{ Occupied labour force } \\
\hline Top $10 \%$ & 0.1 & 0.28 & & & 0.2883 & & & \\
\hline $90 \%$ & 0.9 & 0.72 & & & -0.1607 & & & \\
\hline Total & & & & & 0.1276 & 0.18 & 0.717 & 3.500 \\
\hline $\begin{array}{l}1986 \\
\text { Top } 10 \% \\
90 \%\end{array}$ & $\begin{array}{l}0.1 \\
0.9 \\
\end{array}$ & $\begin{array}{l}0.343 \\
0.657 \\
\end{array}$ & & & $\begin{array}{c}0.4228 \\
-0.2068 \\
\end{array}$ & & & \\
\hline Total & & & & & 0.2160 & 0.29 & 0.737 & 4.699 \\
\hline $\begin{array}{l}1997 \\
\text { Top } 10 \% \\
90 \% \\
\end{array}$ & $\begin{array}{l}0.1 \\
0.9 \\
\end{array}$ & $\begin{array}{l}0.353 \\
0.647 \\
\end{array}$ & & & $\begin{array}{c}0.4452 \\
-0.2135 \\
\end{array}$ & & & \\
\hline Total & & & & & 0.2317 & 0.28 & 0.819 & 4.910 \\
\hline $\begin{array}{l}\text { Bolivia } \\
1996\end{array}$ & Occupied la & Dour force & & & & & & \\
\hline Top 10\% & 0.1 & 0.44 & 0.2636 & 0.1160 & 0.6520 & & & \\
\hline $90 \%$ & 0.9 & 0.56 & 0.3286 & 0.1840 & -0.2640 & & & \\
\hline Total & & & & 0.3000 & 0.3880 & 0.69 & 0.733 & 7.071 \\
\hline $\begin{array}{l}\text { Brazil } \\
1976\end{array}$ & Economicall & $y$ active $p$ & pulation, & all income sourc & & & & \\
\hline $\begin{array}{l}\text { Top 10\% } \\
90 \% \\
\end{array}$ & & & & $\begin{array}{l}0.1890 \\
0.1200\end{array}$ & $\begin{array}{l}0.8120 \\
-0.2970\end{array}$ & & & \\
\hline Total & & & & 0.3090 & 0.5150 & 0.83 & 0.853 & \\
\hline 1990 & & & & & & & & \\
\hline $\begin{array}{l}\text { Top 10\% } \\
90 \%\end{array}$ & & & & $\begin{array}{l}0.1190 \\
0.1530\end{array}$ & $\begin{array}{l}0.7630 \\
-0.2880\end{array}$ & & & \\
\hline Total & & & & 0.2730 & 0.4750 & 0.75 & 0.794 & \\
\hline $\begin{array}{l}1997 \\
\text { Top 10\% } \\
90 \%\end{array}$ & & & & $\begin{array}{l}0.1180 \\
0.1280\end{array}$ & $\begin{array}{c}0.7400 \\
-0.2870\end{array}$ & & & \\
\hline Total & & & & 0.2460 & 0.4530 & 0.70 & 0.817 & \\
\hline
\end{tabular}




\begin{tabular}{|c|c|c|c|c|c|c|c|c|}
\hline & $\begin{array}{l}\text { POPULATION } \\
\text { SHARE } \\
\text { (1) }\end{array}$ & $\begin{array}{l}\text { INCOME } \\
\text { SHARE } \\
(2) \\
\end{array}$ & $\begin{array}{l}\text { TheElL } \\
\text { SHARE } \\
(3) \\
\end{array}$ & $\begin{array}{c}\text { CONTRIBUTION } \\
\text { OF INEQUALITY } \\
\text { WITHIN GROUPS } \\
\text { (4) }\end{array}$ & $\begin{array}{l}\text { CONTRIBUTION OF } \\
\text { INEQUALITY } \\
\text { BETWEEN } \\
\text { GROUPS } \\
(5)\end{array}$ & $\begin{array}{c}\text { TotAL } \\
\text { Thell } \\
\\
(6) \\
\end{array}$ & $\begin{array}{l}\text { SHARE OF } \\
\text { TOTAL } \\
\text { INEQUALITY } \\
\text { FROM TOP 10\% } \\
\quad(7) \\
\end{array}$ & $\begin{array}{c}\text { INCOME OF TOP } \\
10 \% \text { RELATIVE } \\
\text { TO BOTTOM } \\
90 \% \\
(8) \\
\end{array}$ \\
\hline & \multicolumn{8}{|c|}{ Occupied labour force } \\
\hline $\begin{array}{l}\text { Top 10\% } \\
90 \%\end{array}$ & $\begin{array}{l}0.1 \\
0.9\end{array}$ & $\begin{array}{l}0.46 \\
0.54\end{array}$ & $\begin{array}{l}0.234 \\
0.209\end{array}$ & $\begin{array}{l}0.1076 \\
0.1129\end{array}$ & $\begin{array}{c}0.7020 \\
-0.2758\end{array}$ & & & \\
\hline Total & & & & 0.2205 & 0.4261 & 0.65 & 0.825 & 7.667 \\
\hline $\begin{array}{l}1996 \\
\text { Top } 10 \% \\
90 \%\end{array}$ & $\begin{array}{l}0.1 \\
0.9 \\
\end{array}$ & $\begin{array}{l}0.448 \\
0.552 \\
\end{array}$ & $\begin{array}{l}0.269 \\
0.196 \\
\end{array}$ & $\begin{array}{l}0.1205 \\
0.1082 \\
\end{array}$ & $\begin{array}{c}0.6718 \\
-0.2698 \\
\end{array}$ & & & \\
\hline Total & & . & & 0.2287 & 0.4020 & 0.63 & 0.828 & 7.304 \\
\hline $\begin{array}{l}\text { Costa Rica } \\
1988 \\
\text { Top 10\% } \\
90 \%\end{array}$ & Receivers 0 & $\begin{array}{l}f \text { income fr } \\
\\
0.3654 \\
0.6346 \\
\end{array}$ & $\begin{array}{l}\text { om produ } \\
\\
0.1281 \\
0.2850 \\
\end{array}$ & $\begin{array}{l}0.0468 \\
0.1809\end{array}$ & $\begin{array}{c}0.4738 \\
-0.2218 \\
\end{array}$ & & & \\
\hline Total & & & & 0.2277 & 0.2520 & 0.48 & 0.623 & 5.182 \\
\hline $\begin{array}{l}1995 \\
\text { Top } 10 \% \\
90 \% \\
\end{array}$ & $\begin{array}{l}0.1 \\
0.9 \\
\end{array}$ & $\begin{array}{l}0.3597 \\
0.6403 \\
\end{array}$ & $\begin{array}{l}0.1906 \\
0.2650 \\
\end{array}$ & $\begin{array}{l}0.0685 \\
0.1697 \\
\end{array}$ & $\begin{array}{c}0.4634 \\
-0.2186 \\
\end{array}$ & & & \\
\hline Total & & & & 0.2383 & 0.2448 & 0.48 & 0.649 & 5.056 \\
\hline $\begin{array}{l}\text { Jamaica } \\
1989 \\
\text { Top } 10 \% \\
90 \% \\
\end{array}$ & Household & $\begin{array}{l}\text { xpenditure } \\
0.3228 \\
0.6772 \\
\end{array}$ & e per capi & & $\begin{array}{r}0.3783 \\
-0.1926 \\
\end{array}$ & & & \\
\hline Total & & & & & 0.1857 & 0.34 & 0.544 & 4.290 \\
\hline $\begin{array}{l}1996 \\
\text { Top } 10 \% \\
90 \% \\
\end{array}$ & $\begin{array}{l}0.1 \\
0.9 \\
\end{array}$ & $\begin{array}{l}0.2917 \\
0.7083 \\
\end{array}$ & & & $\begin{array}{c}0.3123 \\
-0.1697 \\
\end{array}$ & & & \\
\hline Total & & & & & 0.1426 & 0.25 & 0.568 & 3.706 \\
\hline $\begin{array}{l}\text { Mexico } \\
1984 \\
2.5^{*} \text { mean } \\
<2.5^{*} \text { mean } \\
\end{array}$ & $\begin{array}{c}\text { Rich define } \\
0.0601 \\
0.9399\end{array}$ & $\begin{array}{l}0.2722 \\
0.7278 \\
\end{array}$ & $\begin{array}{l}0.06 \\
0.11 \\
\end{array}$ & $\begin{array}{c}\text { income. Distribu } \\
\begin{array}{c}0.0163 \\
0.0801\end{array} \\
\end{array}$ & $\begin{array}{l}\text { ution among recei } \\
0.1786 \\
-0.0808\end{array}$ & vers of i & ncome & \\
\hline Total & & & & 0.0964 & 0.0977 & 0.19 & 0.588 & 5.849 \\
\hline $\begin{array}{l}1989 \\
2.5^{\star} \text { mean } \\
<2.5^{\star} \text { mean } \\
\end{array}$ & $\begin{array}{l}0.0636 \\
0.9364 \\
\end{array}$ & $\begin{array}{l}0.3306 \\
0.6694 \\
\end{array}$ & $\begin{array}{l}0.17 \\
0.11 \\
\end{array}$ & $\begin{array}{l}0.0562 \\
0.0736 \\
\end{array}$ & $\begin{array}{c}0.2367 \\
-0.0976 \\
\end{array}$ & & & \\
\hline Total & & & & 0.1298 & 0.1391 & 0.27 & 0.726 & 7.271 \\
\hline $\begin{array}{l}1994 \\
2.5^{*} \text { mean } \\
<2.5^{*} \text { mean }\end{array}$ & $\begin{array}{l}0.069 \\
0.931 \\
\end{array}$ & $\begin{array}{l}0.3721 \\
0.6279 \\
\end{array}$ & $\begin{array}{l}0.11 \\
0.13\end{array}$ & $\begin{array}{l}0.0409 \\
0.0816\end{array}$ & $\begin{array}{c}0.2723 \\
-0.1074\end{array}$ & & & \\
\hline Total & & & & 0.1226 & 0.1649 & 0.29 & 0.716 & 7.996 \\
\hline
\end{tabular}




\begin{tabular}{|c|c|c|c|c|c|c|c|c|}
\hline & $\begin{array}{l}\text { PopULATION } \\
\text { SHARE } \\
(1)\end{array}$ & $\begin{array}{l}\text { INCOME } \\
\text { SHARE } \\
(2) \\
\end{array}$ & $\begin{array}{c}\text { TheElL } \\
\text { SHARE } \\
(3) \\
\end{array}$ & $\begin{array}{c}\text { CONTRIBUTION } \\
\text { OF INEQUALITY } \\
\text { WITHIN GROUPS } \\
(4) \\
\end{array}$ & $\begin{array}{l}\text { CONTRIBUTION OF } \\
\text { INEQUALITY } \\
\text { BETWEEN } \\
\text { GROUPS } \\
(5)\end{array}$ & $\begin{array}{c}\text { TOtAL } \\
\text { TheIL } \\
\\
(6) \\
\end{array}$ & $\begin{array}{l}\text { SHARE OF } \\
\text { TOTAL } \\
\text { INEQUALITY } \\
\text { FROM TOP 10\% } \\
\quad(7) \\
\end{array}$ & $\begin{array}{l}\text { INCOME OF TOP } \\
\text { 10\% RELATIVE } \\
\text { TO BOTTOM } \\
90 \% \\
(8)\end{array}$ \\
\hline $\begin{array}{l}1996 \\
2.5^{\star} \text { mean } \\
<2.5^{*} \text { mean } \\
\end{array}$ & $\begin{array}{l}0.0718 \\
0.9282 \\
\end{array}$ & $\begin{array}{l}0.3717 \\
0.6283 \\
\end{array}$ & & $\begin{array}{l}0.13 \\
0.13 \\
\end{array}$ & $\begin{array}{l}0.0483 \\
0.0817 \\
\end{array}$ & $\begin{array}{c}0.2654 \\
-0.1065 \\
\end{array}$ & & \\
\hline Total & & & & 0.1300 & 0.1589 & 0.29 & 0.717 & 7.648 \\
\hline $\begin{array}{l}\text { Peru } \\
1985-86 \\
\text { Top 10\% } \\
90 \% \\
\end{array}$ & $\begin{array}{c}\text { Urban labou } \\
\begin{array}{c}0.1 \\
0.9\end{array}\end{array}$ & $\begin{array}{l}\text { rincome } \\
0.4115 \\
0.5885 \\
\end{array}$ & er hour & & & & & \\
\hline Total & & & & 0.2060 & 0.3320 & 0.54 & 0.618 & 6.293 \\
\hline $\begin{array}{l}1991 \\
\text { Top 10\% } \\
90 \% \\
\end{array}$ & $\begin{array}{l}0.1 \\
0.9 \\
\end{array}$ & $\begin{array}{l}0.379 \\
0.621 \\
\end{array}$ & & & & & & \\
\hline Total & & & & 0.1610 & 0.2740 & 0.44 & 0.630 & 5.493 \\
\hline $\begin{array}{l}1996 \\
\text { Top } 10 \% \\
90 \%\end{array}$ & $\begin{array}{l}0.1 \\
0.9 \\
\end{array}$ & $\begin{array}{l}0.3632 \\
0.6368 \\
\end{array}$ & & & & & & \\
\hline Total & & & & 0.1380 & 0.2480 & 0.39 & 0.642 & 5.133 \\
\hline
\end{tabular}

Source: Consultant reports. 
period when both of these countries suffered their big one-time rises in inequality.

The data can also be used to examine whether inequality within the top $10 \%$ increased significantly during the reforms, which would indicate whether the reforms opened up special earnings opportunities for a favoured few at the top. The answer seems to be yes for all three countries for which the top $10 \%$ Theil is available (Chile, Costa Rica and Mexico). In those three cases, the figure increased between the early and the most recent observation. It is worth noting that all of the increase in Mexico comes in the 1984-89 period. In Brazil or Peru, in contrast, the total Theils indicate a very sharp decline in withingroup inequality.

\section{The Role of University Graduates in Explaining Inequality}

This section examines two sub-groups -workers with and without university education- to see how much the university group has contributed to the level and trend of earnings inequality during the reform period..$^{31}$ The evidence presented in previous chapters indicates that growth is increasingly skill intensive and that many countries have experienced a rise in the skill differential between the university group and the rest of the labour force. The current task is to investigate how much this increased differential has contributed to changes in inequality over the period and whether the new economic model has created a sub-group of winners within the university (or non-university) group. If the latter occurred, it will be reflected in a rise in the within-group Theils.

The contribution of the university group to total inequality is a good deal less than that of the top $10 \%$ of the population. Not all university graduates are in the top $10 \%$, and their wage differential relative to the rest of the population is considerably lower than that of the top $10 \%$ in every case but Brazil. With regard to skill-intensive growth, however, in every case the amount of inequality explained or contributed by university graduates increased. In cases like Argentina, Colombia, Mexico and Peru, these increases are very large. In Argentina, for example, the inequality component due to university graduates rose from $17 \%$ to $47 \%$ of total inequality between 1976 and 1997 . The rise in the university group's contribution to overall inequality was so great that it completely offset favourable trends in the remainder of the population. This is a striking confirmation that growth was increasingly skill

31 This section reports on decompositions carried out on the basis of consultant reports for the nine sample countries. 
intensive in the 1990s. The data do not show whether that is the result of the opening of the economy or whether it simply reflects changes in the nature of technology. Similarly, this analysis cannot determine whether the pattern observed in the sample is representative of the other countries in the region.

The university contribution to total inequality rose between the beginning and the end of the period. In every country in the sample, the absolute change for the university component is higher than the absolute overall change in inequality. This means that rising inequality within the university group is responsible for all the increase in inequality in cases in which inequality increased and that it offset progressive trends in the non-university group in cases in which inequality was constant. To put it another way, earnings inequality would have declined in the region in every country, with the possible exception of Argentina, had it not been for widening inequality within the university group and between it and everyone else. Skill-intensive growth in the new economic model strongly favoured those few in the labour force with university education.

The increase in the university contribution to inequality results from three processes: the increase in the skill differential, the change in the size of the university group, and increased variance within the university group itself. In other words, the university component of inequality rises because growth increases the return of university graduates relative to everyone else, because the size of the group increases or because the new economic model has created a sub-group of big winners within the university group. Which of these is the dominant cause depends on the case. For example, in Argentina between 1974 and 1997, the within-group Theil for university graduates rose by 6.5 points. When combined with the 8 percent rise in the proportion of university graduates in the total, that translates into a 4.8 point increase in the withingroup Theil for university graduates (from 1.2 to 6.0). Over the same period, the between-group Theil rose by 5.6 points (from 1.8 to 7.4 ). Overall, the university group raised the Theil by 10.4 points, and that accounts for over 99\% of the overall increase that was actually observed between 1974 and 1997. Of that increase, $46 \%(4.8 / 10.4)$ comes from rising variance within the university group, while the rest is explained by rising wage differentials. Except for Costa Rica, the within-group contribution is generally smaller in the other countries in the sample, varying from $20 \%$ in Mexico to $33 \%$ in Brazil, Bolivia and Colombia. Most of the increase in university inequality thus comes from rising relative wages for university graduates, not from a rise in inequality within the university group.

Brazil offers a curious contrast to the other countries in the sample. In Brazil the contribution of university graduates to total inequality is far lower than elsewhere in spite of the fact that its skill differential is by far the highest in the region. The reason is that the fraction of the labour force with university education is so small that it simply does not carry much weight in inequality computations. 
This illustrates an important point, as well as a serious problem for those wishing to reduce inequality. As Brazil gradually improves its educational profile, the percentage of university graduates in the labour force is going to rise. If nothing else changes, that improvement is going to increase inequality. For example, in 1976, university graduates made up only $0.3 \%$ of the adult population and earned 8.8 times as much as the non-university group. The total Theil was .81. Suppose that over time the university group were to expand until it accounted for $5 \%$ of the labour force. If the wage differential stayed at 8.8 , the group would have about $31.5 \%$ of total income. Holding the withingroup Theils constant at their 1976 levels, the hypothetical distribution within this better-educated labour force would be a full twenty points higher than the actual 1976 distribution. That means that for countries like Brazil with a very small university-educated population, raising the proportion of university graduates in the labour force would be regressive for a very long time unless it were accompanied by a significant decline in the skill differential. In the case of Brazil, if the university-educated population were to expand from $0.3 \%$ to $5 \%$ of the labour force, Brazil would have to cut its skill differential in half (from 8.8 to 4.2 ) in order to hold the overall Theil constant at its 1976 level. When a small favoured group (university graduates) expands relative to the rest of the population, the result is regressive until the group gets big enough to be more representative of the population as a whole. ${ }^{32}$ Brazil is thus on the rising portion of an educational Kuznets curve.

\section{The Poor}

An investigation of what happened to poverty and the poor during the reform period represents an important change of focus. Whereas the rest of the study examines changes in relative position, this section introduces absolute changes into the picture. There is an important theoretical reason for doing this, in addition to the perfectly natural one of concern for the poor. In order to evaluate distributions in terms of well-being as opposed to simply measuring degrees of inequality, that is, if the goal is to rank one distribution as better than another rather than just less or more equal, the analysis must account for absolute as well as relative changes in income. Suppose a country has a rising level of inequality, but grows rapidly and significantly reduces poverty. That is likely to be preferable to a situation in which high levels of inequality are combined with stagnation and no poverty reduction.

32 This situation reflects an educational Kuznets effect in which a small, high-income component is expanding. Until that group gets so large that the poorly educated group is the minority, the change will be regressive, if the relative incomes of the two groups remain constant. 
From the political perspective, people do make value judgements about income distribution, and the distribution becomes a political issue when it differs significantly from what people think is reasonable or fair. Many factors might enter into such an evaluation, but one that is surely important is the degree of mobility and poverty reduction. During the process of growth, if those at the bottom of the income pyramid are able to move up out of poverty, then even a high degree of inequality may be regarded as reasonable or at least acceptable. If growth is accompanied by significant upward mobility, poverty reduction and improvements in absolute income, while at the same time leading to increased inequality, society may well accept the one as the price for improving the other. Consequently, no study of distribution is complete without some accounting for income growth and poverty reduction.

Data published by ECLAC (1999) show that poverty was reduced significantly in the 1990s. Indeed, according to ECLAC, by 1997 the overall incidence of poverty in the region had finally fallen back to its 1980 level after a rapid increase during the 1980s and early 1990s. Growth under the new economic model may not have lowered inequality, but it definitely lowered poverty. Table VII-3 summarizes the most recent estimates and adds income growth rates and poverty growth elasticities for use in the subsequent discussion.

The data in table VII-3 present several important limitations. First, the series marked with an asterisk come from recently published poverty studies for individual countries. They use different poverty lines and different methodologies from the ECLAC estimates. Each row in the table is internally consistent, but the asterisk series are not necessarily comparable with the ECLAC series or with each other. Consequently, the estimates should not be used for inter-country comparisons, but instead only to establish poverty trends within each country. Because the estimates are not fully comparable across countries, they do not add up to the absolute number of persons in a state of poverty and thus do not represent a regional poverty estimate. However, the trends in each country do offer a pretty good guess on trends in regional poverty incidence and the poverty population for the region as a whole.

Keeping all these data problems in mind, the table points to several conclusions. First, and most important, after a decade of rising poverty in the 1980s, Latin America finally began to make significant progress in reducing poverty in the 1990s. During the 1980s the incidence of poverty rose in all but three or four countries in the region (Morley, 1995), and the absolute number of poor people rose by around $40 \%$. Several researchers have expressed doubts that the new reform model is capable of reversing these trends (Berry, 1998; Bulmer-Thomas, 1996). However, the evidence in the table makes it quite clear that poverty trends finally turned more positive in many countries, although these observations were taken before the downturns in 1998 and 1999 sparked by the Asian crisis. Poverty incidence between 1990 and 1997 (measured as the percentage below the poverty line) has fallen in 13 out of the 18 countries 
Table VII-3

\section{CHANGES IN POVERTY IN THE 1990s}

\begin{tabular}{|c|c|c|c|c|c|c|c|}
\hline \multirow[t]{2}{*}{ Country (YeARS) } & \multicolumn{2}{|c|}{ POVERTY } & \multicolumn{2}{|c|}{ INCOME PER CAPITA } & \multicolumn{2}{|c|}{ Percent change } & \multirow{2}{*}{$\begin{array}{l}\text { POVERTY } \\
\text { ELASTICITY' }\end{array}$} \\
\hline & EARLIEST & LATEST & EARLIEST & LATEST & INCOME & POVERTY & \\
\hline Argentina/Buenos Aires (1990-97) & 0.16 & 0.13 & 4710 & 6512 & 38.26 & -18.75 & -0.4901 \\
\hline Bolivia (1990-97) & 0.47 & 0.44 & 840 & 942 & 12.14 & -6.38 & -0.5257 \\
\hline Brazil (1990-96) & 0.41 & 0.29 & 2942 & 3185 & 8.26 & -29.27 & -3.5435 \\
\hline Chile (1990-96) & 0.39 & 0.20 & 2534 & 3748 & 47.91 & -48.72 & -1.0169 \\
\hline Colombia $(1988-95)^{\star}$ & 0.23 & 0.15 & 1445 & 1705 & 17.99 & -34.78 & -1.9331 \\
\hline Costa Rica (1990-97) & 0.24 & 0.20 & 1924 & 2081 & 8.16 & -16.67 & -2.0425 \\
\hline Dom. Republic (1986-92)* & 0.33 & 0.34 & 817 & 870 & 6.49 & 3.03 & 0.4671 \\
\hline Ecuador (1990-97) & 0.56 & 0.50 & 1264 & 1392 & 10.13 & -10.71 & -1.0580 \\
\hline El Salvador $(1991 / 92-96)^{*}$ & 0.60 & 0.52 & 1049 & 1257 & 19.83 & -13.33 & -0.6724 \\
\hline Honduras (1990-97) & 0.75 & 0.74 & 633 & 670 & 5.85 & -1.33 & -0.2281 \\
\hline Jamaica $\left(1989-95^{\star}\right)$ & 0.25 & 0.22 & 1632 & 1709 & 4.72 & -12.00 & -2.5434 \\
\hline Mexico (1989-96) & 0.39 & 0.43 & 3113 & 3173 & 1.93 & 10.26 & 5.3214 \\
\hline Nicaragua (1985-93) & 0.73 & 0.76 & 771 & 512 & -33.59 & 4.11 & -0.1223 \\
\hline Panama (1991-97) & 0.36 & 0.27 & 2369 & 2702 & 14.06 & -25.00 & -1.7785 \\
\hline Paraguay/Asuncion (1990-96) & 0.37 & 0.40 & 1487 & 1490 & 0.20 & 8.11 & 40.1892 \\
\hline Paraguay rural $(1992-95)^{\star}$ & 0.53 & 0.60 & 1446 & 1494 & 3.32 & 13.21 & 3.9788 \\
\hline Peru (1991-96) & 0.55 & 0.46 & 1728 & 2093 & 21.12 & -16.36 & -0.7747 \\
\hline Uruguay (1990-97) & 0.12 & 0.06 & 2700 & 3437 & 27.30 & -50.00 & -1.8318 \\
\hline Venezuela (1990-97) & 0.34 & 0.42 & 3043 & 3267 & 7.36 & 23.53 & 3.1964 \\
\hline
\end{tabular}

Source: ECLAC, Social Panorama of Latin America, 1998, Santiago, Chile (May 1999). Note: Data for countries marked with an asterisk are taken from Samuel Morley, "La pobreza en tiempos de recuperación económica y reforma en América Latina: 1985-1995", Política macroeconómica y pobreza en América Latina y el Caribe, Enrique Ganuza, Lance Taylor and Samuel Morley (eds.), Madrid, Grupo Mundi-Prensa, United Nations Development Programme (UNDP) (1998). Data for Peru are taken from Javier Escobal D'Angelo, Jaime Saavedra Chanduví and Máximo Torero Cullen, "Los activos de los pobres en el Perú", Documento de trabajo, No. 26, Lima, Study Group for Development (GRADE) (1998).

a Poverty elasticity is percent change in poverty divided by percent change in income.

for which data are available. Unfortunately, the reductions in incidence are often less than the increase in the population, which is why only 9 out of 18 cases show a decline in the absolute number of the poor (Argentina, Brazil, Chile, Colombia, Costa Rica, El Salvador, Jamaica, Peru and Uruguay). In absolute numbers, however, the total reductions in poverty in Argentina, Brazil, Colombia, Chile and Peru appear to be much bigger than the increases in the Dominican Republic, Mexico, Nicaragua, Paraguay and Venezuela. Thus it is almost certain that the absolute number of the poor in these eighteen 
countries declined between 1990 and 1997, even granting the methodological difficulties of adding together poverty estimates from different countries with different poverty lines and periods of coverage.

Poverty trends improved for two main reasons: the resumption of more stable, more rapid growth in many countries, particularly Argentina, Chile, Colombia, Costa Rica, Peru, El Salvador and Uruguay, and the successful control of inflation in Argentina, Bolivia, Brazil and Peru. In Argentina poverty fell by more than half between 1989 and 1991 when the Menem government stopped hyperinflation (Márquez and Morley, 1997). For Bolivia and Peru, the available data do not exactly correspond to the period when inflation was stopped, so it is not possible to know how important stabilization was.

Brazil represents the most important case. There, virtually the entire reduction in poverty occurred during the period 1993-95, when the Plano Real successfully stopped hyperinflation. Some controversy has arisen over poverty estimates for Brazil during this period. If the overall consumer price index is used to adjust the poverty line, the estimated reductions in poverty incidence are far lower than those shown in the table. ECLAC used the actual observed cost of the market basket of goods upon which the poverty line is based. That price index went up far less than the overall consumer price index, which implies that relative prices changed significantly in favour of the poor. Such a change causes a big reduction in poverty levels, because it lowers the poverty line in real terms relative to what it would be using the national price index as a deflator. That is the reason for the big discrepancy in the estimates. This measurement issue is important because of Brazil's size. If poverty incidence only fell by $10 \%$, as estimated by the IDB, rather than $29 \%$ as estimated by ECLAC, the absolute numbers in poverty in 1996 would be almost 13 million higher. That is enough to raise the overall incidence in the region from ECLAC's estimated $36 \%$ to $38.6 \%$. In my view, the ECLAC procedure is the correct one. ${ }^{33}$

While the news that poverty declined is gratifying, it should be tempered by the realization that poverty is still increasing in far too many countries. Even in many of the countries where it has started to decline, both the incidence and the absolute level are still higher than they were in 1980. Furthermore, some of the biggest gains have come from one-time reductions in inflation. Such big changes do not signal the beginning of a trend. They are one-time events, and the improvements will be hard to maintain when economies fall back into recession, as many did in 1998-99.

33 Ricardo Paes de Barros, the Brazilian expert most familiar with this question, agrees with the ECLAC procedure. 
The main reason for the decline in poverty in the region is the economic recovery, not improvements in the distribution of income. ${ }^{34}$ It is now widely accepted that poverty declines when countries grow, even when that growth makes the distribution of income more unequal. This close relation between the level of poverty and the level of economic activity means that the poor will continue to be adversely affected by the volatility and economic cycles that plagued the region in the 1990s.

Figure VII-1 relates the observed changes in poverty shown in table VII3 to the percentage changes in per capita real income for the same period. The straight line in the figure is the simple regression of changes in poverty on changes in income. The fit is not particularly close, but the regression confirms (albeit weakly) that countries which grew also reduced poverty. Excluding Nicaragua, the average poverty-growth elasticity (that is, the percentage reduction in poverty per percent growth in per capita income) is about -1 . That is a low number compared to the rest of the world, which is consistent with the high degree of income inequality in the region. It suggests that the trickle-down benefits of growth are smaller in Latin America than elsewhere. The elasticity column in table VII-3 gives a quick guide to the countries in which growth has a lesser or greater impact on poverty. ${ }^{35}$

Additional evidence confirms the positive developments that have occurred for the least skilled workers. For the nine countries in the sample discussed in chapter VI, direct evidence is available on changes in income variance for workers with primary education or less. That evidence is complemented by average incomes by education level for eight of the same countries. Constructing a relative income series comparing the lowest with the next to lowest education group shows that in every country the least educated closed the income gap between them and the next group. That is consistent with the significant reduction in the within-group Theil contributions of the bottom education groups that occurred in all nine countries in the sample.

Growth under the new economic model has been skill-intensive. It raised the relative incomes of the better educated, and it both extended and expanded the right-hand tail of the income distribution. At the same time, however, it seems to have been shrinking and pulling in the left-hand tail. Partly, of course, that is the result of the reduction in the relative size of the least educated group because of retirement and the higher educational level of new entrants. But from the relative wage data, it seems also to be the result of growth rates

34 Bulmer-Thomas (1996) was right when he argued the new reform model would only improve wellbeing if it raised the growth rate, since it was unlikely to improve distribution in itself. The growth rate has accelerated enough to bring about a modest reduction in the overall level of poverty in spite of lack of progress on equity in most countries.

This elasticity measures the percentage change in poverty per percentage change in income. 
Figure VII-1

INCOME GROWTH AND CHANGES IN POVERTY

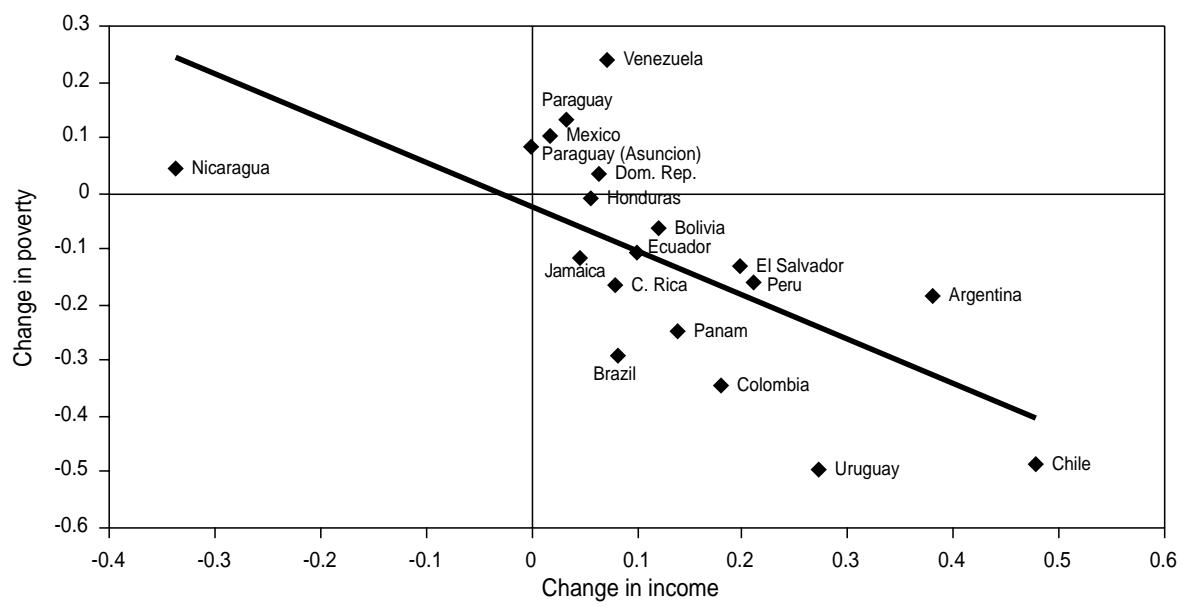

Source: Table VII-3.

rapid enough to put upward pressure on the relative wages of the least skilled. These gains at the bottom of the distribution just about offset the gains for the educated at the top. The overall distribution did not change much, but that does not mean that there were not significant gains for those at the bottom.

\section{E. Reforms and Poverty Reduction}

One of the principal reasons that poverty fell after 1990 is simply that most Latin American countries began growing again. The better growth performance may or may not have resulted from the reforms, but it is interesting to ask whether, after controlling for growth, the reforms had a positive or negative effect on poverty reduction. That is equivalent to asking whether the countries with a higher reform index are above or below the line in figure VII-1. One method for examining this question more systematically is to regress the changes in poverty after 1990 on changes in income for the countries shown in table VII-3. The regression includes the value of the reform index for the year 1990 and an inflation control dummy for Brazil. ${ }^{36}$ The results are displayed as equation 1 in table VII- 4 .

36 The regressions do not include dummies for Argentina or Peru because the first observations in the table come after the bulk of inflation reduction had already taken place. 
Table VII-4

ESTIMATIONS OF CHANGES IN POVERTY

\begin{tabular}{|c|c|c|c|c|}
\hline \multirow[b]{2}{*}{ VARIABLE } & \multicolumn{2}{|c|}{ (1) } & \multicolumn{2}{|c|}{ (2) } \\
\hline & CoEfficient & T STATISTIC & Coefficient & T STATISTIC \\
\hline Constant & 0.298608 & 1.455078 & 0.409457 & 1.496337 \\
\hline Change in income & -0.985624 & -3.533736 & & \\
\hline Inflation dummy (Brazil) & -0.221562 & -1.533985 & -0.144593 & -0.750532 \\
\hline Average reform index 1990 & -0.398230 & -1.281619 & -0.770092 & -1.952196 \\
\hline Adjusted R squared & 0.528728 & & 0.142039 & \\
\hline Standard error of regression & 0.138045 & & 0.186260 & \\
\hline Sum of squared residual & 0.247734 & & 0.485698 & \\
\hline F statistic & 6.983552 & & 2.324435 & \\
\hline Probability (F statistic) & 0.004843 & & 0.134378 & \\
\hline
\end{tabular}

Growth is the main determinant of poverty reduction, and the best estimate of the poverty elasticity is -1 , but controlling inflation helped, too. Its coefficient is negative, though not significant. As to the reforms, they reduced poverty, but their effect is insignificant, although the weak effect could be because the main impact of the reforms is through their effect on growth. To test this, the regression is rerun without the income growth variable (see equation 2 in table VII-4), and in this case the reforms had a significant negative effect on poverty. For the most part, then, their effect must be through growth rather than in addition to growth. Reforms help the poor, but they do so indirectly through their apparently positive effect on the growth rate. 


\section{CHAPTER VIII}

\section{CONCLUSIONS AND POLICY IMPLICATIONS}

The distribution problem is one of the most intractable facing Latin America and the Caribbean. Most countries in the region have very high levels of inequality compared with countries elsewhere in the world, and there is little evidence that those levels are falling. Inequality rose during the adjustments and recessions of the 1970s and 1980s, and in most cases it did not go back down despite economic recovery in the 1990s.

\section{A. Why is Inequality So High in Latin America and the Caribbean?}

As argued above, three contributing factors help explain Latin America's high level of inequality. First, Latin America and the Caribbean have a highly unequal distribution of education and the highest skill differentials for university graduates in the world. The region has made heavy investments in education, but the pattern of these investments has further increased the concentration of human capital ownership in the population. Asia put most of its education dollars into universalizing primary and secondary school coverage, but Latin America let most of its young cohorts drop out after primary school, using the money saved at the secondary school level to expand university education. Since it is mainly the poor who drop out of school, educational inequality rose in the 1990s in every country in the region except Brazil.

Second, the combination of a highly skewed distribution of land and an increase in the growth rate of the labour force in recent decades has driven down the relative wage of the unskilled. Latin America has the most unequal 
distribution of land in the world. The relation of this to the skewed distribution of income is not accidental. Limiting access to land in regions where land is abundant artificially lowers the reservation wage of the landless, particularly when it is accompanied, as it was, by various arrangements which increased the supply of low-wage labour to landowners. Rural-urban migration in the twentieth century reduced the pressure in the countryside, but at the cost of transferring inequality and low wages for the unskilled to the urban sector. That problem was exacerbated in recent decades by increased rates of growth of the labour force as economies passed through the demographic transition. The combination of an unequal distribution of land, rising population growth rates and a failure of the education system to absorb and educate the young has left the region with an oversupply of poorly educated workers. This has had -and will continue to have- significant regressive effects on the distribution of income until it is eliminated by more rapid growth and investments in education, particularly at the secondary level.

Third, the unusually large gap between the average incomes of the rich and those further down the income pyramid adds to inequality. The data show that the segmentation between the rich and everyone else is far greater in the region than in other countries. That is, the rich in Latin America are much richer relative to the remainder of the population than they are elsewhere. In a decomposition of the nine-country sample, the top $10 \%$ of the population accounted for two-thirds to three-fourths of total inequality in the majority of countries. High inequality in the region is not the result of the large gaps between those at the bottom and everyone else. Such gaps exist, but the differences between the typical Latin country and countries elsewhere is not large. What is large is the gap at the top of the distribution.

A complementary factor is the group of university graduates. So far, this group contributes less to overall inequality than the rich because many in the group are not rich. Unlike the rich, however, the contribution of the group to inequality has risen sharply in the post-reform period. In part this reflects the rise in the skill differential for university graduates that has occurred in most countries. But it also reflects a rise in variance within the university group as well. In the nine-country sample, inequality would have fallen in every country had it not been for the rising relative incomes and size of the university group. Skill-intensive growth has favoured this small group of the population, and this has played a significant part in maintaining Latin American inequality at a high level.

\section{B. Inertia in the Distribution}

Unfortunately, it does not appear that growth will improve the distribution statistics very much, if at all. One of the reasons is that growth is more skill- 
intensive now than it used to be. This may be simply a Latin American phenomenon, but it more likely reflects changes in technology that are being felt all over the world. The skill differential or wage premium paid to high school and college graduates has risen in almost every country for which data are available. Consistent with this phenomenon, there is strong evidence that the relation between income and equity is becoming less progressive. Growth that could have been expected to reduce inequality in the 1970s no longer did so in the production conditions of the 1990s. Rather than countries moving down a Kuznets curve towards lower levels of inequality, the Kuznets curves themselves appear to be shifting in a regressive direction.

The rise in the skill differential is mainly a result of the nature of labour demand and the pattern of growth of labour supply. Growth is going to increase the relative demand for skilled labour, while the education system will send better-prepared graduates out into the labour market, increasing the supply of skilled or potentially skilled workers. Whether the skill differential rises or falls depends on which of the two grows most rapidly. Even in the most progressive scenario imaginable, however, the reduction in the wage differential is unlikely to be a large enough to make a significant difference in the overall distribution of earnings. The case of Chile is instructive. The country grew very rapidly after 1987, and it had a small reduction in its skill differential (it is the only country in the sample where that happened), but that narrowing was not sufficient to cause a significant reduction in inequality. Barring sudden drastic shifts in external conditions or macroeconomic shocks, the earnings distribution is mainly determined by the structure of the labour force, and that changes slowly. Because Latin America did not broaden the coverage of high school education in the past, the adult labour force now comprises far too many undereducated workers who are ill-equipped to work in an increasingly information-based workplace. Until the region eliminates that imbalance, growth is likely to cause rising wage differentials in favour of those with high school or university education. Correcting that imbalance is one of the priority tasks facing the region.

Paradoxically, improving the educational structure of the labour force could worsen rather than improve the distribution in the short run. As shown in the case of Brazil, countries with a very small fraction of high-school or university graduates in their labour forces will find that inequality increases when they raise that fraction unless they are able to significantly lower the skill differential at the same time. Of course, reducing the proportion of poorly educated workers helps to offset this perverse effect, but it does not eliminate it altogether. This change in educational structure improves the position of the upper and lower tails of the distribution. At the top, both the number and the income share increase; that is regressive. At the bottom, the number and size shrinks, which is progressive. These progressive and regressive effects seem to just about offset each other. This is one of the principal reasons why 
the overall distribution has not changed much despite substantial growth and structural change.

Another reason why distributions have not improved with growth is because of the very nature of the growth process and the structure of the economy. In some cases growth is more skill intensive than it need be, which exacerbates the tendency toward rising wage differentials. In other cases economies themselves are heterogeneous. Growth starts in a dynamic sector or region, but has low regional or sectoral multiplier effects elsewhere. Latin America features many examples of such heterogeneity, including underdeveloped regions, groups of indigenous people or concentrations of unskilled workers who are unable to perform the tasks needed in the dynamic sector. In all those cases growth is relatively disequalizing. Its trickle-down or spread effect is small.

\section{The Impact of the Reforms}

The evidence on the impact of reforms is mixed. In Argentina, Chile and Mexico, the initial adoption of the reform package coincided with a big onetime upward shift in inequality. In the other countries of the sample, the distribution either stayed constant (e.g., Brazil, Colombia and Costa Rica) or improved (e.g., Bolivia, Jamaica and Peru). In Argentina and Chile the rise in inequality took place during a severe change in institutional arrangements in the labour market under military regimes in the 1970s ${ }^{37}$ It is unclear whether this step was necessary to quite radically reform economic policy in a short period. Those changes in the labour market did not happen in the other countries in the sample, and none of them, with the exception of Mexico between 1984 and 1989, experienced any dramatic change in inequality as they adopted the reforms. In Bolivia and Peru, the improvement in the distribution must have resulted mainly from controlling inflation rather than from the structural reforms, since the post-reform distributions deteriorated in both countries.

The pre- and post-reform evidence suffers from the unavoidable problem that it is impossible to isolate the effect of the reforms from all the other things that were going on at the same time. Econometric analysis is one way of dealing with this problem. The econometric evidence on the effect of the reforms is roughly consistent with the nine country case studies. In the aggregate, the reforms appear to have had a regressive effect on distribution, but that effect is small and only marginally significant. The reason is that reforms in different

37 The same thing happened in Uruguay in the early 1970s and Brazil in the 1960s. In both of these cases the intervention was more related to inflation control than it was to the imposition of reforms. 
areas had offsetting effects on equity. Trade reform was regressive in all of the specifications, but it was insignificant in all but the nationwide sample. Tax reform was unambiguously regressive, and opening up the capital account was unambiguously progressive. The results for tax reform and capital account liberalization are the most robust and significant of the set. For the other two reforms, the data are not good enough to give a clear answer. The reforms, taken together, were thus mildly regressive, but their effect on distribution was relatively small compared to other factors like growth, inflation and changes in education structure.

\section{Policies that Can Help}

The most important single policy that a government can adopt is a growth strategy that produces the highest, most stable growth rate possible. It must not rely excessively on borrowing, since that will affect future growth. Nor can it trigger a significant increase in inflation. Experience teaches that high but unstable growth rates do as much harm as good, while high growth rates that lead to outbreaks of inflation are sure to have a regressive effect. No other task facing government is as important as this one. Rapid, stable growth is a necessary (though not sufficient) condition for reducing poverty and unemployment and for increasing wages for the least qualified.

A complementary goal is for the growth strategy to enable the economy to absorb as much unskilled labour as possible, as long as that does not entail an undue sacrifice in the overall growth rate. The basic distribution problem facing Latin America is to reduce the supply of and increase the demand for unskilled labour. A growth strategy that creates a lot of jobs for unskilled labour takes care of the demand side of that problem, while investments in education will help with the supply part. Two sectors are especially large users of unskilled labour: construction and agriculture. These two should play an important part in an equitable growth strategy. Similarly, the production of tradable goods makes relatively intensive use of unskilled labour.

Another element of an equity-increasing growth strategy is support for underdeveloped regions. Growth is almost always sparked by something that happens in a specific sector or region. The more heterogeneous and separated the various parts of the economy or country are, the less of a multiplier effect the initial impetus will have in other sectors or regions. Governments should aim to increase the spread or linkage effects of growth, for example by improving transportation and communications links in underdeveloped regions or by making a special effort to upgrade worker training and education in such regions.

A very large part of Latin America's distribution problem comes from the large stock of unskilled labour relative to the demand for the sort of services 
such labour can provide. Many years of high population growth rates and inadequate education have saddled the region with too much unskilled labour. Until that backlog is eliminated, wage differentials are unlikely to narrow and the region will not make much progress in terms of equity. Latin America is hostage to past policy failures that are going to take a long time to correct. A labour-intensive growth strategy will help, but educational strategy is even more important in the long run. The goal should be to bring the percentage of those entering the labour market who have at least a high school education as close as possible to $100 \%$. In the course of a few years that will significantly lower the growth rate of unskilled labour and raise the growth rate of skilled labour. Sooner or later skill differentials will begin to fall, and equity will increase. As discussed in chapter III, the big difference between East Asia and Latin America is that the East Asian countries followed just such a policy. They invested in secondary and primary education, whereas Latin America invested in universities and primary schools. The Asian strategy reduced education variance and narrowed wage differentials, but the Latin American strategy did not. That pattern can and should be reversed.

There are two additional reasons why education should play an important part in an equity-increasing growth strategy. First, raising the educational level of the young reduces the colossal waste of human potential represented by the vast numbers of undereducated citizens. How many potential entrepreneurs or scientists are working in agriculture or the informal sector simply because they never got enough education to unlock that potential? In the modern world, human capital is increasingly the key ingredient for growth, which makes education as important as investments in machinery. In a word, expanding education is likely to raise the potential growth rate.

The second reason why universalizing education makes sense is more subjective. Rich or poor, parents are concerned about the future of their children. If the poor perceive that the State provides a good education through high school for all their children, they are likely to accept unequal income distribution for themselves more readily, since they will see that intergenerational inequality is falling, even if the statistics do not capture it. Intergenerational mobility matters, and education is the key to increasing it.

Lowering measured inequality is difficult for practical, political and statistical reasons. Providing education is a promising alternative way of dealing with the inequality problem. It does not directly redistribute income, which is politically difficult, but instead it distributes something that may well be more precious to the poor than income, namely, an opportunity for their children to escape poverty. That is something which is very hard for anyone to oppose.

In recent years, the countries of the region have made significant progress in both reducing poverty and expanding educational coverage for the younger age cohorts, but the distribution indexes do not reflect that progress. It is 
important to understand why this can happen and how it follows from the definitions of inequality that underlie the indexes. Latin America and the Caribbean needs to keep going down the road of more rapid, more labourintensive growth, coupled with continued broadening of the coverage of high school education. That strategy may not be immediately reflected in lower Gini coefficients, but it will lower poverty levels and it will raise real wages for the unskilled. Eventually it will also bear fruit in the form of falling indexes of inequality, although that probably will not happen right away. 



\section{BIBLIOGRAPHY}

Ahluwalia, Montek (1976), "Inequality, poverty and development", Journal of Development Economics, vol. 3, No. 4.

Altimir, Oscar (1996), "Economic development and social equity: a Latin American perspective", Journal of Interamerican Studies and World Affairs, vol. 38, No. 2/3.

Altimir, Oscar and Luis Alberto Beccaria (1999a), “El mercado de trabajo bajo el nuevo régimen económico en Argentina", Reformas económicas series, No. 28 (LC/L.1217), Santiago, Chile, Economic Commission for Latin America and the Caribbean (ECLAC).

(1999b), "Distribución del ingreso en la Argentina", Reformas económicas series, No. 40 (LC/L.1276) Santiago, Chile, Economic Commission for Latin America and the Caribbean (ECLAC).

Anand, Sudhir and S.M. Ravi Kanbur (1993), "The Kuznets process and the inequality-development relationship", Journal of Development Economics, Vol. 40, No. 1.

Barraclough, Solon L. and Arthur Domike (1966), "Agrarian structure in several Latin American countries", Land Economics, vol. 42, No. 4.

Barro, Robert and Jong-Wha Lee (1996), "International measures of schooling years and schooling quality", American Economic Review Papers and Proceedings, vol. 86, No. 2.

Beccaria, Luis (1991), “Distribución del ingreso en la Argentina: explorando lo sucedido desde mediados de los setenta", Desarrollo Económico, vol. 31, No. 123.

Belser, Patrick (1998), “Do Low Asian Labour Standards Hurt Latin America Workers?", paper presented at the Inter-American Development Bank Seminar on Labour Markets, Montevideo. 
Berry, Albert (ed.) (1998), Poverty, Economic Reform, and Income Distribution in Latin America, Boulder, Colorado, Lynne Rienner.

Birdsall, Nancy and Juan Luis Londoño de la Cuesta (1997), “Asset Inequality Does Matter: Lessons from Latin America", OCE Working Paper Series, No. 344, Washington, D.C., Inter-American Development Bank (IDB).

Birdsall, Nancy, Carol Graham and Richard H. Sabot (eds.) (1998), Beyond Tradeoffs: Market Reform and Equitable Growth in Latin America, Washington, D.C., Inter-American Development Bank (IDB) and The Brookings Institution.

Birdsall, Nancy, David Ross and Richard H. Sabot (1995), "Inequality and Growth Reconsidered: Lessons from East Asia", The World Bank Economic Review, vol. 9, No. 3.

Bruno, Michael, Martin Ravallion and Lyn Squire (1996), "Equity and Growth in Developing Countries: Old and New Perspectives on the Policy Issues", Policy Research Working Paper, No. 1563, Washington, D.C., World Bank.

Bulmer-Thomas, Victor (ed.) (1996), The New Economic Model in Latin America and its Impact on Income Distribution and Poverty, New York, St. Martins Press.

Burki, Shahid Javed and Guillermo E. Perry (1997), The Long March: A Reform Agenda for Latin America and the Caribbean in the Next Decade,Washington, D.C., World Bank.

Cárdenas, Mauricio and Raquel Bernal (1999), "Changes in the distribution of income and the new eonomic model in Colombia", Reformas económicas series, No. 36 (LC/L.1227), Santiago, Chile, Economic Commission for Latin America and the Caribbean (ECLAC).

Cardoso, Eliana and Ann Helwege (1992), Latin America's Economy: Diversity, Trends and Conflicts, Cambridge, Massachusetts, The MIT Press.

Carter, Michel R. and Jonathan Coles (1998), "Inequality-reducing growth in agriculture: a market-friendly policy agenda", Beyond Tradeoffs: Market Reform and Equitable Growth in Latin America, Nancy Birdsall, Carol Graham and Richard H. Sabot (eds.), Washington, D.C., Inter-American Development Bank (IDB) and The Brookings Institution.

Clarke, George R.G. (1995), "More evidence on income distribution and growth", Journal of Development Economics, Vol. 47, No. 2.

Cortázar, René, Nora Lustig and Richard H. Sabot (1998), “Economic policy and labor market dynamics", Beyond Tradeoffs: Market Reform and Equitable Growth in Latin America, Nancy Birdsall, Carol Graham and Richard H. Sabot (eds.), Washington, D.C., Inter-American Development Bank (IDB) and The Brookings Institution.

Deininger, Klaus and Lyn Squire (1996), "A new data set measuring income inequality", The World Bank Economic Review, vol. 10, No. 3. 
De Janvry, Alain and Elizabeth Sadoulet (1999), Growth, Poverty and Inequality in Latin America: a Causal Analysis, 1970-1994, Los Angeles, University of California.

De la Torre, Rodolfo (2000), “La distribución factorial del ingreso en el nuevo modelo económico en México", Reformas económicas series, No. 58 (LC/L.1354), Santiago, Chile, Economic Commission for Latin America and the Caribbean (ECLAC).

Duryea, Suzanne and Miguel Székely (1998), “Labor Markets in Latin America: A Supply-Side Story", OCE Working Paper Series, No. 374, Washington, D.C., Inter-American Development Bank (IDB).

ECLAC (Economic Commission for Latin America and the Caribbean (1999), Social Panorama of Latin America, 1998 (LC/G.2050-P), Santiago, Chile, May. United Nations publication, Sales No. E.99.II.G.4.

(1997), The Equity Gap: Latin America, the Caribbean and the Social Summit (LC/G.1954/Rev.1-P), Santiago, Chile, December. United Nations publication, Sales No. E 97.II.G.11.

Edwards, Alejandra Cox (1991), "Wage trends in Latin America", LATHR, No. 18, Washington, D.C., World Bank.

Edwards, Sebastián (1997), "Trade policy, growth and income inequality", American Economic Review Papers and Proceedings, vol. 87, No. 2.

(1995), Crisis and Reform in Latin America: From Despair to Hope, Oxford, Oxford University Press.

Escaith, Hubert y Samuel Morley (2000), "The Impact of Reforms on Growth in Latin America and the Caribbean: An Econometric Estimation", Macroeconomía de desarrollo series, No.1 (LC/L. 1446P), Santiago, Chile, Economic Commission for Latin America and the Caribbean (ECLAC).

Escobal D'Angelo, Javier, Jaime Saavedra Chanduví and Máximo Torero Cullen (1998), "Los activos de los pobres en el Perú", Documento de trabajo, No. 26, Lima, Study Group for Development (GRADE).

Ffrench-Davis, Ricardo and Dagmar Raczynski (1990), "The impact of global recession and national policies on living standards: Chile, 1973-1987", Technical Note, No. 97, third edition, Santiago, Chile, Economic Research Corporation for Latin America (CIEPLAN).

Ffrench-Davis, Ricardo and Helmut Reisen (eds.) (1998), Capital Flows and Investment Performance: Lessons from Latin America, Paris, OECD Development Centre and Economic Commission for Latin America and the Caribbean (ECLAC).

Fields, Gary (1994), “Data for measuring poverty and inequality changes in the developing countries", Journal of Development Economics, Vol. 44, No.1.

Ganuza, Enrique, Lance Taylor and Samuel Morley, (eds.) (1998), Política macroeconómica y pobreza en América Latina y el Caribe, Madrid, Grupo Mundi-Prensa, United Nations Development Programme (UNDP). 
Hausmann, Ricardo and Roberto Rigobón (1993), Government Spending and Income Distribution in Latin America, Washington, D.C., Inter-American Development Bank (IDB).

Hoffman, Rodolfo (1998), Desigualdade e pobreza no Brasil no periodo 1979-96 e a influencia da inflacão e do salario minimo, Campinas, University of Campinas (UNICAMP).

IDB (Inter-American Development Bank) (1998), Economic and Social Progress in Latin America, 1998-1999 Report, Washington, D.C.

(1997), Economic and Social Progress in Latin America, 1997 Report, Washington, D.C.

(1996), Economic and Social Progress in Latin America, 1996 Report, Washington, D.C.

Jácome Hidalgo, Luis, Carlos Larrea and Rob Vos (1998), "Políticas macroeconómicas. Distribución y pobreza en el Ecuador", Política macroeconómica y pobreza en América Latina y el Caribe, Enrique Ganuza, Lance Taylor and Samuel Morley (eds.), Madrid, Grupo Mundi-Prensa, United Nations Development Programme (UNDP).

Jemio, Luis Carlos (1999), "Reformas, politicas sociales y equidad en Bolivia", Reformas económicas series, No. 38 (LC/L.1274), Santiago, Chile, Economic Commission for Latin America and the Caribbean (ECLAC). Jiménez, Luis Felipe (1997), "Distribución del ingreso, shocks y políticas macroeconómicas", Financiamento del desarrollo series, No. 44 (LC/ L.1006), Santiago, Chile, Economic Commission for Latin America and the Caribbean (ECLAC).

Kay, Cristóbal (1998), "The Complex Legacy of Latin America's Agrarian Reform", Working Paper Series, No 268, The Hague, Institute of Social Studies (ISS).

King, Damien and Sudhanshu Handa (2000), "Changes in the distribution of income and the new economic model in Jamaica", Reformas económicas series, No. 57 (LC/L.1353), Santiago, Chile, Economic Commission for Latin America and the Caribbean (ECLAC).

Kuznets, Simon (1955), "Economic growth and income inequality", The American Economic Review, vol. 45, No.1.

Larrañaga, Osvaldo J. (1999), "Distribución de ingresos y crecimiento económico en Chile", Reformas económicas series, No. 35 (LC/L.1226), Santiago, Chile, Economic Commission for Latin America and the Caribbean (ECLAC).

Londoño, Juan Luis and Miguel Székely (1997), “Persistent Poverty and Excess Inequality: Latin America, 1970-1995", OCE Working Paper Series, No. 357, Washington, D.C., Inter-American Development Bank (IDB). 
Lora, Eduardo (1997), "A decade of structural reforms in Latin America: what has been reformed and how to measure it", Document presented to the Annual Meeting of the Board of Governors of the Inter-American Development Bank (IDB), Barcelona, Spain.

Lora, Eduardo and Felipe Barrera (1997), "A Decade of Structural Reform in Latin America: Growth, Productivity and Investment Are Not What They Used to Be", OCE Working Paper Series, No. 350, Washington, D.C., Inter-American Development Bank (IDB).

Lora, Eduardo and Gustavo Márquez (1998), "The Employment Problem in Latin America: Perceptions and Stylized Facts", paper presented at the Seminar "El empleo en América Latina: cuál es el problema y cómo enfrentarlo", Cartagena, Colombia.

Márquez, Gustavo (1998), "El desempleo en América Latina y el Caribe a mediados de los 90", paper presented at the Inter-American Development Bank Seminar on Labour Markets, Montevideo.

Márquez, Gustavo and Samuel Morley (1997), "Poverty and the Employment Problem in Argentina", SDS Working Paper Series, No. 97-103, Washington, D.C., Inter-American Development Bank (IDB).

Mejía, José Antonio and Rob Vos (1997), "Poverty in Latin America in the Caribbean: An Inventory, 1980-95", Working Paper Series, vol. 1, No. 4, Washington, D.C., Inter-American Development Bank (IDB), InterAmerican Institute for Social Development (INDES).

Morley, Samuel (1998), "La pobreza en tiempos de recuperación económica y reforma en América Latina: 1985-1995", Política macroeconómica y pobreza en América Latina y el Caribe, Enrique Ganuza, Lance Taylor and Samuel Morley (eds.), Madrid, Grupo Mundi-Prensa, United Nations Development Programme (UNDP).

(1995), Poverty and Inequality in Latin America: The Impact of Adjustment and Recovery in the 1980s, Baltimore, The Johns Hopkins University Press.

Morley, Samuel A., Roberto Machado and Stefano Pettinato (1999), "Indexes of Structural Reform in Latin America", Reformas económicas series, No. 12 (LC/L.1166), Santiago, Chile, Economic Commission for Latin America and the Caribbean (ECLAC).

Neri, Marcelo and José Márcio Camargo (1999), "Structural Reforms, Macroeconomic Fluctuations and Income Distribution in Brazil", Reformas económicas series, No. 39 (LC/L.1275), Santiago, Chile, Economic Commission for Latin America and the Caribbean (ECLAC).

Ocampo, José Antonio and Lance Taylor (1998), "Trade liberalisation in developing economies: modest benefits but problems with productivity growth, macro prices and income distribution", Economic Journal, vol. 108, No. 3.

Ocampo, José Antonio and others (1998), “Macroeconomía, ajuste estructural y equidad en Colombia: 1978-1996", Política macroeconómica y pobreza 
en América Latina y el Caribe, Enrique Ganuza, Lance Taylor and Samuel Morley (eds.), Madrid, Grupo Mundi-Prensa, United Nations Development Programme (UNDP).

Paes de Barros, Ricardo and others (1993), "Welfare, Inequality, Poverty and Social Conditions in Brazil over the Last Three Decades", paper presented at a Brookings Institution conference.

Psacharopoulos, George and others (1997), "Poverty and Income Distribution in Latin America: the Story of the 1980s", Technical Paper, No. 351, Washington, D.C., World Bank.

Ravallion, Martin and Shaohua Chen (1997), "What can new survey data tell us about recent changes in distribution and poverty?", The World Bank Economic Review, vol. 11, No. 2.

Robbins, Donald (1996), HOS Hits Facts, Facts Win: Evidence on Trade and Wages in the Developing World, Cambridge, Massachusetts, Harvard Institute for International Development.

(1995), Trade, Trade Liberalization and Inequality in Latin America and East Asia: Synthesis of Seven Country Studies, Cambridge, Massachusetts, Harvard Institute for International Development.

Rodrik, Dani (1998), "Who needs capital account convertibility?", Should the IMF Pursue Capital-Account Convertibility?, Stanley Fischer and others (eds.), Essays in International Finance, No. 207, Princeton, Princeton University.

Ros, Jaime (1999), “La liberalización de la balanza de pagos en México: efectos en el crecimiento, el empleo y la desigualdad salarial", paper presented at the UNDP, ECLAC and IDB Conference on the Effect of Liberalizing the Balance of Payments on Employment, Income Distribution, Poverty and Growth, Rio de Janeiro.

Saavedra, Jaime and Juan José Diaz (1999), "Desigualdad de ingreso y del gasto en el Perú antes y después de las reformas estructurales", Reformas económicas series, No. 34 (LC/L.1225), Santiago, Chile, Economic Commission for Latin America and the Caribbean (ECLAC). Sánchez, Fabio T. (ed.) (1998), La distribución del ingreso en Colombia, Bogotá, National Planning Department.

Sen, Amartya (1973), On Economic Inequality: the Radcliffe Lectures, Oxford, Clarendon Press.

Sheahan, John and Enrique V. Iglesias (1998), "Kinds and causes of inequality in Latin America", Beyond Tradeoffs: Market Reform and Equitable Growth in Latin America, Nancy Birdsall, Carol Graham and Richard H. Sabot (eds.), Washington, D.C., Inter-American Development Bank (IDB) and The Brookings Institution.

Spilimbergo, Antonio, Juan Luis Londoño and Miguel Székely (1997), “Income Distribution, Factor Endowments, and Trade Openness", OCE Working Paper Series, No. 356, Washington, D.C., Inter-American Development Bank (IDB). 
Stallings, Barbara and Wilson Peres (2000), Growth, Employment, and Equity: The Impact of Economic Reforms in Latin America and the Caribbean, Washington, D.C., The Brookings Institution Press.

Summers, Robert and Alan Heston (1995), The Penn World Tables: Version 5.6, diskette version.

Székely, Miguel (1998), The Economics of Poverty, Inequality and Wealth Accumulation in Mexico, New York, St. Martins Press.

Székely, Miguel and Marianne Hilgert (1999), "What's Behind the Inequality We Measure: An Investigation Using Latin American Data", OCE Working Paper Series, No. 409, Washington, D.C., Inter-American Development Bank (IDB).

Theil, Henri (1972), Statistical Decomposition Analysis: with Applications in the Social and Administrative Sciences, Amsterdam, North-Holland.

Thiesenhusen, William C. (1995), Broken Promises: Agrarian Reform and the Latin American Campesino, Boulder, Colorado, Westview.

Trejos, Juan Diego (1999), "Reformas económicas y distribución del ingreso en Costa Rica", Reformas económicas series, No. 37 (LC/L.1228), Santiago, Chile, Economic Commission for Latin America and the Caribbean (ECLAC).

Weller, Jürgen (2000), Reformas económicas, crecimiento y empleo: los mercados de trabajo en América Latina y el Caribe, Santiago, Chile, Economic Commission for Latin America and the Caribbean (ECLAC) and Fondo de Cultura Económica. (English translation: Economic Reforms, Growth and Employment: Labour Markets in Latin America and the Caribbean, Santiago, Chile, ECLAC, 2001).

(1998), "Los mercados laborales en América Latina: su evolución en el largo plazo y sus tendencias recientes", Reformas económicas series, No. 11 (LC/L.1160), Santiago, Chile, Economic Commission for Latin America and the Caribbean (ECLAC).

Williamson, Jeffrey G. (1997), "Globalization and inequality: past and present", World Bank Research Observer, vol. 12, No. 1.

Wood, Adrian (1997), “Openness and wage inequality in developing countries: the Latin American challenge to East Asian conventional wisdom", World Bank Economic Review, vol. 11, No.1. (1994), North-South Trade, Employment and Inequality: Changing Fortunes in a Skill-Driven World, Oxford, Clarendon Press.

World Bank (1995), "Argentina's Poor: a Profile", World Bank Report, No. 3318-AR, Washington, D.C. 

APPENDIX 


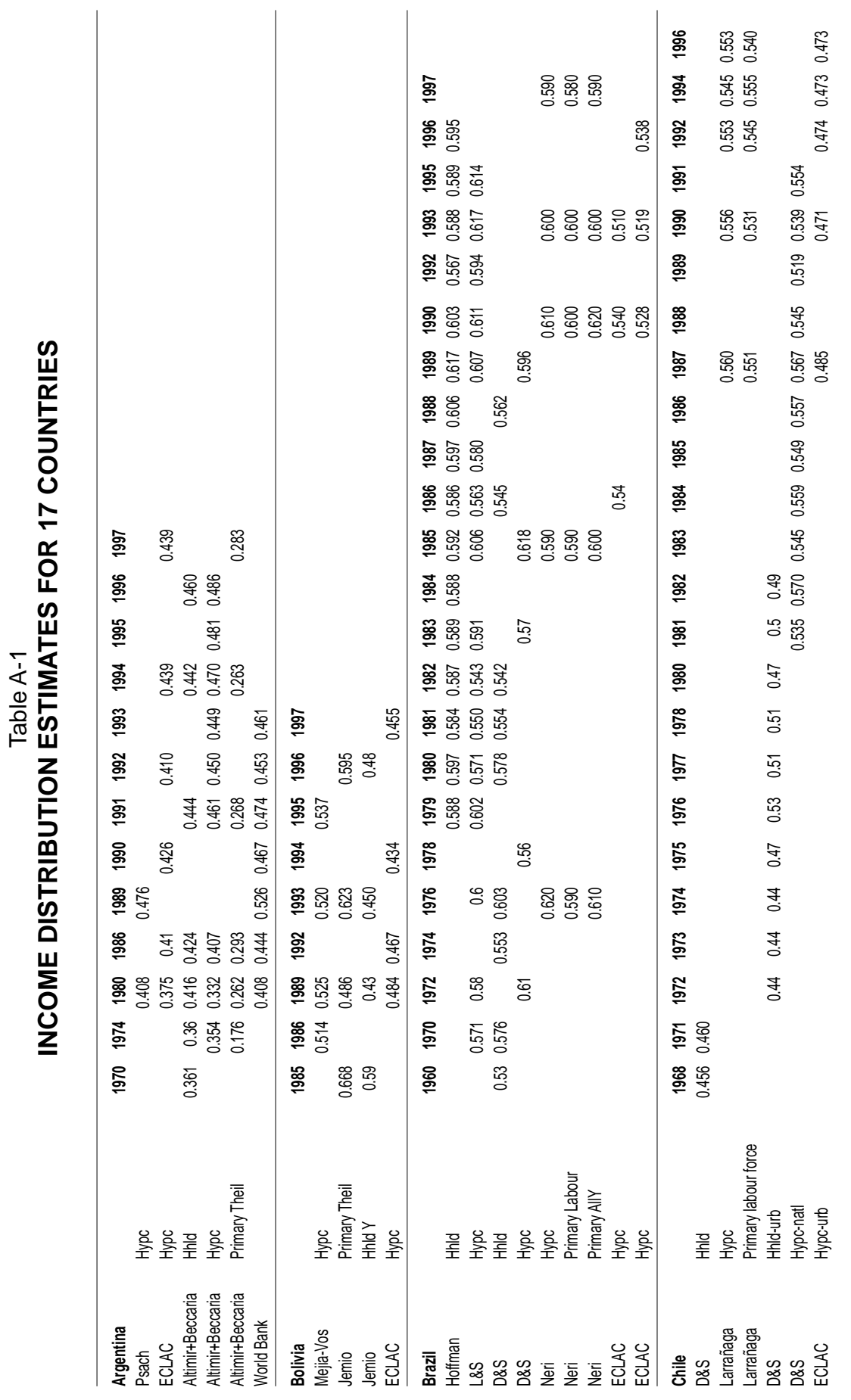




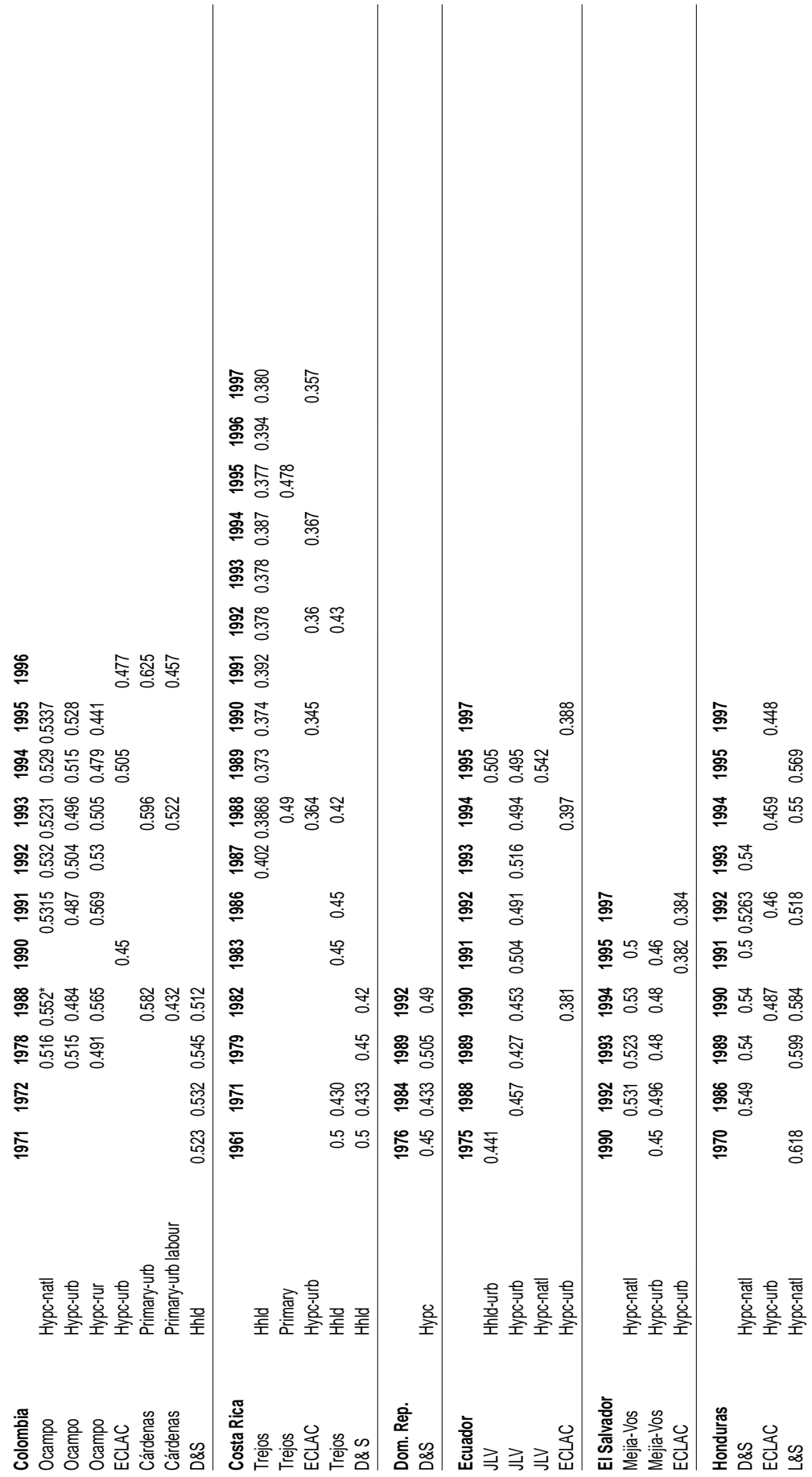




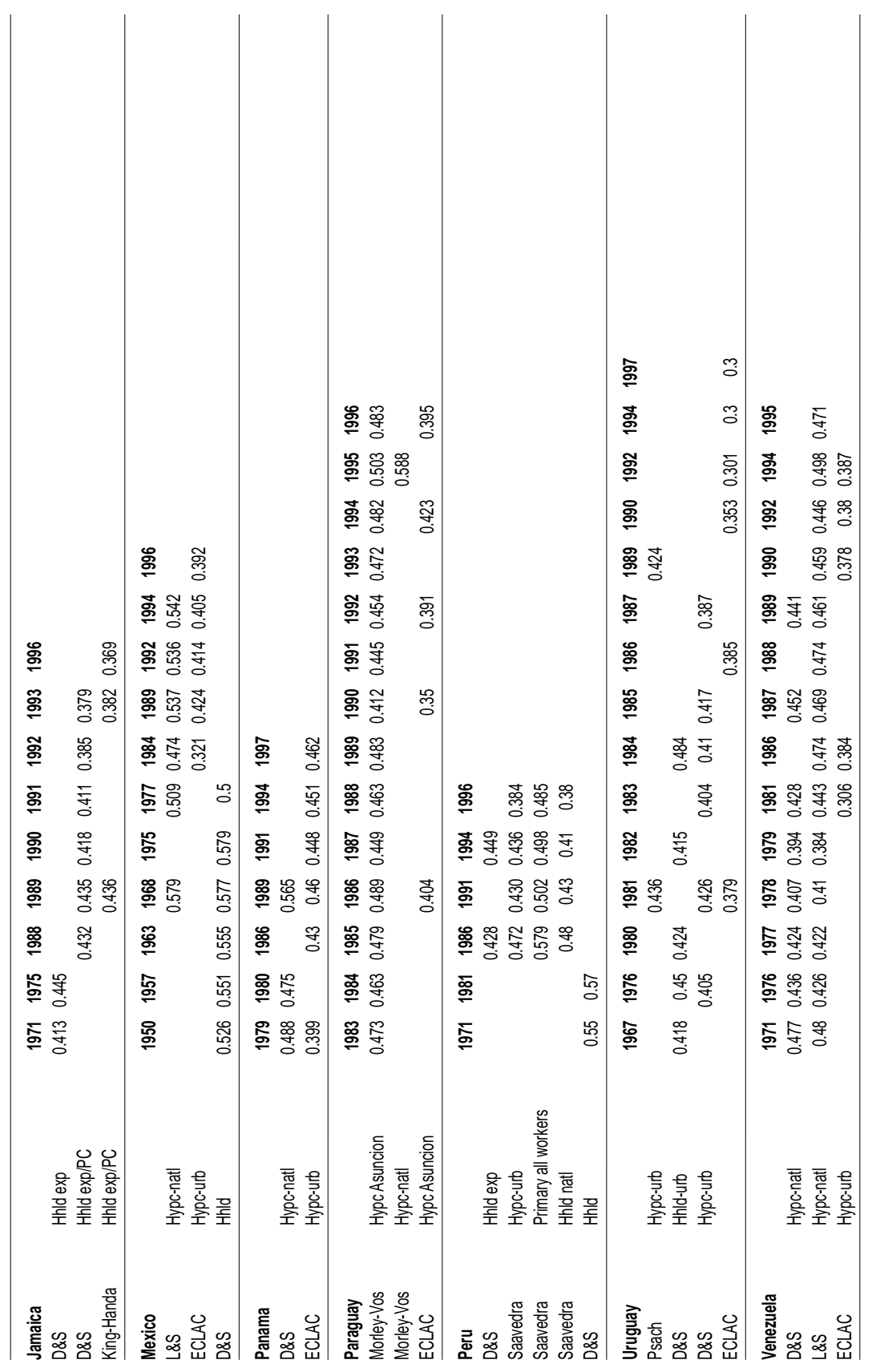




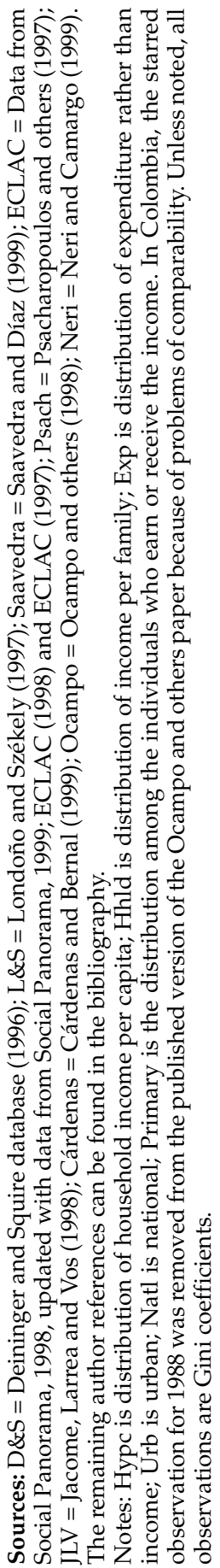


